University of Tennessee Health Science Center UTHSC Digital Commons

\title{
Signaling Induced by Inflammatory Mediators in the Rodent Pulmonary Microvasculature
}

\author{
Rachel Escue Helms \\ University of Tennessee Health Science Center
}

Follow this and additional works at: https://dc.uthsc.edu/dissertations

Part of the Medical Cell Biology Commons, and the Medical Physiology Commons

\section{Recommended Citation}

Helms, Rachel Escue (http://orcid.org/0000-0001-5027-7153), "Signaling Induced by Inflammatory Mediators in the Rodent Pulmonary Microvasculature" (2018). Theses and Dissertations (ETD). Paper 471. http://dx.doi.org/10.21007/etd.cghs.2018.0468. 


\title{
Signaling Induced by Inflammatory Mediators in the Rodent Pulmonary Microvasculature
}

\begin{abstract}
Acute lung inflammation (ALI), stemming from a disproportionate and detrimental immune response, may arise from or complicate other disease states, leading to the often-fatal acute respiratory distress syndrome (ARDS). Because of the many culpable factors and differing points of induction, pinning down the signaling mechanisms involved in the morbidity of this disorder as well as defining an effective treatment has proved problematic. However, the most detrimental characteristic of this condition is seen regardless of the development of the response: increased microvascular permeability. Because of the architecture and the size of the pulmonary microvascular network, the lungs have a resident, sequestered population of leukocytes that are able to rapidly respond to injury or infection, but may also contribute to the pathology of ALI/ARDS by increasing endothelial barrier dysfunction. Many inflammatory mediators dictate the course and gravity of the response by inducing endothelial cytoskeletal reorganization, such as induction of actin stress fibers, cell rounding and contraction, and dissociation of interendothelial junctions.
\end{abstract}

Thrombin is a well-studied mediator that has been shown to be barrier-disruptive rapidly increases microvascular permeability. Sphingosin-1-phosphate (S1P) is a more novel, less understood mediator that has been shown to mediate basal vascular permeability as well as to enhance barrier integrity in inflammation. Inflammatory signaling may also expand throughout the lungs through intercellular communication via gap junctions composed of connexins, such as Connexin 43 (Cx43). Herein, we explored how intercellular communication through $\mathrm{Cx} 43$-containing gap junctions mediates thrombininduced signaling as well as the interplay between thrombin- and S1P-induced signaling on the pulmonary microvascular barrier.

We isolated and perfused lungs from rats and mice, a physiologically-relevant model to study lung inflammation. We found that focal micropuncture instillations of thrombin were able to induce responses related to hyperpermeability (including, changes in intracellular $\mathrm{Ca} 2+$, increased F-actin polymerization, and increased reactive oxygen species generation) both in microvessels directly treated with thrombin and those far outside the instilled region (up to $1000 \mu \mathrm{m}$ away), and the expansion of signaling into the untreated microvessels was due to intercellular communication mediated by $\mathrm{Cx} 43$. For the F-actin polymerization response, we determined that the specific second messenger being communicated and propagating the thrombin-induced increase was inositol trisphosphate (IP3). We also found that, though thrombin induced increases in mean $\mathrm{Ca} 2+$ in cultured cells, it instead induced increases in the amplitude of cytosolic $\mathrm{Ca} 2+$ oscillations in pulmonary microvessels. While we observed that untreated primary pulmonary microvascular endothelial cells and pulmonary microvessels from mice lacking endothelial Cx43 displayed higher levels of the S1P receptor, S1P2, thrombin induced an increase in S1P2 expression that was dependent on the presence of $\mathrm{Cx} 43$. While S1P itself was able to partially rescue barrier integrity following thrombin treatment, we show for the first time that S1P2 signaling substantially contributes to thrombin-induced endothelial hyperpermeability, and that inhibiting S1P2 significantly reduced thrombininduced permeability increases.

\section{Document Type}

Dissertation

\author{
Degree Name \\ Doctor of Philosophy (PhD)
}




\section{Program}

Biomedical Sciences

Research Advisor

Kaushik Parthasarathi, PhD

\section{Keywords}

connexin 43 , endothelial, inflammation, pulmonary, sphingosine-1-phosphate, thrombin

\section{Subject Categories}

Medical Cell Biology | Medical Physiology | Medical Sciences | Medicine and Health Sciences 


\title{
Signaling Induced by Inflammatory Mediators in the Rodent Pulmonary Microvasculature
}

\author{
A Dissertation \\ Presented for \\ The Graduate Studies Council \\ The University of Tennessee \\ Health Science Center
}

\author{
In Partial Fulfillment \\ Of the Requirements for the Degree \\ Doctor of Philosophy \\ From The University of Tennessee
}

By

Rachel Escue Helms

December 2018 
Chapter 3 (C) 2017 by Elsevier

All other materials (C) 2018 by Rachel Escue Helms. All rights reserved. 


\section{DEDICATION}

To Maximilian: this work is dedicated to you, as is everything I do in my life. 


\section{ACKNOWLEDGEMENTS}

I would like to thank my parents and brother, for their unwavering support throughout the whole of my academic career, and my husband, for loving me and talking me down off of ledges when things became too much.

I owe more than I can put into words to my mentor, Dr. Kaushik Parthasarathi. I have been stupidly lucky to have been guided by someone as truly caring and encouraging as he.

I would also like to acknowledge Dr. Kathirvel Kandasamy, who spent innumerable hours teaching me the isolated perfused lung methodology, which is the foundation of this work.

Finally, I would like to thank the members of my committee, Dr. Adebowale Adebiyi, Dr. Anjaparavanda Naren, Dr. Charles Leffler, and Dr. Rajashekhar Gangaraju, for their guidance and their time. 


\begin{abstract}
Acute lung inflammation (ALI), stemming from a disproportionate and detrimental immune response, may arise from or complicate other disease states, leading to the often-fatal acute respiratory distress syndrome (ARDS). Because of the many culpable factors and differing points of induction, pinning down the signaling mechanisms involved in the morbidity of this disorder as well as defining an effective treatment has proved problematic. However, the most detrimental characteristic of this condition is seen regardless of the development of the response: increased microvascular permeability. Because of the architecture and the size of the pulmonary microvascular network, the lungs have a resident, sequestered population of leukocytes that are able to rapidly respond to injury or infection, but may also contribute to the pathology of ALI/ARDS by increasing endothelial barrier dysfunction. Many inflammatory mediators dictate the course and gravity of the response by inducing endothelial cytoskeletal reorganization, such as induction of actin stress fibers, cell rounding and contraction, and dissociation of interendothelial junctions.
\end{abstract}

Thrombin is a well-studied mediator that has been shown to be barrier-disruptive rapidly increases microvascular permeability. Sphingosin-1-phosphate (S1P) is a more novel, less understood mediator that has been shown to mediate basal vascular permeability as well as to enhance barrier integrity in inflammation. Inflammatory signaling may also expand throughout the lungs through intercellular communication via gap junctions composed of connexins, such as Connexin 43 (Cx43). Herein, we explored how intercellular communication through $\mathrm{Cx} 43$-containing gap junctions mediates thrombin-induced signaling as well as the interplay between thrombin- and S1P- induced signaling on the pulmonary microvascular barrier.

We isolated and perfused lungs from rats and mice, a physiologically-relevant model to study lung inflammation. We found that focal micropuncture instillations of thrombin were able to induce responses related to hyperpermeability (including, changes in intracellular $\mathrm{Ca}^{2+}$, increased $\mathrm{F}$-actin polymerization, and increased reactive oxygen species generation) both in microvessels directly treated with thrombin and those far outside the instilled region (up to $1000 \mu \mathrm{m}$ away), and the expansion of signaling into the untreated microvessels was due to intercellular communication mediated by $\mathrm{Cx} 43$. For the F-actin polymerization response, we determined that the specific second messenger being communicated and propagating the thrombin-induced increase was inositol trisphosphate (IP3). We also found that, though thrombin induced increases in mean $\mathrm{Ca}^{2+}$ in cultured cells, it instead induced increases in the amplitude of cytosolic $\mathrm{Ca}^{2+}$ oscillations in pulmonary microvessels. While we observed that untreated primary pulmonary microvascular endothelial cells and pulmonary microvessels from mice lacking endothelial $\mathrm{Cx} 43$ displayed higher levels of the S1P receptor, S1P2, thrombin induced an increase in S1P2 expression that was dependent on the presence of $\mathrm{Cx} 43$. While S1P itself was able to partially rescue barrier integrity following thrombin treatment, we show for the first time that $\mathrm{S} 1 \mathrm{P} 2$ signaling substantially contributes to 
thrombin-induced endothelial hyperpermeability, and that inhibiting S1P2 significantly reduced thrombin-induced permeability increases. 


\section{TABLE OF CONTENTS}

CHAPTER 1. INTRODUCTION .................................................................................

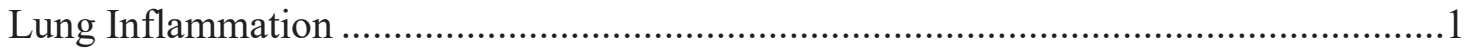

Pulmonary Vasculature ..................................................................................



Mechanisms of Endothelial Barrier Dysfunction ...................................................

Common Inflammatory Mediators Affecting Microvascular Permeability ..................6

Expansion of Inflammatory Signaling ................................................................. 7

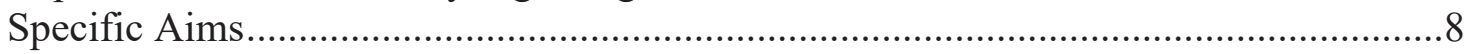

CHAPTER 2. THE ISOLATED PERFUSED RODENT LUNG MODEL ................9

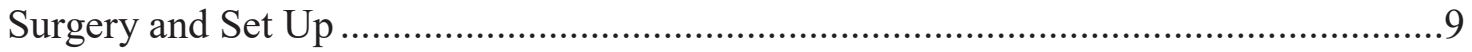

Delivery of Dyes and Reagents to Pulmonary Microvessels ......................................10

\section{CHAPTER 3. THROMBIN INDUCES INOSITOL TRISPHOSPHATE- MEDIATED SPATIALLY EXTENSIVE RESPONSES IN LUNG}

MICROVESSELS .............................................................................................15

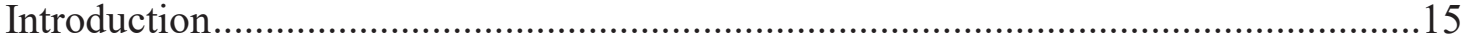

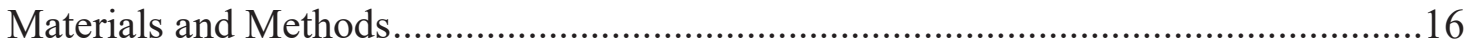

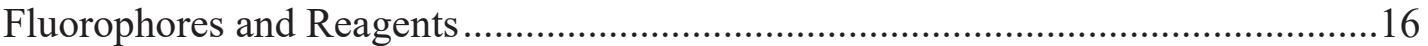

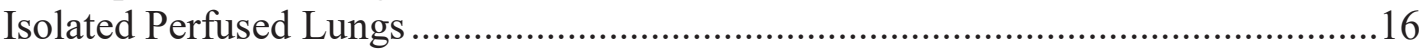

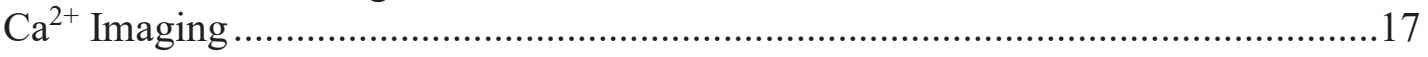

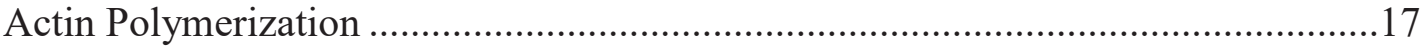

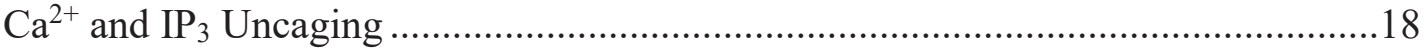

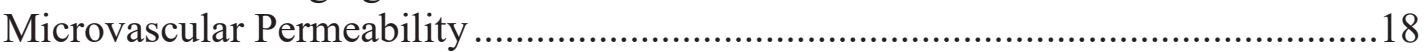

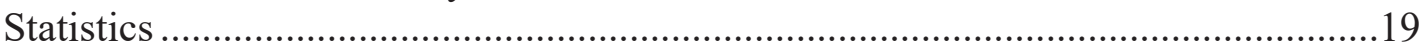

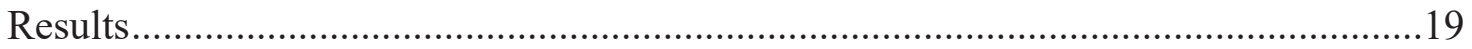

Induction of Microvascular Permeability by Thrombin .....................................19

Microvessel Actin Stress Fiber Formation ....................................................... 19

Microvessels Are the Source of Thrombin-Induced Responses .............................21

Lack of Endothelial Cx43 Limits Actin Stress Fiber Formation ..............................25

Inhibiting Endothelial ER Ca ${ }^{2+}$ Release Limits Actin Stress Fiber Formation..........25

$\mathrm{IP}_{3}$ Mediates the Spatially Extensive Actin Stress Fiber Formation........................28

Thrombin Increases the Magnitude of ER-Dependent $\mathrm{Ca}^{2+}$ Oscillation in Lung

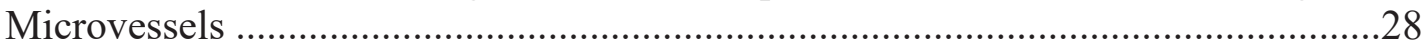

Focal Release of Caged-IP 3 Induces Cx43-Dependent $\mathrm{Ca}^{2+}$ Responses in

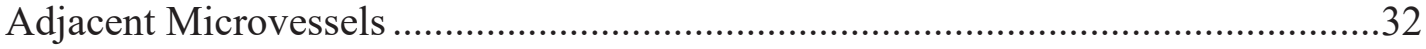

Thrombin Mediates Spatially Extensive Increases in Microvessel Permeability .......32

Discussion

\section{CHAPTER 4. COOPERATIVE SIGNALING OF THROMBIN AND S1P2 IN BARRIER DYSFUNCTION ..............................................................................41}

Introduction. 


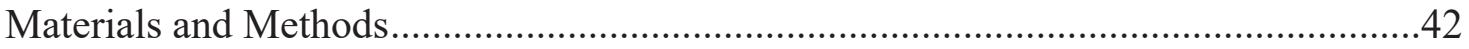

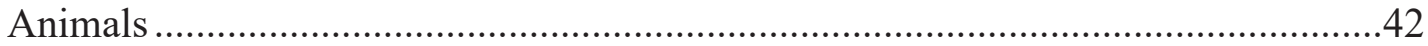

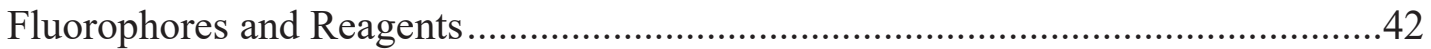

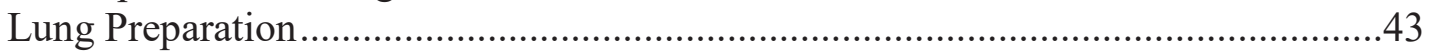

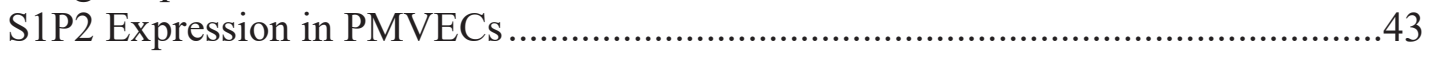

S1P2 Expression in Pulmonary Microvessels...................................................43

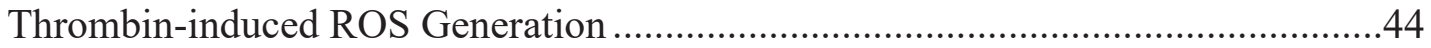

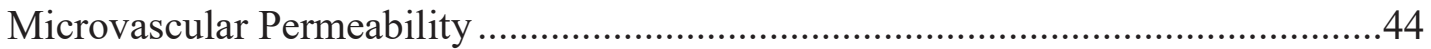



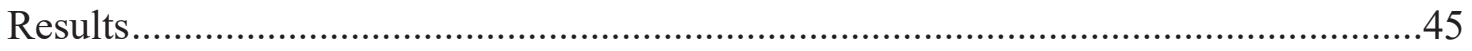

Thrombin Induces Differing Effects on S1P2 Expression in Both PMVECs and

Microvessels in $\mathrm{Cx} 43^{\mathrm{fl} / \mathrm{fl}}$ and EC-Cx43-/- Mice .....................................................45

S1P2 expression in PMVECs isolated from $\mathrm{Cx} 43^{\mathrm{fl} / \mathrm{fl}}$ and $\mathrm{EC}-\mathrm{Cx} 43^{-/-}$mouse lungs following thrombin treatment.......................................................... 45

S1P2 expression in pulmonary microvessels................................................. 45

Induction of ROS Generation by Thrombin in Pulmonary Microvessels.................47

S1P2 Signaling Contributes to Thrombin-Induced Increase in Pulmonary

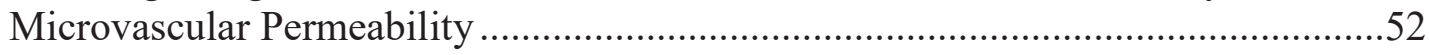

$\mathrm{S} 1 \mathrm{P}$, through its receptor S1P2, increases lung microvascular permeability ....... 52

Inhibition of S1P2 signaling pathways blocks thrombin-induced ROS

generation in $\mathrm{Cx} 43 \mathrm{fl} / \mathrm{fl}$ pulmonary microvasculature...................................... 61

Increases in permeability induced by S1P and thrombin are due to increases

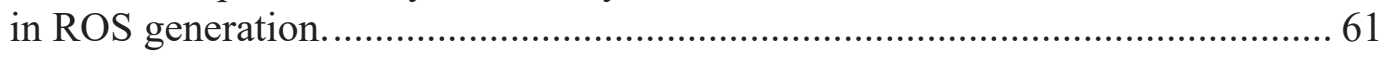

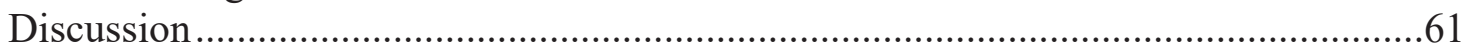

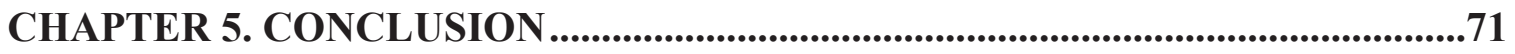

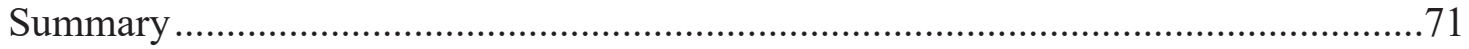

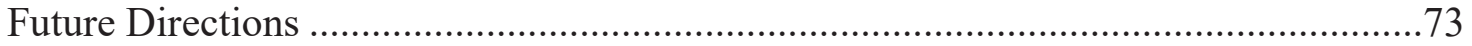

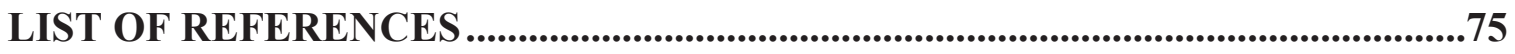

VITA 


\section{LIST OF FIGURES}

Figure 2-1. Diagram of perfusion set up in IPL......................................................11

Figure 2-2. Delivery of dyes via superfusion ...........................................................12

Figure 2-3. Delivery of dyes via microcatheter ........................................................13

Figure 2-4. Delivery of dyes via micropuncture ........................................................14

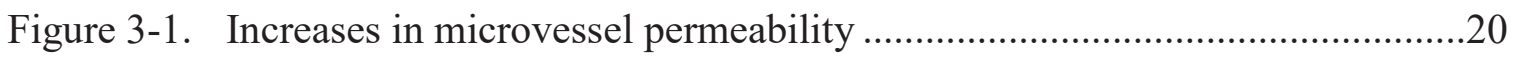

Figure 3-2. Changes in F-actin formation in lung microvessels.....................................22

Figure 3-3. Methodological controls for Thrombin-induced responses in lung

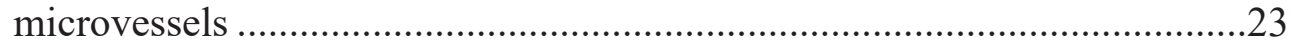

Figure 3-4. Effect of endothelial Cx43 on F-actin formation..........................................26

Figure 3-5. Effect of $\mathrm{IP}_{3} \mathrm{R}$ inhibition on F-actin formation .........................................2

Figure 3-6. Effect of focal IP 3 R inhibition in lung microvessels of $\mathrm{Cx}_{4} 3^{\mathrm{fl} / \mathrm{fl}}$ mice..........29

Figure 3-7. Thrombin-induced $\mathrm{Ca}^{2+}$ responses in lung microvessels..............................30

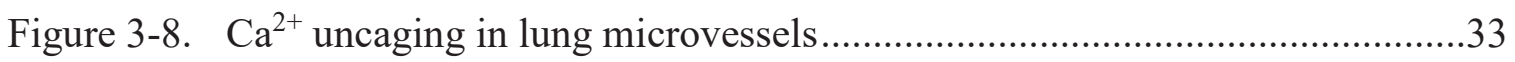

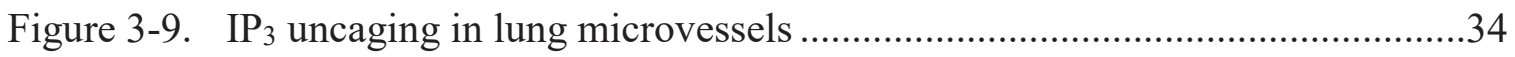

Figure 3-10. Effect of inhibiting intercellular communication on microvessel

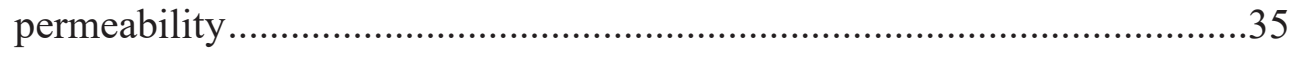

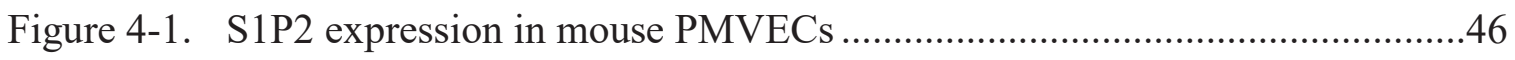

Figure 4-2. Baseline S1P2 expression in mouse pulmonary microvessels......................48

Figure 4-3. S1P2 expression in microvessels of $\mathrm{Cx} 43^{\mathrm{fl} / \mathrm{fl}}$ mouse lungs instilled with PBS or Thrombin

Figure 4-4. S1P2 expression in microvessels of EC-Cx $43^{-/-}$mouse lungs instilled with PBS or Thrombin

Figure 4-5. Comparison of S1P2 expression following Thrombin treatment in pulmonary microvessels of $\mathrm{Cx} 43^{\mathrm{fl} / \mathrm{fl}}$ and $\mathrm{EC}-\mathrm{Cx} 43^{-/ /}$mouse lungs

Figure 4-6. Induction of ROS generation following Thrombin micropuncture instillation in microvessels of $\mathrm{Cx} 43^{\mathrm{fl} / \mathrm{fl}}$ mouse lungs 
Figure 4-7. Induction of ROS generation following Thrombin micropuncture instillation in microvessels of EC-Cx $43^{-/ /}$mouse lungs

Figure 4-8. Comparison of ROS generation following Thrombin treatment in pulmonary microvessels of $\mathrm{Cx} 43^{\mathrm{f} / / \mathrm{f}}$ and $\mathrm{EC}-\mathrm{Cx} 43^{-/ /}$mouse lungs

Figure 4-9. S1P2 signaling in pulmonary microvascular permeability ……………........58

Figure 4-10. S1P2 signaling in Thrombin-induced ROS generation.................................62

Figure 4-11. Inhibition of ROS generation in S1P- and Thrombin-induced

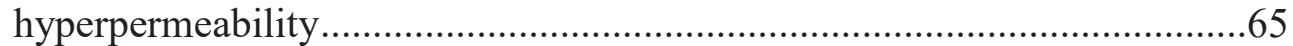




\section{LIST OF ABBREVIATIONS}

$\begin{array}{ll}\text { AC } & \text { adenylate cyclase } \\ \text { AJ } & \text { adherens junction } \\ \text { ALI } & \text { acute lung inflammation } \\ \text { ARDS } & \text { acute respiratory distress syndrome } \\ \text { cAMP } & \text { cyclic adenosine monophosphate } \\ \text { CLP } & \text { cecal-ligation and puncture } \\ \text { Cx43 } & \text { Connexin 43 } \\ \text { ER } & \text { endoplasmic reticulum } \\ \text { HGF } & \text { hepatocyte growth factor } \\ \text { HMGB1 } & \text { high-mobility group box 1 } \\ \text { IP3 } & \text { inositol trisphosphate } \\ \text { IPL } & \text { isolated perfused lung } \\ \text { LPS } & \text { lipopolysaccharide } \\ \text { NET } & \text { neutrophil extracellular trap } \\ \text { Nox2 } & \text { NADPH oxidase 2 } \\ \text { PAR-1 } & \text { protease-activated receptor-1 } \\ \text { PEEP } & \text { positive end-expiratory pressure } \\ \text { PMVEC } & \text { pulmonary microvascular endothelial cell } \\ \text { ROCK } & \text { Rho-kinase } \\ \text { ROS } & \text { reactive oxygen species } \\ \text { S1P } & \text { sphingosine-1-phosphate } \\ \text { SphK } & \text { sphingosine kinase } \\ \text { tBHQ } & \text { tert-Butylhydroquinone } \\ \text { TLR4 } & \text { toll-like receptor 4 } \\ \text { TNFa } & \text { tumor necrosis factor alpha } \\ \text { TJ } & \text { tight junction } \\ \text { TRPC } & \text { transient receptor potential canonical } \\ \text { VE-cadherin } & \text { vascular endothelium cadherin } \\ \text { VILI } & \text { ventilator-induced lung injury } \\ \text { XeC } & \text { Xestospongin C } \\ & \end{array}$




\section{CHAPTER 1. INTRODUCTION}

\section{Lung Inflammation}

Although unchecked inflammation leading to endothelial barrier disruption can be detrimental throughout the body, inflammation in the lungs can be particularly hazardous and life threatening. Acute lung inflammation (ALI), and its more grave form acute respiratory distress syndrome (ARDS), results from extensive inflammation in the lungs that is associated with increased microvascular permeability, alveolar flooding, and impaired gas exchange[1,2]. While these conditions have been extensively studied, ARDS maintains a high morbidity and mortality rate, particularly in critically ill patients where this severe lung inflammation occurs secondary to other conditions, such as sepsis, shock, or high-risk surgery [3,4]. Despite advancements in understanding of the pathophysiology ALI/ARDS, advancements in treatment have been sparse. The incidence in intensive care unit patients and mortality of ARDS has not significantly lessened since it was first described in $1967[3,5,6]$. Treatment is largely supportive, dependent on symptom management and mechanical ventilation, and, due to the heterogeneity in the development and presentation of severe pulmonary inflammation, pharmacological interventions are lacking [6-8]. Understanding the development and progression of this injurious condition, specifically within the pulmonary microvasculature, has been and remains crucial to combating this hyperinflammatory event.

\section{Pulmonary Vasculature}

The endothelial barrier is composed of a monolayer of endothelial cells in close association with one another through interendothelial junctions, specifically adherens junctions (AJs) and tight junctions (TJs), formed through the homotypic association of the protein components in the plasma membrane of adjacent endothelial cells[9]. The semi-permeability of the endothelial barrier is due to the presence of these interendothelial junctions which allow the endothelium to regulate the paracellular passage of small molecules[10]. AJs, which account for approximately $80 \%$ of interendothelial junction complexes, are formed from the interaction of vascular endothelial cadherin (VE-cadherin) proteins between neighboring endothelial cells; TJs are similarly composed of members of either the occludin or claudin protein families [4, 9]. AJs, as well as TJs, are able to associate with the cytoskeleton via members of the actin-binding protein families catenins and zonula occludens, respectively[10]. In the normal pulmonary endothelium, cytoskeletal tethering forces within and between endothelial cells help to maintain the tight vascular barrier, and the association between VE-cadherin and the cortical actin band helps to strengthen the AJs[1,9]. However, in inflammation, cytoskeletal rearrangement and formation of actin stress fibers leads to endothelial cell contraction and the disruption of AJs, which promotes formation of interendothelial gaps and an increase in permeability[9]. 
Compared to other organ systems, the lungs possess the highest ratio of endothelial cells to other resident cell types[11]. This is due to the large, dense capillary network required for the gas exchange that takes place here. In the alveolar capillaries, the endothelial cells are particularly thin and are typically separated from the airway cells only by the basement membrane[12]. In addition, the pulmonary capillaries are generally narrower than what is seen in the systemic vasculature and are subject to lower perfusion pressures $[11,13,14]$. Because of this specific organization in the lung, under normal conditions there remains a large pool of leukocytes, including neutrophils, monocytes, and lymphocytes, within the microvasculature, and this allows for a more rapid immune response during inflammation[15]. However, also because of the organization of the lung capillaries, these marginated immune cells may wreak havoc on the endothelium during inflammation, releasing pro-inflammatory mediators and toxic oxidant species that contribute to endothelial apoptosis and increased permeability [1, 16]. As a short diffusion distance is essential for adequate oxygenation of blood flowing in pulmonary capillaries, increased permeability and edema in these tissues carries severe body-wide consequences.

\section{Initiation of Lung Inflammation}

Given that the airways are directly and continuously exposed to the environment, as well as the size and proximity of the vasculature, this substantial population of endothelial cells are particularly vulnerable to infection and injury [1]. Lung inflammation, including the cases that proceed to ALI and ARDS, may be initiated through two routes, either direct or indirect injury to the lung $[1,6,17]$. Because of the assortment of different conditions and insults that can have lung inflammation as an end result, it is difficult to outline the particular events leading up to the more fatal cases [17]. However, the defining and most critical characteristic is the increased pulmonary microvascular permeability, and the other major side effects of alveolar flooding, decreased gas exchange, and lung edema, are either a result of or worsened by this principal dysfunction $[10,18,19]$. See Table 1-1 for a list of various causes of severe, detrimental lung inflammation.

Two major events that may lead to severe lung inflammation are sepsis and injury caused by mechanical ventilation. Sepsis is the systemic inflammatory response to infection, and is the most prevalent cause of ICU deaths that has ALI/ARDS as a comorbidity [8, 20-24]. In infection, pathogen-associated molecular patterns (PAMPs), typically consisting of bacterial or fungal cell wall components, are recognized by pattern-recognition receptors (PRRs) expressed on various cell types, including endothelial. [25-27]. The best studied examples of these are the PAMP lipopolysaccharide (LPS) which is recognized by the PRR toll-like receptor 4 (TLR4). Lung inflammation and sepsis go hand-in-hand: while Gram-negative sepsis is the most common cause of ARDS, bacterial pneumonia may also cause sepsis [19, 28, 29]. Cecal ligation and puncture (CLP) models of sepsis have shown that there is an upregulation of the RhoA effector protein Rho kinase 1 (ROCK1), which can contribute to increased 
Table 1-1. Direct and indirect causes of severe lung inflammation

\begin{tabular}{ll}
\hline Direct & Indirect \\
\hline Infectious pathogens (ex. & Ischemia/reperfusion[2] \\
lipopolysaccharide)[7, 30] & \\
Aspiration injury[8,17,22, 30] & Pancreatitis[8] \\
Allergens[30] & Severe burns[8] \\
Toxic gases[8, 30] & Mass transfusion[8, 22] \\
Barotrauma/Volutrauma[30] & Sepsis[2, 4, 7, 17, 22, 31] \\
Mechanical ventilation injury[8, 22, 30] & Severe trauma/Shock[8, 17, 22] \\
Pneumonia[7, 8, 17, 22] & Drug reactions/overdose[8, 22] \\
Lung contusions[8,22, 30] & Multiple/long bone fractures[8] \\
Airway obstruction[8] & Cardiopulmonary bypass[8] \\
Fat emboli[22] & \\
\hline
\end{tabular}


microvascular permeability by disrupting AJs and endothelial cell contraction [10, 32, 33]. There is also increased activation of the coagulation cascade in sepsis, which may contribute to microthrombus formation and microvascular occlusion $[2,10]$.

While mechanical ventilation is a major intervention in treating many critical illnesses, it may worsen or even cause severe lung inflammation and injury in what is termed ventilator-induced lung injury (VILI) $[8,29]$. In the past, mechanical ventilation was given with high tidal volumes, which has been shown to induce pro-inflammatory responses, leading to an increase in adhesion molecules on lung microvascular endothelial cells, as well as over-inflation of the alveoli $[22,30]$. In one study in mice infected with Streptococcus pneumoniae, mechanical ventilation resulted in increased lung permeability and decreased blood oxygenation compared to mice with pneumonia alone [29]. In cases where inflammation in the lung has already progressed to the point that there is increased vascular permeability or edema, blood flow in the area may be compromised to the point which mechanical ventilation yields ventilation-perfusion mismatch [1]. This ventilator dead space contributes to the over-inflation of the lungs such that the endothelial cells become stretched, damaging both already inflamed tissues as well as unaffected areas $[1,8]$. However, low tidal volumes also carry risks because of the necessary increase in respiratory rates that may lead to hypercapnia [22, 29]. Current strategies to prevent VILI involve low tidal volume with high positive end-expiratory pressure (PEEP), which combined help to mitigate overstretch injury as well as the collapse of alveoli [8, 34-36].

\section{Mechanisms of Endothelial Barrier Dysfunction}

A major path through which increased permeability is achieved is through endothelial cytoskeletal remodeling. Inflammatory mediators induce endothelial activation, which often includes the involvement of Rho family GTPases, RhoA and Rac1 [9, 37]. In healthy endothelium, Rac1 is the predominant active GTPase regulating the actin cytoskeleton in a barrier-protective manner, mediating the stability of the cortical actin band as well as the association between the actin cytoskeleton and the AJs/TJs[9]. In disease states, inflammatory mediators induce the activation of the RhoA, and its downstream effector ROCK, which affects actin dynamics in a barrierdestabilizing manner $[9,10]$. In addition to promoting actin stress fiber formation over cortical actin band formation, RhoA induces endothelial cell contraction and rounding $[10,37]$. Hepatocyte growth factor (HGF) induces the activation of Rac1, and in a two-hit model of ALI (induction of VILI and treatment with thrombin), treatment with HGF decreased lung vascular leak and infiltration of immune cells into lung tissue [38]. ExoS and ExoT, the cytotoxins responsible for increases in permeability associated with Pseudomonas aeruginosa-induced lethal pneumonia, were found to significantly decrease Rac 1 activation and increase RhoA activation within 10 minutes of treatment in lung endothelial monolayers [39].

Inflammatory mediators, particularly those activating G-protein coupled receptors, will also induce an increase in intracellular $\mathrm{Ca}^{2+}$ through the emptying of 
internal $\mathrm{Ca}^{2+}$ stores [40]. This emptying of $\mathrm{Ca}^{2+}$ stores is able to, in turn, stimulate external calcium entry through the activation of transient receptor potential canonical (TRPC) channels [9] A major TRPC protein in the endothelium is TRPC6. LPS activation of TLR4 subsequently leads to an increase in $\mathrm{Ca}^{2+}$, and LPS airway instillation was unable to induce increases in lung permeability in a TRPC6 knockout mouse line [41].The increase in $\mathrm{Ca}^{2+}$ leads to the $\mathrm{Ca}^{2+}$ /calmodulin dependent activation of myosin light chain kinase (MLCK), which phosphorylates myosin II [37]. Through this the actomyosin motor is activated which increases intracellular tension through the crossbridging interactions between actin and myosin fibers. This subsequently results in the pulling apart of the interendothelial junctions and contributes to the rounding of endothelial cells $[9,37]$.

In addition to the changes to the cytoskeleton due to endothelial cell activation by pro-inflammatory mediators, damage caused by leukocytes is also a major contributor to increases in microvascular permeability. As explained earlier, the unique architecture of the lung capillary network creates an environment where leukocytes (specifically neutrophils) may become marginated and is also the site of leukocyte migration into targeted tissues. In normal endothelium, there is some baseline expression of adhesion molecules but intravascular shear forces and the endothelial glycocalyx prevent leukocyte adhesion as well as adhesion molecules exposure; in inflammation, however, activated endothelial cells upregulate production of chemokines and adhesion molecules (such as P-selectin, E-selectin, and ICAM1) presented on the luminal surface and various proinflammatory mediators also initiate loss of proteins composing the glycocalyx, further exposing the adhesion molecules[1, 13, 42-45]. Increases in these responses result in recruitment and accumulation of leukocytes at the targeted tissues [24, 44].

Traditionally, the steps in leukocyte movement across the endothelial barrier are rolling, adhesion, and diapedesis. Neutrophils, however, are typically wider than the pulmonary capillary diameter, and they must undergo a shape change to pass through [11-13]. Activation of the neutrophils during inflammation only increases their stiffness and therefore the transit time through the microvasculature $[13,40]$. For this reason, while other systemic beds see neutrophil extravasation primarily in post-capillary venules, in the lungs this is primarily observed in the capillaries, and rolling is not thought to occur in this transendothelial migration [11, 26, 40, 42]. Neutrophils trapped in these capillaries can result in microvascular blockage and contribute to hyperpermeability through the release of cytotoxic agents, such as reactive oxygen species (ROS), antimicrobial peptides, proteases, and lytic enzymes [46, 47]. In addition, neutrophils have been shown to undergo a specific type of cell death in which they extrude neutrophil extracellular traps (NETs): nuclear DNA strands in web-like structures that act to entrap pathogens $[47,48]$. NETs have been shown to further induce cytotoxicity and endothelial cell death, in addition to contributions to permeability and microvascular occlusion [47]. In one study of transfusion-related ALI, antibodies directed against histones (a component of NETs) lead to reduced lung edema and mortality[48]. In sepsis, depletion of neutrophils has been shown to be protective to the lungs $[1,13,26]$. In one influenza model of ALI, neutrophil-depleted mice showed no signs of respiratory distress or 
development of NETs [49]. Thus, while immune cells are necessary for recovery, overzealous activation of leukocytes may exacerbate inflammation.

\section{Common Inflammatory Mediators Affecting Microvascular Permeability}

While there are many causes and factors that may precede lung inflammation, the signaling involved is often initiated by the same common inflammatory mediators.

In inflammation, the coagulation cascade is activated and leads to the production of thrombin at sites of pulmonary microembolism $[1,50]$. Within the coagulation cascade, the serine protease thrombin cleaves fibrinogen to fibrin, allowing for fibrin deposition and clotting $[2,51,52]$. Thrombin binds protease-activated receptor-1 (PAR1), a G-protein coupled receptor [50]. Activation of PAR-1 leads to generation of inositol trisphosphate $\left(\mathrm{IP}_{3}\right)$, which then binds its receptors at the endoplasmic reticulum (ER) and causes ER store $\mathrm{Ca}^{2+}$ release as well as subsequent external $\mathrm{Ca}^{2+}$ entry.. This increase in intracellular calcium has been shown to underlie the thrombin-induced actions of endothelial cell contraction, increased microvascular permeability, and increased actin polymerization and stress fiber formation $[53,54]$. In addition, activation of PAR-1 by thrombin also induces activation of NADPH oxidase 2 (Nox2), leading to the production of ROS, and activation of RhoA, both of which further contribute to thrombin-induced disruption of AJs and increases in barrier permeability [10,51].

LPS, as mentioned earlier, is an essential component of Gram-negative bacterial cell walls (ex: Escherichia coli) that is recognized by and activates TLR4 on endothelial cells $[41,55]$. TLR4 activation has been shown to induce the decreased expression of VE-cadherin and the disruption of AJs, and initiates the activation of pro-inflammatory signaling pathways leading to cytokine expression and microvascular barrier disruption through RhoA/ROCK activation $[19,41,56]$ In a study using human microvascular endothelial cells in culture, inhibiting ROCK prevented the LPS-induced MLC phosphorylation and decrease in transendothelial resistance [10]. In an in vivo study in which LPS was injected intravenously to induce ALI, blocking ROCK attenuated both LPS-induced lung edema and neutrophil emigration [33]. Another pro-inflammatory mediator that induces endothelial barrier disruption is tumor necrosis factor alpha $(\mathrm{TNF} \alpha) . \mathrm{TNF} \alpha$ is an early inflammatory cytokine that activates its receptor TNFR 1 on endothelial cells $[19,45,57]$. TNF $\alpha$ induces expression of other inflammatory mediators (such as ICAM1, IL-1 $\beta$, and IL-8) through activation of the transcription factor NF- $\mathrm{B}$, as well as induces the degradation of the endothelial glycocalyx through the activation of heparanase $[45,57]$. In endothelial cells, TNF $\alpha$ can also induce the formation of actin stress fibers [26]. While the concentration of TNF $\alpha$ in BAL fluid has been shown to correlate with the development of ALI/ARDS, a clinical trial of a monoclonal antibody directed against it did not show improved survival rates [58, 59].

One example of a barrier-protective inflammatory mediator is cyclic adenosine monophosphate (cAMP) [9]. cAMP is a second messenger generated from ATP by adenylate cyclase (AC) at the plasma membrane and is degraded by phosphodiesterases. 
cAMP has been shown to stabilize the cortical actin ring and strengthen interendothelial junctions, and decrease or prevent the expression of pro-inflammatory cytokines, leading to increased endothelial barrier integrity in inflammation[28]. Pretreatment with the AC activator forskolin significantly decreased the ability of LPS to induce hyperpermeability in human lung microvascular endothelial cells in culture [55]. In a CLP-sepsis induction of ALI, increases in permeability could be blocked by using a phosphodiesterase inhibitor [60]. While generation of cAMP at the membrane induces barrier-protective effects, lung microvascular endothelial cells also express a soluble form of $\mathrm{AC}$ (AC10) that exists in the cytosol [28]. Activation of AC10 has been shown to induce increased microvascular permeability and may be stimulated by the presence of bicarbonate. In one ex vivo model of LPS-induced lung inflammation, increases in permeability could be prevented with the use of an AC10 inhibitor or removal of bicarbonate from the perfusate [28].

Sphingosine-1-phosphate (S1P) is a lysophospholipid signaling molecule that is involved in the regulation of a multitude of cellular processes including embryonic vascular development, cell proliferation and motility, angiogenesis, and immune and allergic responses [61-65]. The expression of S1P, as well as its receptors and enzymes involved in its synthesis, has been found to be increased in inflammation and cancer [65, 66]. S1P is derived from the deacetylation of ceramide to sphingosine, followed by phosphorylation by sphingosine kinase (SphK) [67].Two isoforms of SphK exist, SphK1 and SphK2, with SphK1 being the most abundant as well as the rate-limiting enzyme in S1P synthesis $[62,67]$. The receptors for S1P are a family of G-protein coupled receptors (S1P1-5) that are expressed in a variety of cell types, particularly in endothelial cells [62]. $\mathrm{S} 1 \mathrm{P} 1$ is the predominate receptor in endothelial cells, and is by far the most extensively studied [68]. One of the main contributions of S1P1 in endothelial cells is enhancement of the endothelial barrier. S1P1 signals exclusively through $\mathrm{G}_{\alpha \mathrm{i}}$, resulting in activation of Rac1 $[61,69]$. This leads to enhancement of the endothelial barrier through translocation of VE-cadherin to AJs, cytoskeletal rearrangement, and subsequent spreading of endothelial cells to close interendothelial gaps $[37,61]$. In contrast, S1P2, another S1P highly expressed receptor in endothelial cells, signals through $\mathrm{G}_{\alpha \mathrm{i}}$ as well as $\mathrm{G}_{\alpha \mathrm{q}}$ and $\mathrm{G}_{\alpha 12 / 13}$, which leads to preferential activation of RhoA over Rac1 [61, 69]. This evokes opposite, barrier destructive effects of disruption of AJs, endothelial cell contraction, and induction of actin stress fibers [9, 37, 61]. Because of the opposing responses following activation of the two S1P receptors, the balance of S1P1 and S1P2 signaling is said to maintain vascular tone $[66,70,71]$. However, because of the larger role of the S1P1 receptor, S1P is generally considered a barrier-supportive inflammatory mediator [62].

\section{Expansion of Inflammatory Signaling}

Excessive inflammation can spread outside of the injured or infected tissues to surrounding healthy tissues [72]. This expansion of inflammatory signaling can be observed in ARDS. One of the requirements for a diagnosis is the presence of bilateral infiltrates in the lungs, observed in chest radiographs as opacities in both lungs $[3,7,73]$. This suggests that not only is inflammation spreading throughout a lung, but also that this signaling is able to spread between the two lungs. While the reason for this spread of 
inflammation is unclear, recent evidence points to the movement of second messengers through gap junctions as the causative mechanism.

Gap junctions facilitate the direct exchange of ions and small molecules between adjacent cells [74]. They are composed of connexin subunits; 6 connexins form 1 hemichannel or connexon, and connexons from two adjacent cells form the functioning gap junction channel [75]. Gap junctions are known to allow the propagation of signaling molecules in a variety of cell types [76-78]. In pulmonary endothelium, Connexin 43 (Cx43) is abundantly expressed and has been shown to be the major connexin involved in the spread of inflammatory signaling. Increases in endothelial permeability induced by the inflammatory mediators, thrombin and LPS occurred in tandem with increases in Cx43 expression, and inhibiting intercellular communication through gap junctions mitigates the increases in permeability [56, 79-81]. Cx43-containing gap junctions clearly contribute to the spatial expansion of inflammatory signaling, and as more is elucidated as to the exact mechanisms involved in this propagation of signaling, such as specific second messengers involved, new and more-effective therapies may be developed to limit it.

\section{Specific Aims}

For as much as has been studied on this ubiquitous inflammatory event, the many gaps of that knowledge allow severe lung inflammation to remain an often deadly condition. Increased microvascular permeability has been shown to be the most common symptom, regardless of etiology. However, many of the traditional methods of studying the specific responses within the endothelium are unable to adequately capture or illustrate the mechanism behind endothelial monolayer disruption. To that end, the goal of this project is to study signaling induced by inflammatory mediators in a physiologically relevant model to elucidate signaling molecules involved in the hyperpermeability response. This will be specifically addressed by employing the isolated perfused rodent lung model to:

1. Define spatially-expansive, barrier-disruptive signaling induced by thrombin

2. Determine specific second messengers mediating this spatial expansion

3. Explore the interplay between signaling induced by both thrombin and S1P

These points will all be addressed in the following with the intention of identifying previously unknown mechanisms by which excessive inflammatory responses may be curtailed. 


\section{CHAPTER 2. THE ISOLATED PERFUSED RODENT LUNG MODEL}

The majority of what we know about inflammatory signaling processes comes from studies done in cell cultures. Barrier permeability in particular lends itself easily to experiments using endothelial monolayers grown on transwell inserts, allowing for precise measurement of the passage of molecules from the apical to basal compartments. There are numerous advantages to studying inflammatory signaling in cells: there are established cell lines readily available; cell culture itself is relatively easy and inexpensive; and a large scale of results may be obtained in a short amount of time. However, both the conditions in which cells are cultured and the results obtained therein may not always coincide with in vivo observations. Cultured endothelial cells may lose their phenotype with successive passages and are missing the interactions with other cell types within their respective tissues [18]. In addition, some studies rely on endothelial cells that originate from completely different organs, such as using HUVECs to make determinations about lung inflammation [82-85]. In short, there is a vacuum for more physiologically-relevant methods.

One such solution for this would be studies employing intravital microscopy of the lung, in which a sedated and anesthetized animal has a transparent window implanted in their thoracic cavity allowing for imaging [31]. However, imaging with this specific technique is complicated by the constant movement of the lungs, due to blood flow and ventilation. However, these obstacles are removed in the isolated perfused lung (IPL) model. IPL is an ex vivo model in which the lungs are surgically removed from the animal, perfused at a constant rate, and kept constantly inflated [31, 86]. Maintaining continuous physiological pressures in the airways and vasculature allows for a highly stable surface that is well-suited for imaging, and the results gained from this model more closely mimic in vivo observations compared to monolayer studies [84, 86].

\section{Surgery and Set Up}

Prior to surgery, the perfusion system is set up at the microscope, and the perfusate media (used to supplement the collected, autologous blood) is warmed to $37^{\circ} \mathrm{C}$. After sedating and anesthetizing the rat or mouse, the trachea of the rodent is cannulated. Next, the skin covering the chest is removed. Heparin is injected directly into the heart (.5-1 mg), allowed to circulate for approximately 30 seconds, and then the nowheparinized blood is collected through the same syringe. Following this, either the ventral chest wall is severed longitudinally and kept open with a rib separator (in the rat), or the ribs are cut away entirely (in the mouse). Incisions are made in the heart first below the opening of the pulmonary artery and then at the apex of the heart. Through these incisions cannulae are placed in the pulmonary artery and into the left atrium, respectively. Finally, the trachea is severed above the cannula, and the lungs and heart are excised. They are then placed in a dish containing gauze that has been pre-wet with saline. This dish is then transferred to the microscope and perfusion system. 
Immediately following transfer, the pulmonary artery and left atrial cannulae are connected to the perfusion tubing and the tracheal cannula is connected to a separate airway tubing. Prior to the start of perfusion, the lungs are inflated with room air. The collected blood is added into the pre-warmed perfusate media, and the peristaltic pump (which evenly and continuously directs flow through the pulmonary artery cannula and out the left atrial cannula) is started (Figure 2-1). The perfusate media used to replace or supplement the autologous blood, in addition to being pre-warmed, also contains sugars, physiological salts, and albumin to maintain cellular processes, $\mathrm{pH}$, and permeability [86, 87].

\section{Delivery of Dyes and Reagents to Pulmonary Microvessels}

The physical stability of the IPL is ideal for microscopy studies, and this method is often employed in real-time fluorescence imaging experiments. While fluorescent dyes may be added directly to the perfusate, it is often more prudent to expose and image only a section of the microvasculature. There are three main methods to accomplish this: superfusion, catheter infusion, and micropuncture instillations.

In superfusion, a catheter connected to a syringe pump is suspended above the lung. The reagent is then allowed to drip directly onto the lung surface (Figure 2-2). Normally, the lung surface will be first fixed and/or permeabilized to ensure effective distribution of dyes or antibodies to the microvessels. Catheter infusions allow for a more controlled delivery of reagents. With this method, a microcatheter is fed through the left atrium and wedged into the microvasculature. Because red blood cells in the microvasculature may block or obscure fluorescence, microvessels are first cleared of these cells by an infusion of perfusate media prior to delivery of fluorescence dyes or reagents. (Figure 2-3). The most delicate and precise method is micropuncture instillations. The beveled tip of a glass micropipette connected via tubing to a syringe is used to pierce a post-capillary venule (approximately $20 \mu \mathrm{m}$ in width) (Figure 2-4). The instilled reagent is mixed with a fluorescent dye, and the size of the instillation is viewed through the microscope and regulated by the pressure used to compress the syringe. This also allows for precise delineation of the microvessels receiving the substance. These methods are sometimes used in conjunction with one another, such as first clearing a section of the vasculature via a catheter before performing micropuncture.

In summary, IPL is an ex vivo method in which the microenvironment is maintained to replicate different physiological parameters to what is observed in vivo. Several techniques are employed to supply controlled and precise delivery of dyes and reagents to pulmonary microvessels, allowing for fluorescence studies that provide results more closely related to what is seen in the organism compared to what is observed in cell culture studies. 




Figure 2-1. Diagram of perfusion set up in IPL

Diagram showing the isolated lungs and the flow of blood and media through the perfusion system. Beginning at the perfusate reservoir, the blood and perfusate media passes through the peristaltic pump. The pump thrusts the liquid forward at a constant rate and pressure, as opposed to the pulsation pumping of the heart. The liquid then passes through an air trap which eliminates air bubbles, thereby preventing pulmonary embolism. The tubing section following the pump is gathered in a spiral such that the perfusate media flowing through spends a prolonged time in the $37^{\circ} \mathrm{C}$ water bath. The perfusate then is pumped into the lungs through the pulmonary artery cannula, circulates, and then is pumped back out through the left atrial cannula. The pressure in the tubing connected to the pulmonary artery and the left atrial cannulae, as well as the tubing connected to the tracheal cannula, is monitored via a pressure transducer. The pressures in the pulmonary artery, left atrial, and tracheal tubing are maintained at $3 \mathrm{~cm} \mathrm{H}_{2} \mathrm{O}, 10$ $\mathrm{cm} \mathrm{H}_{2} \mathrm{O}$, and $5 \mathrm{~cm} \mathrm{H}_{2} \mathrm{O}$ respectively. 


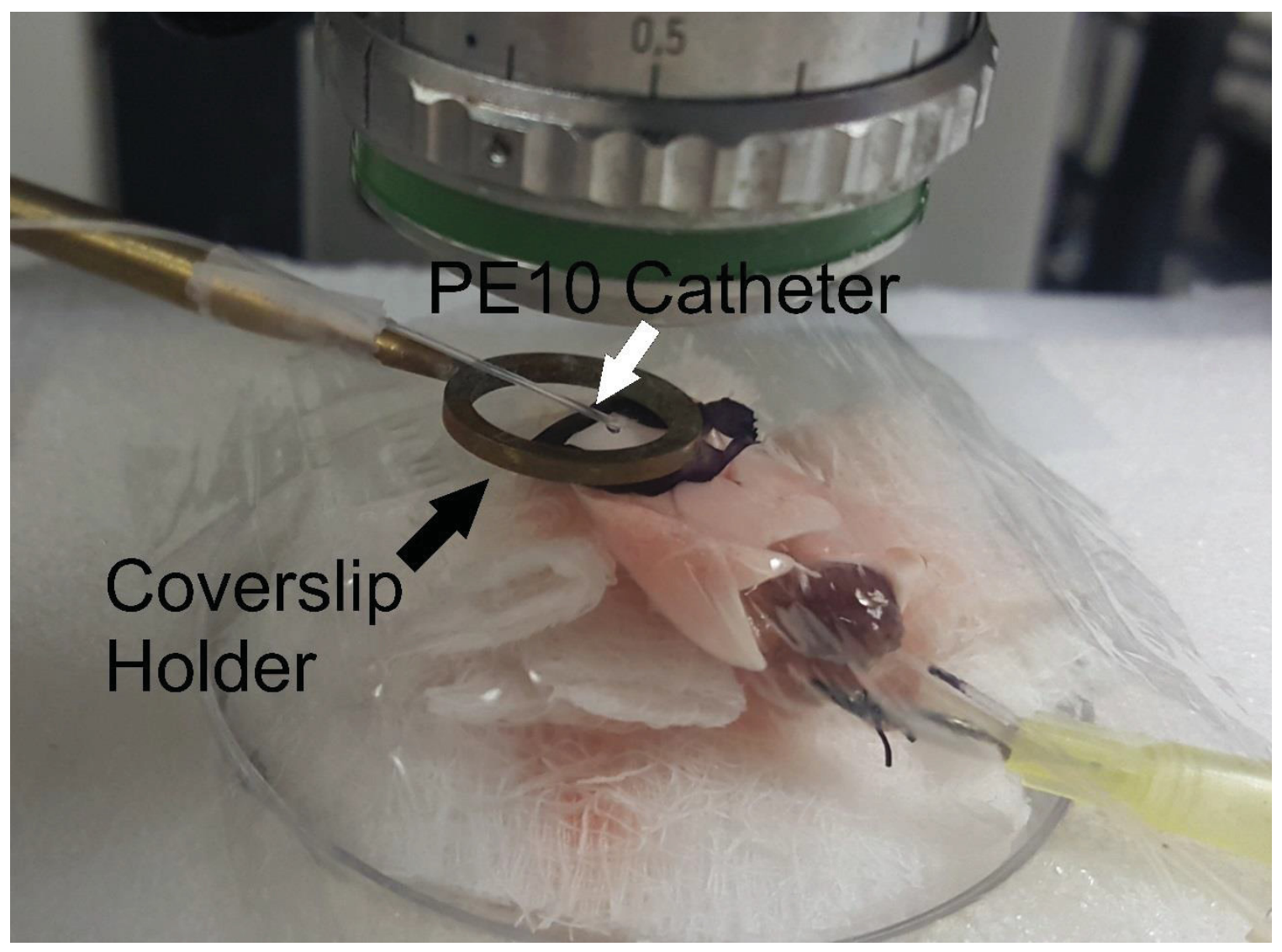

Figure 2-2. Delivery of dyes via superfusion

Image depicts set up for superfusion delivery of dyes and reagents to the mouse lung surface. A PE10 microcatheter (white arrow) is affixed to a coverslip holder (black arrow), and the superfusate is allowed to drip directly onto the lung tissue. Under the microscope, the edge of the catheter may be precisely positioned to a targeted microvascular bed at the lung surface. 


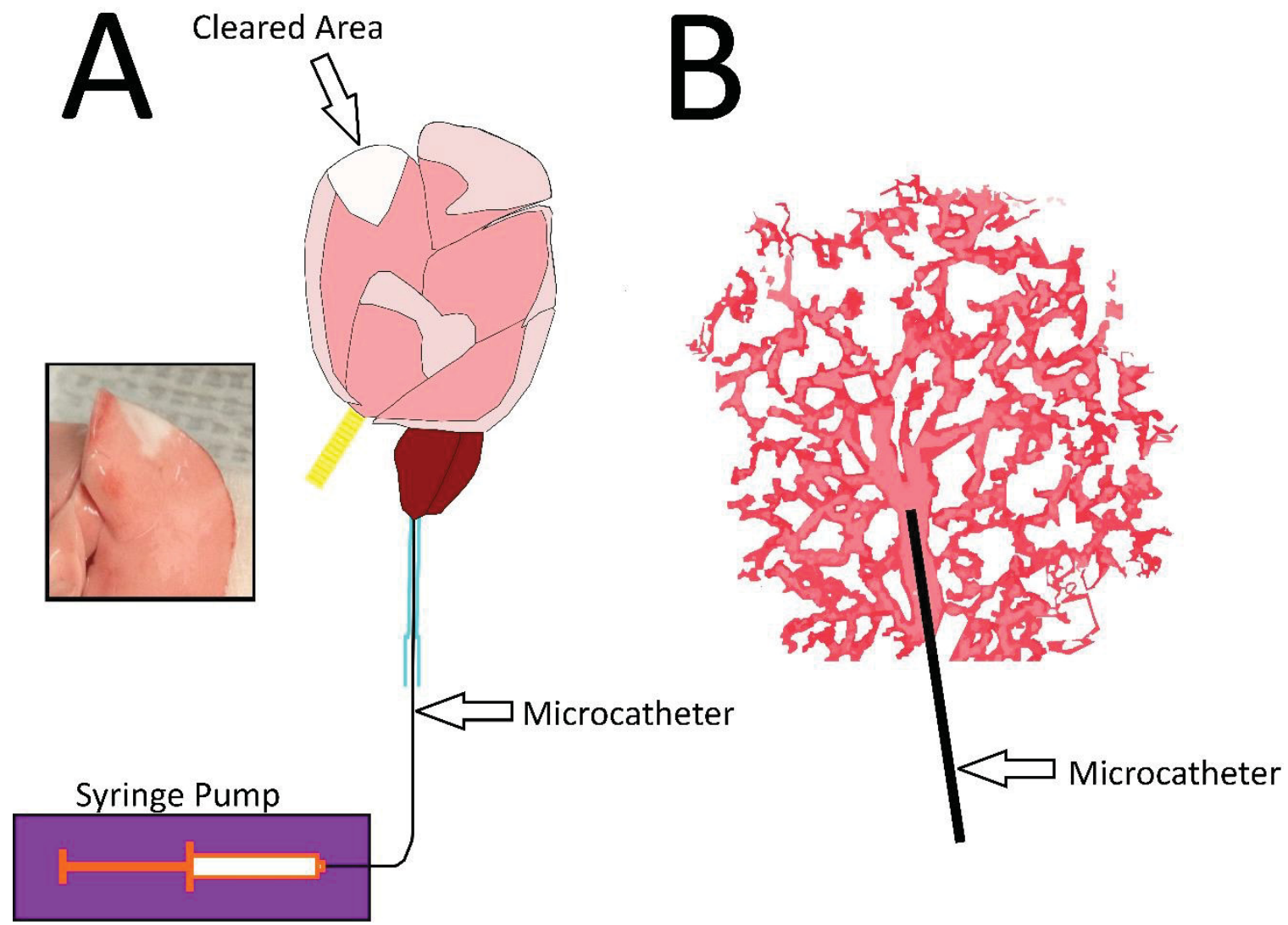

Figure 2-3. Delivery of dyes via microcatheter

Diagrams and image showing placement of microcatheter into pulmonary microvessels. (A) Diagram depicts the placement of the PE10 microcatheter through the LA cannula. The microcatheter is attached to a filled syringe on a pump. Inset shows cleared area following catheter delivery of HBS. (B) Diagram depicts microcatheter wedged into a larger vessel and delivering an infusion to all smaller, branching microvessels. 

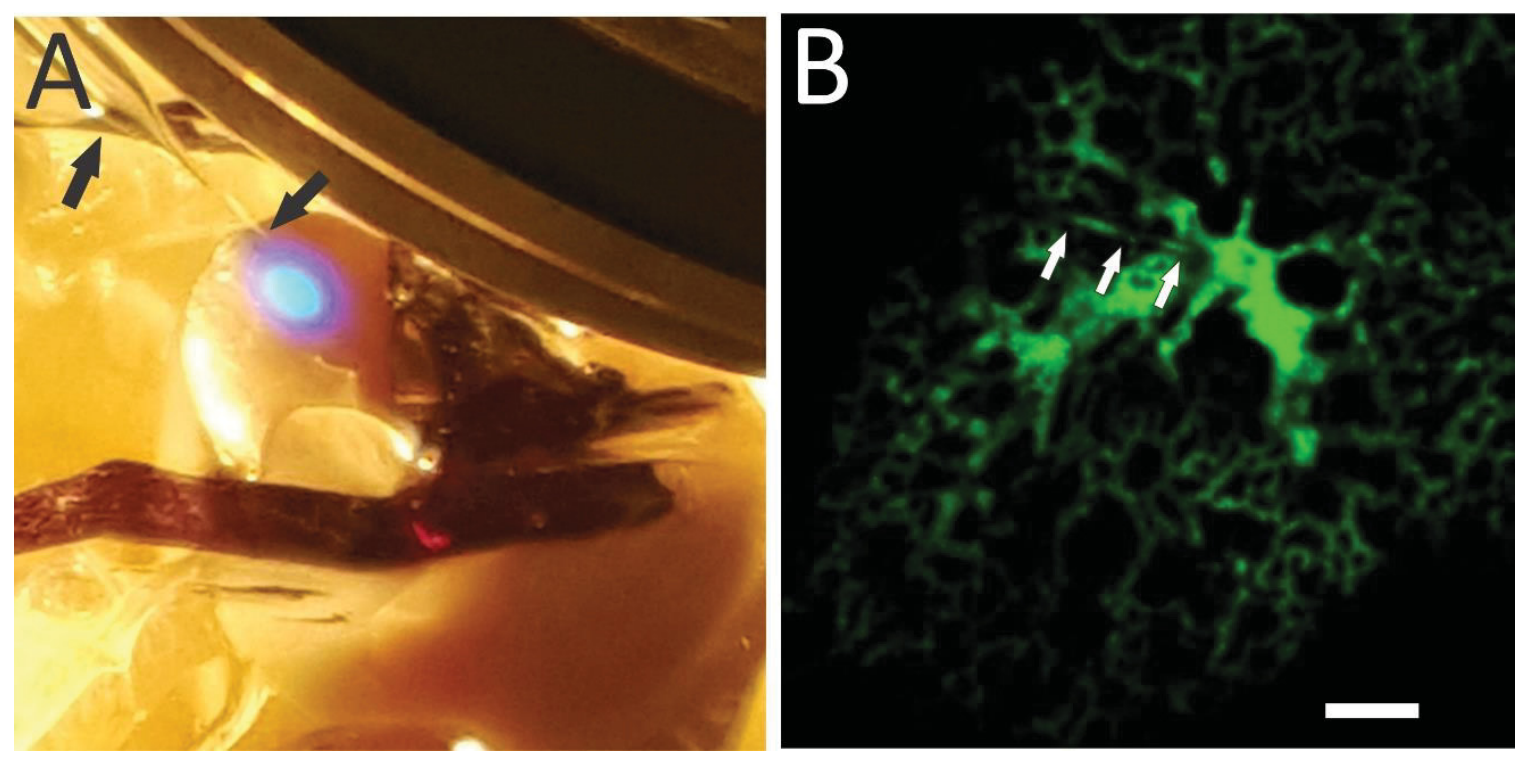

Figure 2-4. Delivery of dyes via micropuncture

Images showing micropuncture delivery of fluorescent dye. (A) Image shows set up of micropuncture. Here, blue light is used to identify the tip of the micropipette (black arrows) under the microscope. (B) Confocal image following micropuncture instillation delivery of fluorescent dye into microvasculature. Filled micropipette is visible (white arrows). Bar $-50 \mu \mathrm{m}$. 


\section{CHAPTER 3. THROMBIN INDUCES INOSITOL TRISPHOSPHATE- MEDIATED SPATIALLY EXTENSIVE RESPONSES IN LUNG MICROVESSELS*}

\section{Introduction}

Compartmentalization is being increasingly recognized as a mechanism for eliciting unique responses via a similar set of second messengers. In this regard, cellular signaling that results from activation of plasma membrane receptors may depend on compartmentalized regulation of second messengers. Thus, experimental models that induce second messenger increases throughout an entire cell may be inadequate substitutes to elucidate responses resulting from receptor-mediated increases in second messengers.

Intercellular diffusion of second messengers, including $\mathrm{Ca}^{2+}, \mathrm{IP}_{3}, \mathrm{cAMP}$, and ATP, facilitates the induction of responses at sites remote from the stimulus site and also coordinates responses among a larger group of cells [88-92]. The predominant second messenger is dependent on the stimulus and defines the remote response. For example, in lungs, remote induction of pulmonary arteriolar vasoconstriction by hypoxia is mediated by membrane depolarization [93, 94]. In contrast, induction of P-selectin expression and surfactant secretion in response to cell-wide increases in $\mathrm{Ca}^{2+}$ depends on intercellular diffusion of $\mathrm{Ca}^{2+}[81,90,95]$. In the latter studies that implicate $\mathrm{Ca}^{2+}$ as the diffusing second messenger, the cell-wide $\mathrm{Ca}^{2+}$ increases were achieved by photolytic uncaging of $\mathrm{Ca}^{2+}$ in single cells. However, since $\mathrm{Ca}^{2+}$ signaling is compartmentalized, other second messengers may predominate in the induction of remote responses when intracellular $\mathrm{Ca}^{2+}$ increases are elicited via activation of plasma membrane receptors. To delineate this possibility, alternate models that activate specific plasma membrane receptors on cells located within a spatially restricted region may need to be utilized.

In lung inflammation, a variety of inflammatory mediators activate G-protein coupled receptors and induce the release of ER-stored $\mathrm{Ca}^{2+}$. In the case of thrombin and PAR-1 activation, this increase in intracellular $\mathrm{Ca}^{2+}$ drives the increases in microvascular permeability as well as F-actin formation [96-98]. Given the compartmentalization intrinsic to $\mathrm{Ca}^{2+}$ signaling and that thrombin induces both $\mathrm{IP}_{3}$ generation and $\mathrm{Ca}^{2+}$ release, we utilized thrombin to define the specific second messenger diffusing through endothelial connexin-containing gap junctions.

In the lungs, the gap junction protein $\mathrm{Cx} 43$ is abundantly expressed, and intercellular communication through $\mathrm{Cx} 43$-containing gap junctions has been shown to

*Reprinted from The American Journal of Pathology. Vol 187 /4. Rachel Escue, Kathirvel Kandasamy, and Kaushik Parthasarathi. Thrombin Induced Inositol Trisphosphate-Mediated Spatially Extensive Response in Lung Microvessels, 921-935, Copyright (2017), with permission from Elsevier 
mediate the expansion of inflammatory signaling $[79,80]$. In studies focusing on lung microvessels, $\mathrm{Cx} 43$ has been shown to mediate the $\mathrm{Ca}^{2+}$-dependent process of surfactant secretion and P-selectin expression as well as thrombin-induced increases in permeability. In the case of thrombin-induced signaling, it is unclear which second messenger is being communicated to elicit these responses. As PAR-1 activation induces increases in $\mathrm{IP}_{3}$ and $\mathrm{Ca}^{2+}$, and $\mathrm{Cx} 43$ has been shown to facilitate the communication of both, in this study we chose to investigate which specific second messenger is being communicated in in situ pulmonary microvessels and is mediating the spatial expansion of thrombin-induced responses [89, 90, 99]

\section{Materials and Methods}

\section{Fluorophores and Reagents}

The cell permeable $\mathrm{Ca}^{2+}$ indicators, Fura $2 \mathrm{AM}(10 \mu \mathrm{M})$, Fluo 8 AM $(20 \mu \mathrm{M})$, Fluo4 $(10 \mu \mathrm{M})$, and the nuclear stain Hoeschst-33342 $(10 \mu \mathrm{g} / \mathrm{ml})$ were from Tef Labs (Austin, TX). The F-actin marker CF488A-Phalloidin $(0.5 \mathrm{U} / \mathrm{ml})$ was from Biotium (Hayward, CA). Thrombin (5-10 U/ml), rhodamine-dextran $70 \mathrm{kDa}(\mathrm{RDx} 70 ; 0.5 \mathrm{mg} / \mathrm{ml})$, rhodamine dextran 40kDa, $(\mathrm{RDx} 40 ; 0.5 \mathrm{mg} / \mathrm{ml})$ and fluorescein isothiocyate $20 \mathrm{kDa}$ (FDx20; $0.5 \mathrm{mg} / \mathrm{ml}$ ) were from Sigma (St. Louis, MO). The ER Ca ${ }^{2+}$-ATPase pump inhibitor, tert-butylhydroquinone (tBHQ; $10 \mu \mathrm{M})$ and ER $\mathrm{IP}_{3}$-receptor $\left(\mathrm{IP}_{3} \mathrm{R}\right)$ blocker, Xestospongin $\mathrm{C}(\mathrm{XeC} ; 25 \mu \mathrm{M})$ were from EMD Millipore (Billerica, MA). Cell


from Invitrogen (Grand Island, NY). The transfection reagent, Chariot $(1 \mathrm{mg} / \mathrm{ml})$ was from Active Motif (Carlsbad, CA). The Cx43-gap junction inhibiting peptide, Gap27 $(190 \mu \mathrm{M})$ was custom synthesized by Genemed Synthesis (San Antonio, TX).

Fluorophores and reagents were infused into microvessels in a $\mathrm{Ca}^{2+}$-rich HEPES-buffered Ringer's solution (HBS; $150 \mathrm{mM} \mathrm{Na}^{+}, 5 \mathrm{mM} \mathrm{K}, 1 \mathrm{mM} \mathrm{Ca}{ }^{2+}, 1 \mathrm{mM} \mathrm{Mg}{ }^{2+}, 10 \mathrm{mM}$ glucose, $20 \mathrm{mM}$ HEPES) with $4 \%$ dextran $(40 \mathrm{kDa})$ and $1 \%$ fetal bovine serum at a final $\mathrm{pH}$ of 7.4. Phosphate buffered saline with $\mathrm{Ca}^{2+}$ and $\mathrm{Mg}^{2+}$ was from GE Life Sciences.

\section{Isolated Perfused Lungs}

Animals were treated in accord with protocols approved by the Institutional Animal Care and Use Committee of the University of Tennessee Health Science Center. Animals were given ad libitum access to food and water, and placed on a 12-h light-dark cycle. Male Sprague-Dawley rats weighing 250-350g were purchased from a commercial vendor. Male endothelial specific-Cx43 knockout $\left(E C-C x 43^{--}\right)$mice on a C57BL/6J background were bred in our animal facility, following the process previously reported $[90,100]$. Age matched floxed $\mathrm{Cx} 43\left(C x 43^{f l f l}\right)$ mice were used as controls. Isolated blood-perfused lungs were prepared from rats and mice, as reported [101, 102]. Briefly, animals were anesthetized by intraperitoneal injection of ketamine and xylazine. Heparin was injected via cardiac puncture and the animals were exsanguinated. Cannulae were 
inserted into the trachea, left atrium, and pulmonary artery to inflate and perfuse blood into the lungs, respectively. The lungs and heart were removed en bloc and transferred to the microscope stage. The lungs were constantly inflated and continuously pumpperfused with warmed, autologous blood at $10 \mathrm{ml} / \mathrm{min}$ (rat) and $2 \mathrm{ml} / \mathrm{min}$ (mouse).

Pressures in the pulmonary artery, left atrium, and airway were maintained at 10, 3, and 5 $\mathrm{cm} \mathrm{H} 2 \mathrm{O}$, respectively. The lungs were kept moist with saline.

For vascular delivery of fluorophores and agents into a microvessel network, a PE10 microcatheter was inserted through the left atrial cannula and wedged into a microvessel. An infusion of HBS was used to establish blood-free conditions in a small area of the lung. For delivery into single microvessels, a micropipette was filled with the appropriate agent and then attached to a pipette holder. A micromanipulator (MO-202U; Narishige, Japan) was used to guide the pipette holder to the vessel of interest, micropuncture the vessel, and then instill the agent or fluorophore.

\section{$\mathrm{Ca}^{2+}$ Imaging}

In a small region of rat lungs cleared of blood, Fura2 AM was infused into microvessels through the microcatheter for 30 minutes. After a 30 min HBS wash, the microvessels were excited at 340 and $380 \mathrm{~nm}$. Fluorescence images were continuously captured at $515 \mathrm{~nm}$ either every 10 seconds or every 1 second, as indicated, using a microscope (BX61WI, Olympus) coupled to a high sensitivity camera [103]. Following a 10 -minute baseline fluorescence capture, we infused either 5 or $10 \mathrm{U}$ of thrombin over 10-15 minutes. Subsequently, the microvessels were flushed with HBS, followed by a second infusion of thrombin. For, blocking experiments, the inhibitor was infused following the wash-off of the first thrombin infusion. Endothelial cytosolic $\mathrm{Ca}^{2+}$ was determined using Fura2 340/380 emission ratio in $3 \mu \mathrm{m}$ x $3 \mu \mathrm{m}$ regions along the vessel wall for both venules and capillaries [103].

\section{Actin Polymerization}

In a region of mouse lungs, cleared of blood using Ringer's infusion, an alveolus near a target venule was filled with $2 \%$ Sudan black in oil by micropuncture and acted as a marker. The target venule was then micropunctured, and thrombin $(5 \mathrm{U} / \mathrm{ml})+\mathrm{RDx} 70$ $(0.5 \mathrm{mg} / \mathrm{ml})$ was instilled over 10 minutes. RDx70 fluorescence was used to determine the spatial distribution of the instilled thrombin. Subsequently, the thrombin-treated and adjacent thrombin-free regions were fixed and permeabilized by superfusing the lung surface with 3.7\% paraformaldehyde, followed by $0.05 \%$ Triton X-100, for 20 min each, respectively. The superfusion solutions were delivered via a PE10 microcatheter connected to an infusion pump (BSP-8000; Braintree Scientific, Braintree, MA). The superfusate flow rate was maintained at $10 \mu \mathrm{l} / \mathrm{min}$. The microcatheter was positioned so that the opening was centered directly above the alveolus instilled with the Sudan Black marker. The spread of the superfusate over the lung surface was restricted via an opening cut in a plastic film placed over the lung surface. Following fixing and permeabilization, 
the thrombin-treated and adjacent thrombin-free regions were superfused with blocking buffer containing $5 \%$ bovine serum albumin for $20 \mathrm{~min}$. Finally, the region was treated with CF488A-phalloidin (0.5 U/ml) [104] and Hoeschst-33342 $(10 \mu \mathrm{g} / \mathrm{ml})$ for $20 \mathrm{~min}$ to stain F-actin and nuclei, respectively. After a Ringer's wash, the microvessels were imaged via a confocal microscope (Zeiss LSM710). In studies used to determine the role of $\mathrm{Cx} 43$, the experiments were repeated in $E C-C x 43^{-/-}$mice. To inhibit $\mathrm{IP}_{3}$-dependent responses, $\mathrm{XeC}$ was infused for 30 minutes prior to thrombin instillation.

During imaging, in addition to obtaining confocal images of the thrombininstilled region, images of the regions adjoining the thrombin-treated region were also captured. The images were captured in all directions extending away from the region of thrombin instillation. To reduce introduction of possible image artifacts by the lung curvature and possible change in image focus due to lung movement, a z-stack of images was captured at each $\mathrm{x}-\mathrm{y}$ setting. Using this set of images, a montage, typically 1500 microns $x 1500$ microns was stitched. In generating the montage, image sections with the best focus were selected from the z-stack of images. The use of different z-planes introduced small differences in fluorescence intensity along the entire length of the montage. CF488A-phalloidin fluorescence intensity was measured at randomly selected sites. The intensity measurements were obtained from the z-plane in which the measurement was in maximum focus. We typically quantified fluorescence intensity at more than 50 sites in each direction away from the thrombin-treated region for each experiment.

\section{$\mathrm{Ca}^{2+}$ and $\mathrm{IP}_{3}$ Uncaging}

We cleared a region of isolated rat lungs by infusing Ringer's solution through a left atrial microcatheter. Then, we infused either Fluo4 AM or Fluo8 AM for 30 min. Subsequently, we either infused caged-Ca ${ }^{2+}$ (NP-EGTA) for $30 \mathrm{~min}$ or caged-IP 3 (NPE$\left.\mathrm{IP}_{3}\right)+$ Chariot $(1 \mathrm{mg} / \mathrm{ml})$ for $30 \mathrm{~min}$. Following a $30 \mathrm{~min}$ stabilization period, we captured images of microvessel Fluo8 or Fluo4 fluorescence (1 image/s) using the upright microscope (BX61WI). To uncage NP-EGTA or NPE-IP ${ }_{3}$, we exposed a defined region of the microvasculature to UV illumination (355 nm; $15 \mathrm{~s}$ ) using a UV laser system (DPSL-355-30, RappOptoelectronic, Germany). Uncaging-induced responses in microvessels were captured for several minutes after exposure to the UV illumination.

\section{Microvascular Permeability}

In a region cleared of blood using a microcatheter in an isolated blood-perfused rat lung, a mixture of thrombin $(5 \mathrm{U} / \mathrm{ml})$ plus $\mathrm{RDx} 70(0.5 \mathrm{mg} / \mathrm{ml})$ was instilled via micropuncture over 10 minutes. RDx70 fluorescence was used to determine the microvessel distribution of thrombin. After thrombin instillation, FDx20 was infused into the thrombin-instilled and adjacent microvessels via the microcatheter for one hour. An image of the FDx20 fluorescence in microvessels was taken every minute using an upright microscope (Olympus BX61WI). After one hour, FDx20 infusion was stopped 
and replaced with HBS. Imaging was continued at one image per minute for 30 minutes. As reported, images were used to determine the FDx20 fluorescence at random sites both within and outside of the micropuncture instillation region [81]. The ratio of maximum FDx20 fluorescence during the FDx20 infusion (peak) to that after a 10 minute HBS wash (residual), termed 'normalized fluorescence' was used as an estimate of microvascular permeability at the measurement sites.

\section{Statistics}

All data are reported as mean \pm SEM. All multiple groups were compared with Kruskal-Wallis One Way ANOVA on Ranks followed by pair-wise multiple comparisons by Dunn's method. Pairs of data were analyzed using rank-sum test. Significance was set at $\mathrm{p}<0.05$.

\section{Results}

\section{Induction of Microvascular Permeability by Thrombin}

Thrombin-induced increase in fluid permeability across endothelial monolayers is well established [84, 105, 106]. In contrast, the effect of thrombin on fluid flux across microvessels is not clear. To determine this, thrombin was continuously instilled into rat lung microvessels by micropuncture for $10 \mathrm{~min}$ (Figure 3-1A). Subsequently, permeability of single microvessels was determined using the FDx20 residual fluorescence method [81]. Images show that the residual FDx20 fluorescence was higher in thrombin-treated than in Ringer's-treated microvessels (Figure 3-1B-E). Quantifying changes in single microvessels revealed that the normalized fluorescence was lower for thrombin-treated microvessels (Figure 3-1F). These results indicated that thrombin increased microvascular permeability in lung microvessels.

\section{Microvessel Actin Stress Fiber Formation}

In endothelial monolayers, thrombin-induced barrier perturbation occurs in tandem with cytoskeletal remodeling, which includes formation of actin stress fibers [107-109]. However, in in situ microvessels it is unclear whether thrombin-induced fluid flux is accompanied by actin stress fiber formation. To define this, a mixture of thrombin and $\mathrm{RDx} 70$ was continuously instilled for $10 \mathrm{~min}$ into microvessels of isolated bloodperfused $C \times 43^{f l / f l}$ mouse lungs using a micropipette. RDx70 helped identify the blood vessels to which the thrombin spread. Confocal images of RDx70 fluorescence captured during the infusion procedure suggested that thrombin spread from the micropunctured vessel into adjacent blood vessels, though the spread was restricted to microvessels 

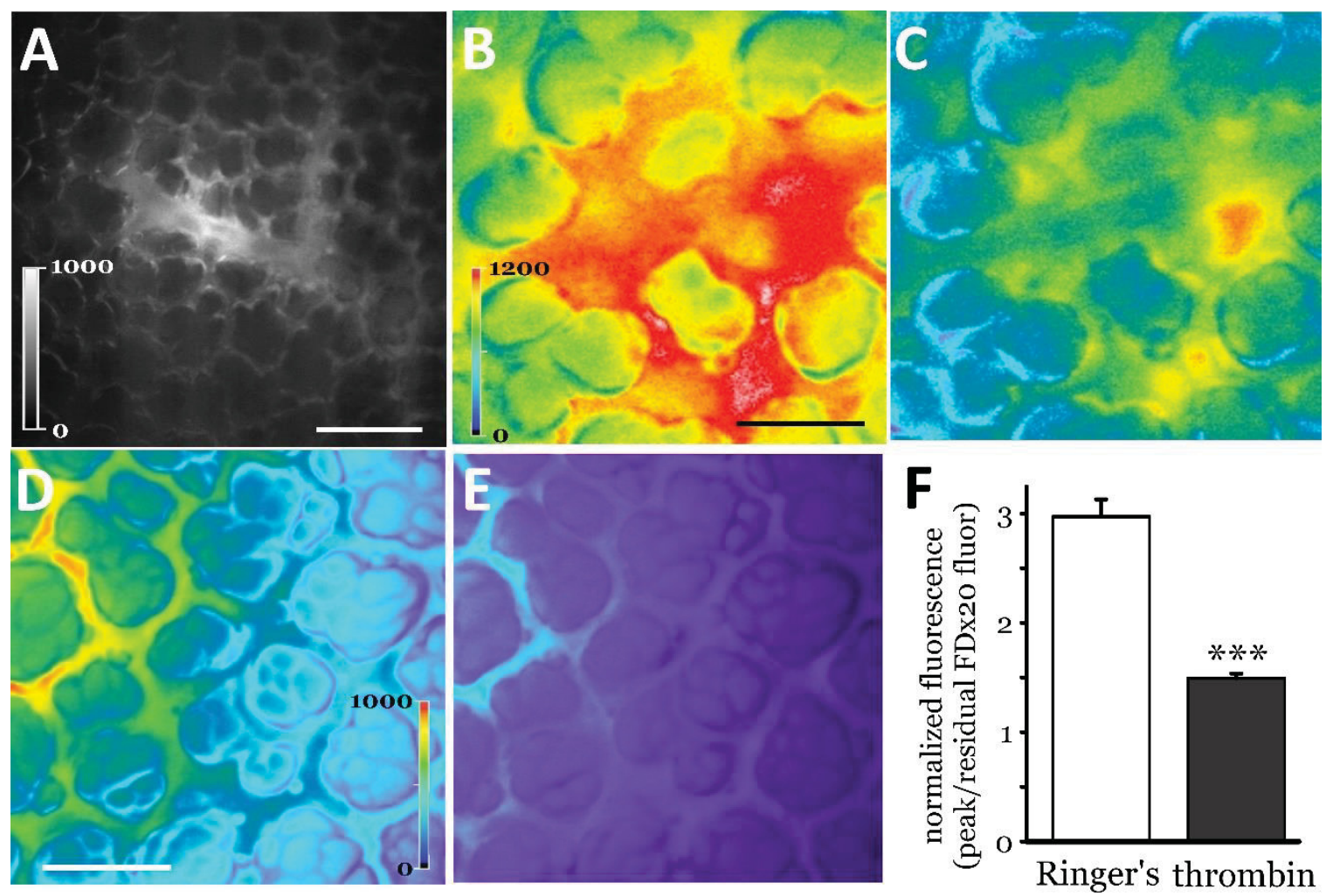

Figure 3-1. Increases in microvessel permeability

(A) Monochrome image shows vascular distribution of rhodamine fluorescence after instillation of thrombin $(5 \mathrm{U} / \mathrm{ml})+\mathrm{RDx} 70(0.5 \mathrm{mg} / \mathrm{ml})$ into a single microvessel of a rat lung. Note that the mixture distributed only to a small number of microvessels. Bar - 100 $\mu \mathrm{m}(\mathrm{B}, \mathrm{C}) \mathrm{FDx} 20(0.5 \mathrm{mg} / \mathrm{ml})$ was infused into thrombin-treated microvessels for $60 \mathrm{~min}$ followed by a Ringer's wash. Pseudocolored images show peak (B) and residual (C) fluorescence of FDx20 in the thrombin-treated vessels. Bar - $100 \mu \mathrm{m}(\mathrm{D}, \mathrm{E})$

Pseudocolored images show peak (D) and residual (E) FDx20 fluorescence in Ringer'streated microvessels. Bar - $100 \mu \mathrm{m}$ (F) Bar graph shows normalized FDx20 fluorescence quantified in single thrombin- and Ringer's-treated microvessels. $n=3$ lungs for Ringer'streated group, $\mathrm{n}=8$ lungs for thrombin-treated group. ${ }^{* * *}=\mathrm{p}<0.001$ compared to Ringer's response. 
located within $200 \mu \mathrm{m}$ from the micropuncture site (Figure 3-2A). Thus, the instilled thrombin remained localized within a small number of microvessels.

Fluorophore-tagged phalloidin is a marker for actin cytoskeleton in endothelial monolayers [110-112]. Hence, we utilized phalloidin tagged to the fluorophore CF488A to determine F-actin formation in in situ lung microvessels. Confocal images of untreated microvessels of $C x 43^{f l / f l}$ mouse lungs indicated that the CF488A fluorescence was low at baseline (Figure 3-2B). Images captured without labeling vessels with CF488Aphalloidin did not reveal any fluorescence, thus excluding the possibility that tissue autofluorescence contaminated CF488A fluorescence (Figure 3-2C).

In response to instillation of PBS as vehicle control, the CF488A fluorescence in microvessels remained similar to that at baseline (Figure 3-2D). The fluorescence was similar in both the PBS-instilled vessels and those located outside the PBS-instilled region. Thus, the instillation procedure by itself did not modify F-actin magnitude in microvessels. In contrast, instillation of thrombin into microvessels resulted in a higher vascular CF488A fluorescence (Figure 3-2E). Montages of confocal images revealed that the CF488A fluorescence was high both in microvessels directly treated with thrombin and also in vessels located outside the thrombin-treatment region. The high fluorescence was evident even in microvessels located more than $1000 \mu \mathrm{m}$ from the outer boundary of the thrombin-treated region (Figure 3-2E). However, in vessels located at increasing distances from the edge of the thrombin-instilled region, the fluorescence steadily declined to baseline levels (Figure 3-2E). Quantifying the CF488A fluorescence in thrombin-treated microvessels revealed that the fluorescence was $80 \%$ higher compared to baseline (Figure 3-2F). In addition, in microvessels located outside the thrombin-instilled region, the CF488A fluorescence was 60\% higher compared to baseline. The data indicate an increase in F-actin both in microvessels treated with thrombin and in those located outside the thrombin-instilled region. Thus, thrombin increases F-actin even in microvessels spatially remote from those directly treated with thrombin.

\section{Microvessels Are the Source of Thrombin-Induced Responses}

Vascular instillations were used to define thrombin-mediated changes in endothelial permeability and F-actin. To exclude the possibility that observed responses were due to the instilled thrombin leaking into the alveolar compartment and initiating responses in epithelial cells, thrombin was instilled with RDx40, a fluorescence marker with a similar molecular weight as thrombin and thus, capable of closely following thrombin distribution spatially. Confocal images of RDx40 captured post-instillation indicated that its distribution was similar to that for RDx70 (Figure 3-3A). Moreover, CF488A-phalloidin fluorescence changes in response to vascular thrombin instillation was similar when either RDx70 or RDx40 was used as the marker (Figure 3-3B, E). In additional experiments, we determined the extent to which alveolar epithelial F-actin increased in response to thrombin. Toward this, we instilled together thrombin, RDx70, and the nuclear marker, Hoechst 33342 into alveoli. Subsequently, we instilled 


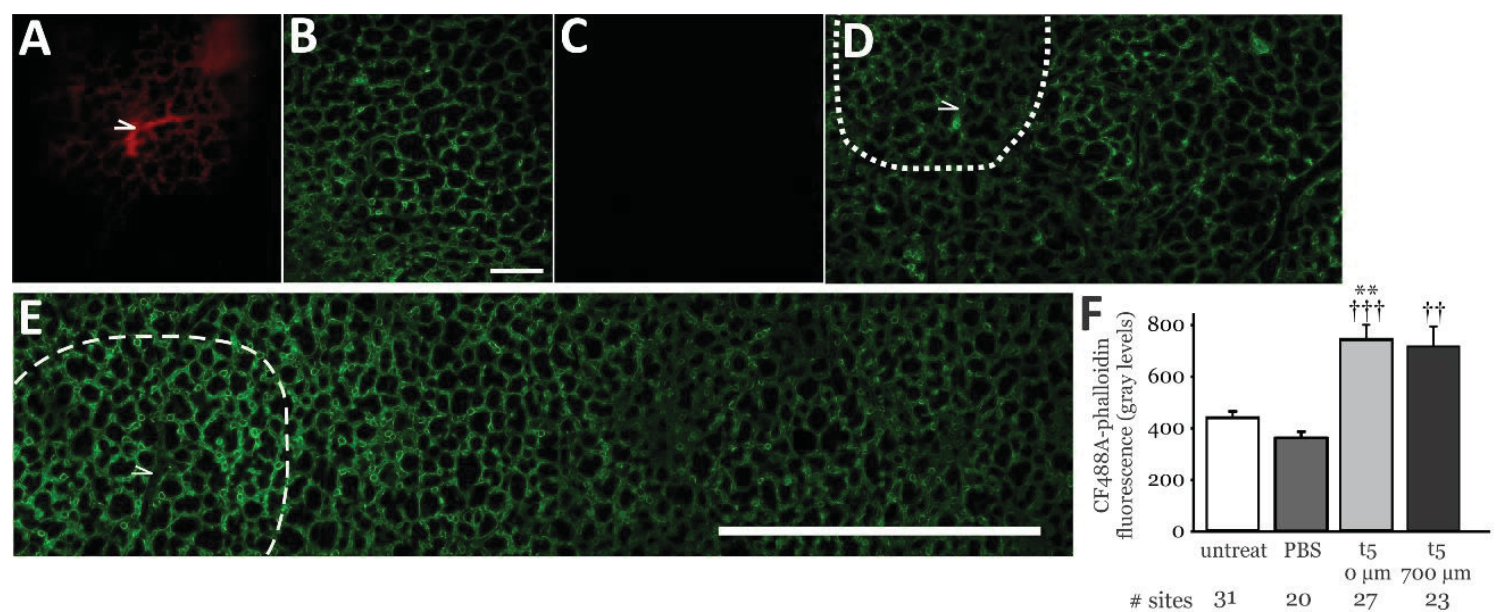

Figure 3-2. Changes in F-actin formation in lung microvessels

(A) Confocal image composite of rhodamine fluorescence shows the vascular distribution of thrombin $(5 \mathrm{U} / \mathrm{ml})+\mathrm{RDx} 70$ mixture at the end of the instillation into a single microvessel (arrowhead) in $\mathrm{Cx} 43^{\mathrm{fl} / \mathrm{fl}}$ mouse lung. (B) Confocal image shows CF488Aphalloidin fluorescence in untreated microvessels of a $\mathrm{Cx} 43^{\mathrm{fl} / \mathrm{fl}}$ mouse. Bar - $100 \mu \mathrm{m}$. (C) Image shows autofluorescence in microvessels of a $\mathrm{Cx} 43^{\mathrm{fl} / \mathrm{fl}}$ mouse captured at the same excitation and emission settings used for capturing CF488A-phalloidin fluorescence. Bar - $100 \mu \mathrm{m}$. (D) A montage of confocal images shows CF488A-phalloidin fluorescence in lung microvessels of a $\mathrm{Cx} 43^{\mathrm{fl} / \mathrm{fl}}$ mouse after PBS instillation. Arrowhead - site of PBS instillation. Dashed line - outer boundary of PBS instillation. Bar - $100 \mu \mathrm{m}$. (E) Montage of confocal images shows CF488A-phalloidin fluorescence in $\mathrm{Cx} 43^{\mathrm{fl} / \mathrm{fl}}$ mouse lung microvessels located within and outside the thrombin-treated region. Arrowhead - site of thrombin instillation. Dashed line - outer boundary of thrombin-treated region. Bar - 500 $\mu \mathrm{m}$. (F) Graph shows CF488A-phalloidin fluorescence in microvessels for the various treatments indicated. $* *=p<0.01$ compared to untreated response, $\uparrow \uparrow=p<0.01, \uparrow \dagger \uparrow=$ $\mathrm{p}<0.001$, respectively compared to PBS response. Untreat - no instillation; PBS - PBS instillation; $\mathrm{t} 5$ - thrombin $(5 \mathrm{U} / \mathrm{ml})$ instillation; o $\mu \mathrm{m}$ - microvessels located within the thrombin-instilled region; $700 \mu \mathrm{m}$ - microvessels located 700-1000 $\mu \mathrm{m}$ away from the outer edge of the thrombin- instilled region. \# sites -number of measurement sites included in analysis. $n=3$ lungs for the un-instilled, $n=3$ for PBS-instilled and $n=4$ for thrombin- instilled groups. 
Figure 3-3. Methodological controls for Thrombin-induced responses in lung microvessels

(A) Confocal image composite shows distribution of rhodamine fluorescence in $\mathrm{Cx} 43^{\mathrm{fl} / \mathrm{fl}}$ mouse lung microvessels following instillation of thrombin $(5 \mathrm{U} / \mathrm{ml})+\mathrm{RDx} 40$ mixture. Arrowhead - site of instillation. (B) Montage of confocal images show CF488Aphalloidin fluorescence in microvessels following micropuncture instillation of thrombin $(5 \mathrm{U} / \mathrm{ml})+\mathrm{RDx} 40$. White dashed line - outer boundary of the thrombin-instilled region. Arrowhead - site of instillation (C,D) Thrombin (5 U/mL), RDx70, and Hoechst 33342 together were instilled into alveoli of $\mathrm{Cx} 43^{\mathrm{fl} / \mathrm{fl}}$ mouse lungs followed by instillation of $3.7 \%$ paraformaldehyde into the same alveoli. Then the thrombin-treated region was superfused with CF488A-phalloidin, as detailed in Methods. Confocal image shows CF488A-phalloidin fluorescence alone in the thrombin-instilled region (C). Confocal image shows CF488A-phalloidin fluorescence with Hoechst 33342-stained nuclei (blue) (D). Note Hoechst 33342-stained nuclei represent cells treated with thrombin. Bars - 100 $\mu \mathrm{m}$. (E) Bar graph shows CF488A-phalloidin fluorescence following microvessel instillation of either thrombin + RDx40 (RDX40) or thrombin + RDx70 (RDX70). (F) Bar graph shows CF488A-phalloidin fluorescence at measurement sites in the absence of any treatment (untreat) or after alveolar instillation of thrombin (alv instill). \# sites number of measurement sites included in analysis. $\mathrm{n}=3$ for both groups. 

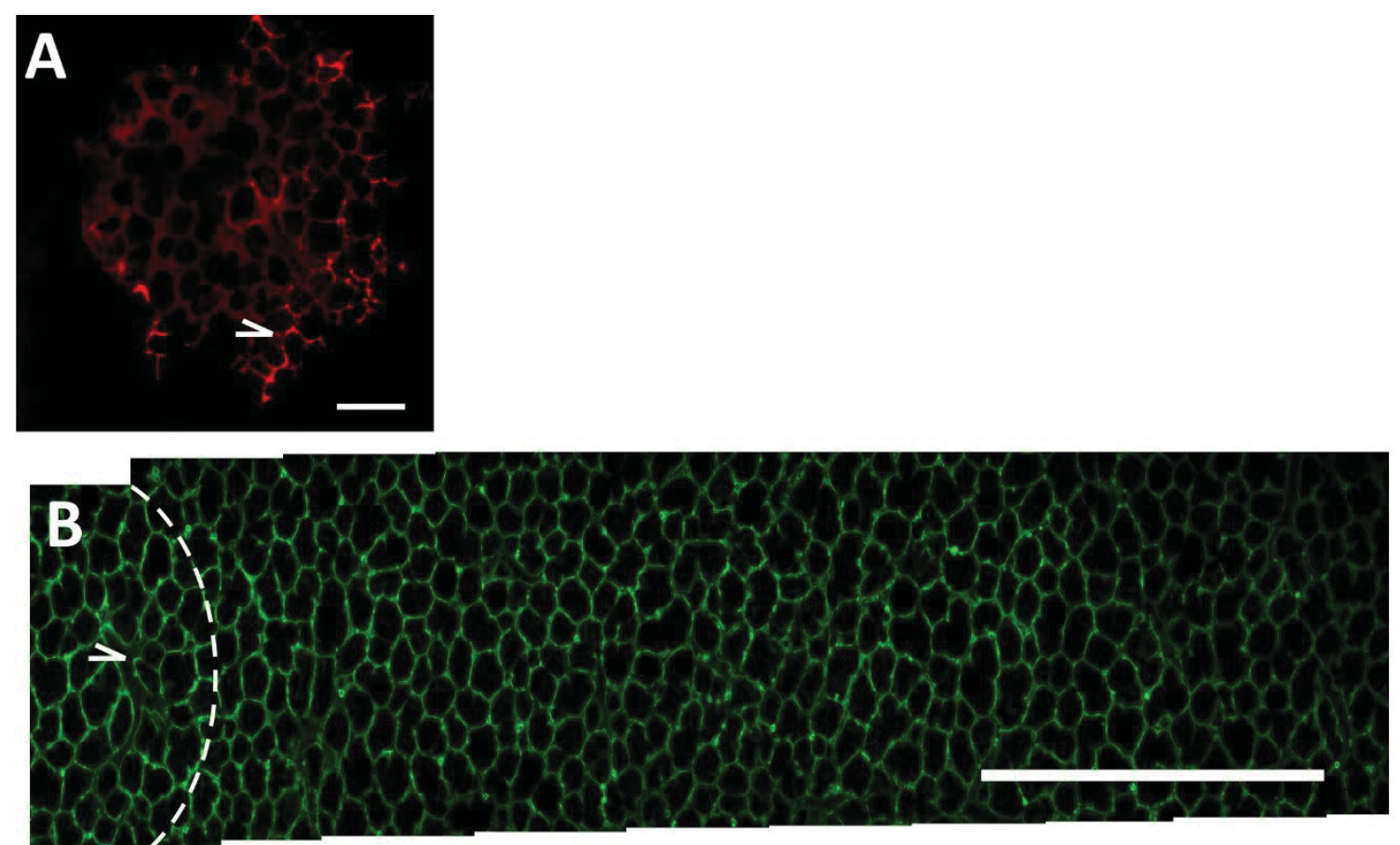

CF488A-phalloidin

+Hoechst 33342
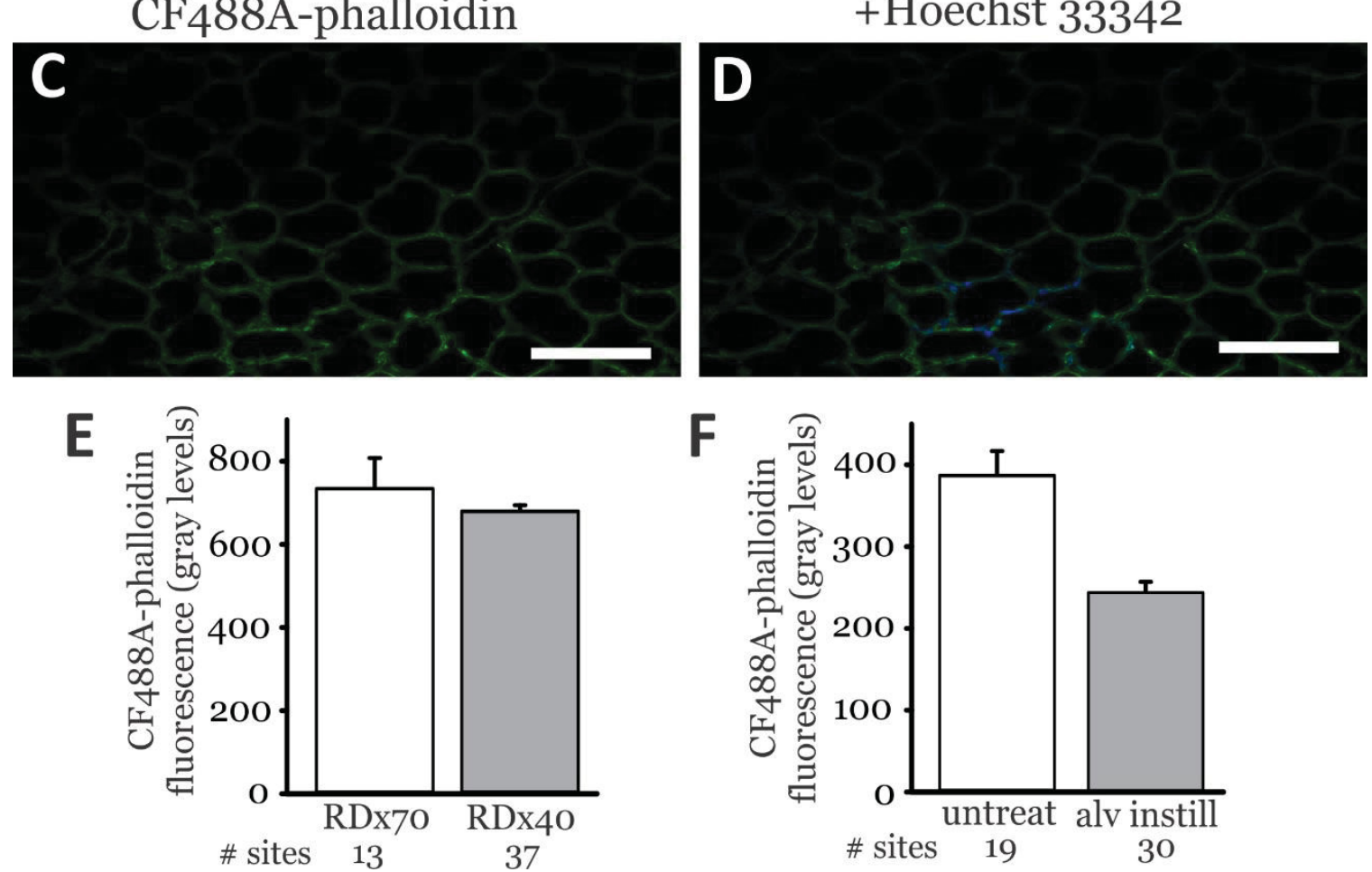
paraformaldehyde into the same alveoli, thus restricting the fixing process to the thrombin-treated alveoli. Finally, the thrombin-treated regions were superfused with CF488A-phalloidin. At the same imaging settings used for vascular thrombin instillation, the CF488A-phalloidin fluorescence in response to alveolar thrombin instillation was similar to that at baseline (Figure 3-3C, D, F). Moreover, the images revealed that the Factin levels were similar in both the thrombin-treated and -free alveoli. Taken together, these experiments suggest that the endothelium predominantly contributed to the observed responses to microvascular thrombin instillation.

\section{Lack of Endothelial Cx43 Limits Actin Stress Fiber Formation}

Interendothelial $\mathrm{Cx} 43$ gap junctions mediated P-selectin [80] expression and endothelial permeability in microvessels located spatially remote from the site of insult $[81,90]$. To determine whether $\mathrm{Cx} 43$ gap junctions played a role in F-actin formation in microvessels located outside the thrombin-treated region, we instilled thrombin in lung microvessels of $E C-C x 43^{-/}$mice. Confocal images of CF488A-phalloidin fluorescence in microvessels of $E C-C x 43^{-/}$mouse lungs at baseline reveal that the fluorescence was similar to that in $C x 43^{f l f l}$ mouse lung microvessels at baseline. (Figure 3-4A). Further, the images also show that thrombin treatment resulted in only a small increase of CF488A-phalloidin fluorescence in $E C-C x 43^{-/}$mouse lungs (Figure 3-4B).

Quantifying CF488A fluorescence in single microvessels revealed that in $E C$ $C x 43^{--}$mice, thrombin instillation resulted in a $20 \%$, but insignificant, increase in the fluorescence compared to that in Ringer's-instilled microvessels (Figure 3-4C). Moreover, in microvessels located outside the thrombin-treated region, the CF488A fluorescence remained at baseline levels. This lack of increase in CF488A fluorescence was in direct contrast to that observed in $C x 43^{f l / f l}$ mouse lung microvessels. Thus, the data suggest that the thrombin-induced increase in F-actin in microvessels was blunted in the absence of endothelial Cx 43 .

\section{Inhibiting Endothelial ER Ca ${ }^{2+}$ Release Limits Actin Stress Fiber Formation}

Thrombin causes release of $\mathrm{Ca}^{2+}$ from ER stores, which has been indicated to underlie F-actin formation in endothelial monolayers [98, 113, 114]. Hence, we determined whether the increase in $\mathrm{F}$-actin in mouse lung microvessels was dependent on ER store $\mathrm{Ca}^{2+}$ release. Toward this, ER Ca ${ }^{2+}$ release was inhibited using $\mathrm{XeC}$, an established inhibitor of $\mathrm{IP}_{3} \mathrm{R}$ on $\mathrm{ER}[103,115,116]$. $\mathrm{XeC}$ was infused into microvessels in a small region of $\mathrm{Cx} 43^{\mathrm{fl} / \mathrm{fl}}$ mouse lungs via a venous microcatheter. Subsequently, thrombin was instilled by micropuncture into a subset of XeC-treated microvessels. XeCpretreatment blunted the thrombin-induced increase in CF488A-phalloidin fluorescence (Figure 3-5A, B). The blunting was evident in all microvessels within the $\mathrm{XeC}$-treated region (Figure 3-5C). Thus, the data indicate that $\mathrm{IP}_{3}$-dependent $\mathrm{ER}$ store $\mathrm{Ca}^{2+}$ release mediated the thrombin-induced microvessel F-actin formation in both the thrombintreated and -free regions. 

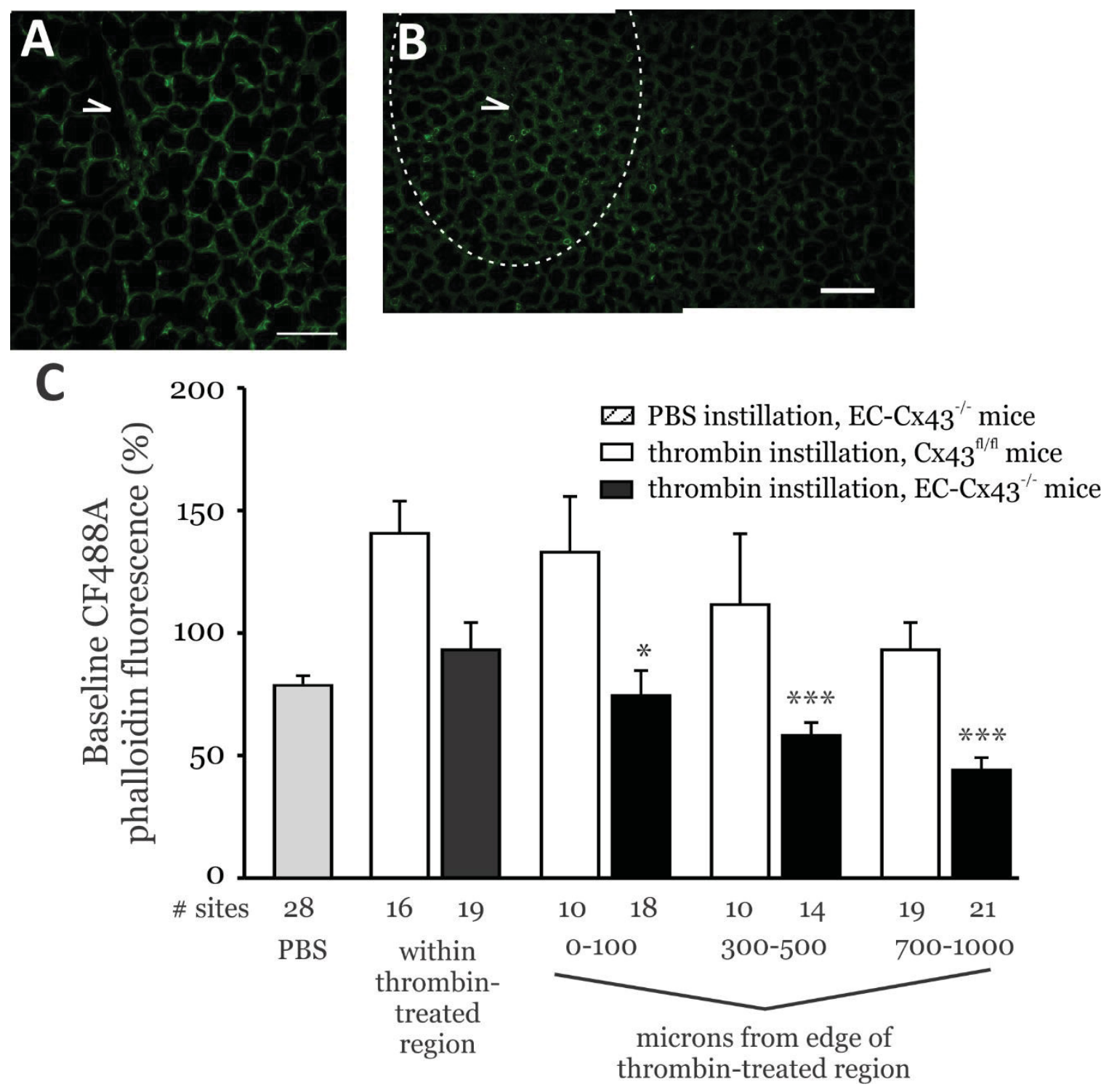

Figure 3-4. Effect of endothelial Cx43 on F-actin formation

Thrombin $(5 \mathrm{U} / \mathrm{ml})$ or PBS was instilled into microvessels in a focal region of lungs from EC-Cx $43^{-/-}$mice. (A) Confocal image composite shows CF488A-phalloidin fluorescence following PBS instillation. (B) Montage of confocal images show CF488A-phalloidin fluorescence following thrombin instillation. Arrowheads - site of PBS or thrombin instillation. Dashed line - outer boundary of thrombin-treated region. Bars - $100 \mu \mathrm{m}$. (C) Bar graph shows CF488A-phalloidin fluorescence normalized to baseline levels in microvessels within and outside (at indicated distances away) the thrombin-instilled region. Data from microvessels of $\mathrm{Cx} 43^{\mathrm{fl} / \mathrm{fl}}$ mice shown for comparison (white bars). \# sites -number of measurement sites included in analysis. $n=4$ lungs per treatment group. $*=\mathrm{p}<0.05, * * *=\mathrm{p}<0.001$, compared to data from thrombin-instilled microvessels of $\mathrm{Cx} 43^{\mathrm{fl} / \mathrm{fl}}$ mice. 

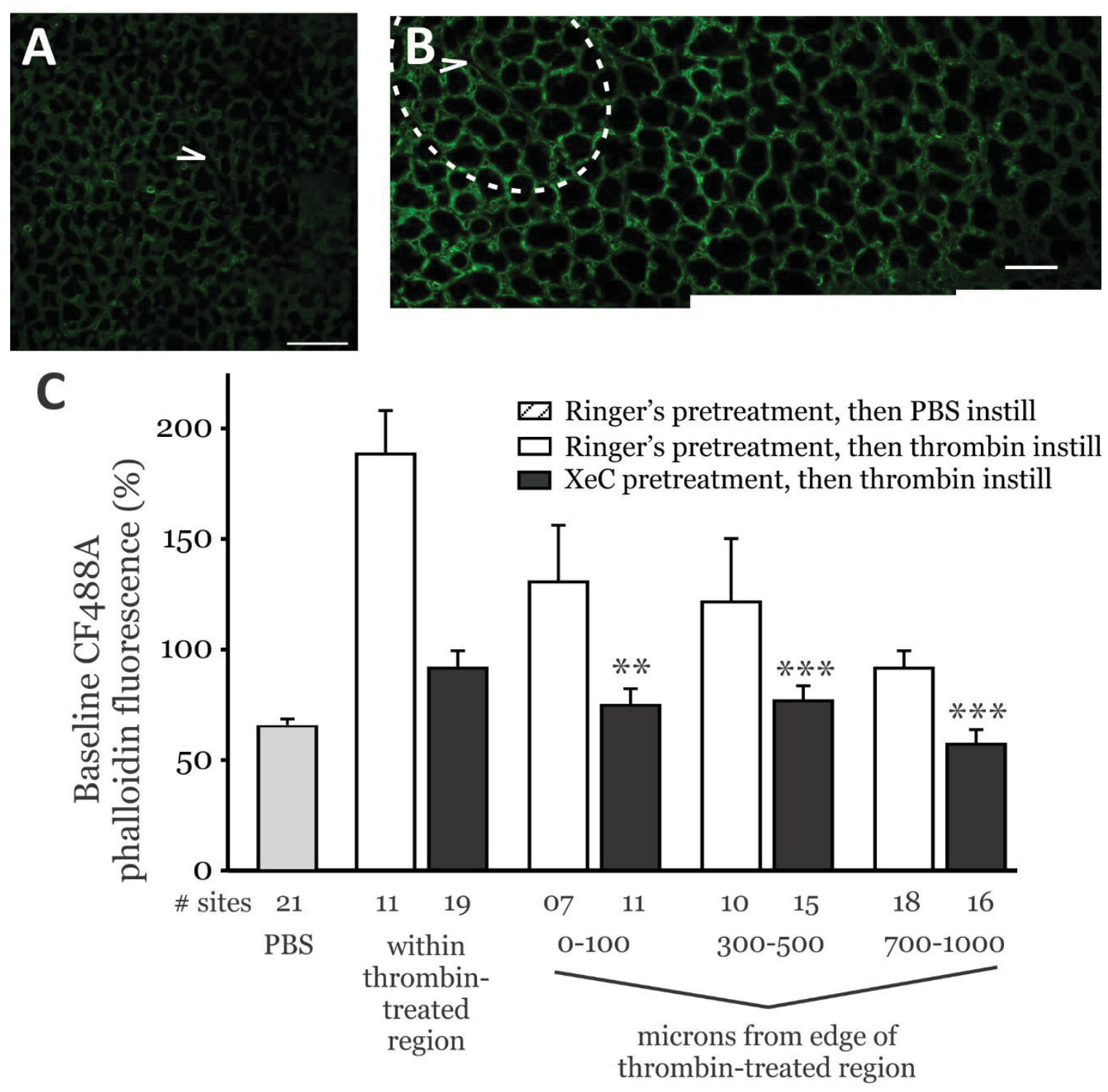

Figure 3-5. Effect of $I P_{3} R$ inhibition on F-actin formation

ER $\mathrm{IP}_{3} \mathrm{R}$ inhibitor, XeC $(25 \mu \mathrm{M})$ or Ringer's was infused into lung microvessels of $\mathrm{CX} 43^{\mathrm{fl} / \mathrm{fl}}$ mice followed by instillation of PBS or thrombin $(5 \mathrm{U} / \mathrm{ml})$ into a small subset of XeC-treated microvessels. (A) Confocal image composite shows CF488A-phalloidin fluorescence in Ringer's pretreated and PBS-instilled microvessels. (B) Montage of confocal images show CF488A-phalloidin fluorescence in XeC pretreated and thrombininstilled microvessels. Arrowheads - site of instillation. Dashed line - outer boundary of thrombin-treated region. Bars - $100 \mu \mathrm{m}$. (C) Bar graph shows CF488A-phalloidin fluorescence normalized to baseline levels in microvessels within and outside (at indicated distances away) the thrombin-instilled region. Black and white bars show data from XeC- and Ringer's-pretreated microvessels, respectively. \# sites -number of measurement sites included in analysis. $\mathrm{n}=4$ lungs per treatment group. $* *=\mathrm{p}<0.01$, $* * *=p<0.001$, compared to data from Ringer's-pretreated thrombin-instilled microvessels. 


\section{IP $_{3}$ Mediates the Spatially Extensive Actin Stress Fiber Formation}

Gap junctions facilitate the intercellular transfer of both $\mathrm{Ca}^{2+}$ and $\mathrm{IP}_{3}[89,90]$. Thus, interendothelial diffusion of either $\mathrm{IP}_{3}$ or $\mathrm{Ca}^{2+}$ from the thrombin-treated microvessels could have caused the increase in F-actin in microvessels located outside the thrombin-treated region. Hence to define the specific second messenger involved, we instilled $\mathrm{XeC}$ into microvessels in a small lung region of $\mathrm{Cx} 43^{\mathrm{fl} / \mathrm{fl}}$ mice, followed by instillation of thrombin into an adjacent region that overlapped the $\mathrm{XeC}$-treatment region (Figure 3-6B). Labeling microvessels with CF488A-phalloidin revealed that the fluorescence was low in the $\mathrm{XeC}$-instilled microvessels, but high everywhere else. Quantifying the response revealed that CF488A-phalloidin fluorescence remained at baseline levels only in the $\mathrm{XeC}$-treated microvessels (Figure 3-6C). Thus, the data clearly indicate that thrombin-induced increase in F-actin was evident in the $\mathrm{XeC}$-free, but absent in the $\mathrm{XeC}$-treated regions. In contrast, when $\mathrm{XeC}$ was replaced with PBS, the thrombin-induced increase in CF488A fluorescence was evident in all microvessels, including those instilled with PBS (Figure 3-6A, C). These data suggest that the thrombin-induced response was blunted only in microvessels pretreated with $\mathrm{XeC}$. Together the results suggest that $\mathrm{IP}_{3}$, but not $\mathrm{Ca}^{2+}$, was the second messenger mediating the thrombin-induced spatially extensive responses in microvessels.

\section{Thrombin Increases the Magnitude of ER-Dependent $\mathrm{Ca}^{2+}$ Oscillation in Lung Microvessels}

In endothelial monolayers, thrombin induces $\mathrm{IP}_{3}$-dependent release of ER store $\mathrm{Ca}^{2+}$, which increases mean endothelial cytosolic $\mathrm{Ca}^{2+}[112-114]$. However, the characteristic of the thrombin-induced $\mathrm{Ca}^{2+}$ response in lung microvessels is not clear. Emerging discussion suggests differences in signaling between lung microvessels and lung microvascular endothelial cells in culture [84]. Thus, we hypothesized that $\mathrm{Ca}^{2+}$ responses to thrombin in microvessels may differ from that reported in endothelial monolayers. To test this, we infused thrombin into microvessels of isolated bloodperfused rat lungs loaded with Fura2 AM. Changes in the ratio of Fura2 fluorescence at 340 and $380 \mathrm{~nm}$ excitation indicated that thrombin infusion increased $\mathrm{Ca}^{2+}$ levels in lung microvessels (Figure 3-7A-D). Quantifying the $\mathrm{Ca}^{2+}$ response over the duration of the experiment, as reported [103], indicated that thrombin increased the magnitude of cytosolic $\mathrm{Ca}^{2+}$ oscillations in lung microvessels (Figure 3-7F). Infusing thrombin into the same microvessels for a second time duplicated the $\mathrm{Ca}^{2+}$ response (Figure 3-7F).

To determine the $\mathrm{Ca}^{2+}$ source, the experiments were repeated after treating microvessels with $\mathrm{XeC}$. $\mathrm{XeC}$ pretreatment blunted the thrombin-induced increase in oscillation amplitude (Figure 3-7E, G). Quantifying the amplitude of $\mathrm{Ca}^{2+}$ oscillations indicated a concentration-dependent response to thrombin (Figure 3-7H). $\mathrm{XeC}$ and tBHQ, an inhibitor of ER $\mathrm{Ca}^{2+}$-ATPase pumps [117], both blunted the increase in $\mathrm{Ca}^{2+}$ oscillation amplitude (Figure 3-7I). Together, the data suggest that thrombin increases $\mathrm{IP}_{3}$-mediated ER $\mathrm{Ca}^{2+}$ release leading to increases in the magnitude of cytosolic $\mathrm{Ca}^{2+}$ oscillations in lung microvessels. 

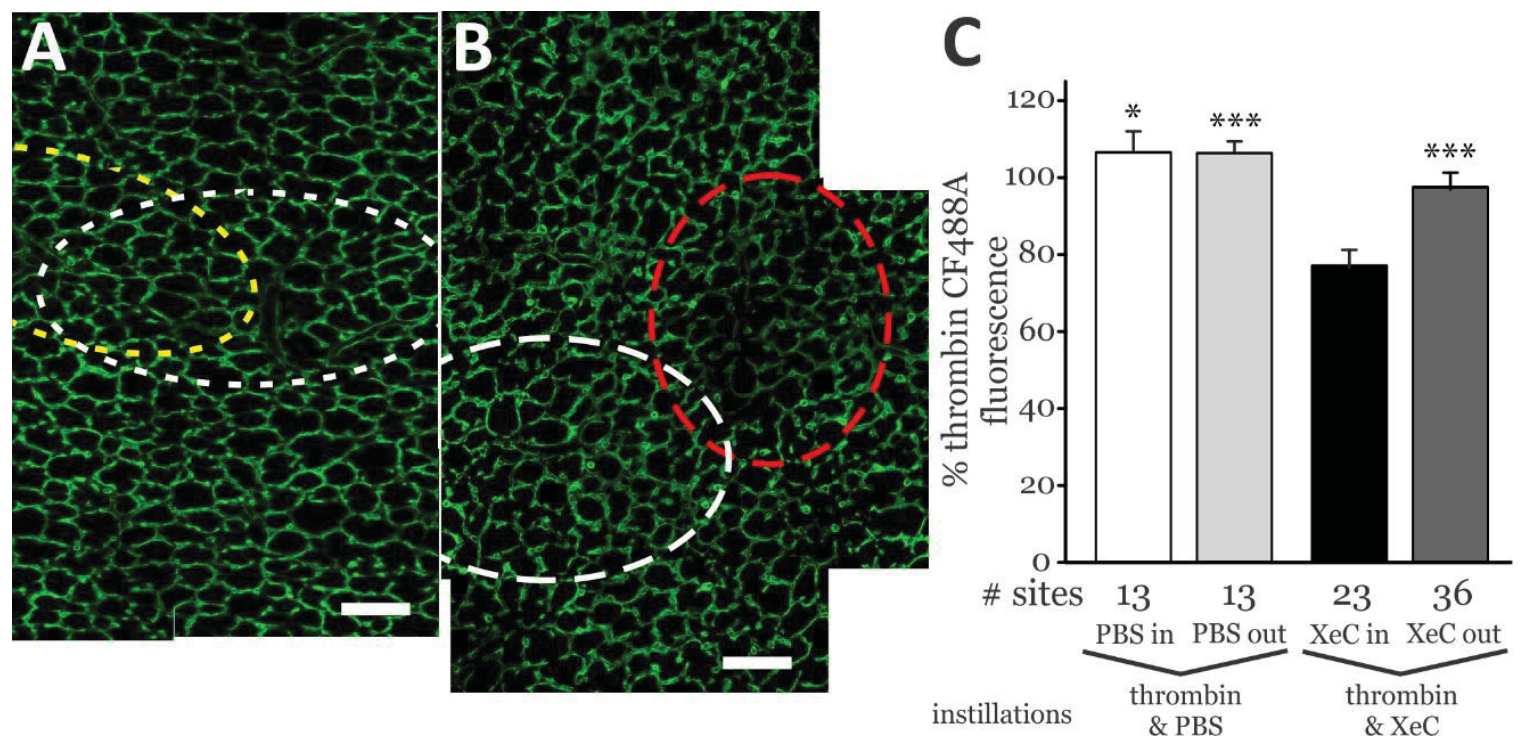

Figure 3-6. Effect of focal $\mathrm{IP}_{3} \mathrm{R}$ inhibition in lung microvessels of $\mathrm{Cx} 43^{\mathrm{f} / \mathrm{fl}}$ mice (A) Montage of confocal images show CF488A-phalloidin fluorescence in microvessels following separate intravascular instillation of thrombin $(5 \mathrm{U} / \mathrm{ml}$; white outline) and PBS (yellow outline) into overlapping regions. Bar - $100 \mu \mathrm{m}$. (B) Montage of confocal images showing CF488A-phalloidin fluorescence in microvessels following separate intravascular instillation of thrombin ( $5 \mathrm{U} / \mathrm{ml}$; white outline) and $\mathrm{XeC}(25 \mu \mathrm{M}$; red outline) into overlapping regions. Bar - $100 \mu \mathrm{m}$. (C) Bar graph compares CF488Aphalloidin fluorescence in single microvessels located in the various regions as indicated. PBS in - within PBS-instillation region; $\mathrm{XeC}$ in - within $\mathrm{XeC}$-instillation region; $\mathrm{PBS}$ out - outside PBS- and thrombin-instillation regions; $\mathrm{XeC}$ out - outside $\mathrm{XeC}$ - and thrombininstillation regions. Average fluorescence of microvessels within the thrombin-instilled region was used to normalize the fluorescence data of other regions. $*=p<0.05$, $* * *=p$ $<0.001$ compared to $\mathrm{XeC}$ in, respectively. \# sites -number of measurement sites included in analysis. $\mathrm{n}=4$ lungs per treatment group. 
Figure 3-7. Thrombin-induced $\mathrm{Ca}^{2+}$ responses in lung microvessels

(A-E) Pseudocolored images show fluorescence due to excitation at 340 and $380 \mathrm{~nm}$ in Fura2 AM loaded rat lung microvessels (A-B), the ratio of the fluorescence at 340 and 380 at baseline (C), during thrombin $(10 \mathrm{U} / \mathrm{ml})$ infusion (D) and during thrombin $(10$ $\mathrm{U} / \mathrm{ml})$ infusion after pretreatment with $\mathrm{XeC}(25 \mu \mathrm{M})(\mathrm{E})$. Bar - $10 \mu \mathrm{m}$. (F) Tracings show temporal changes in the Fura2 AM fluorescence ratio (F340/F380) in response to a dual infusion of thrombin $(10 \mathrm{U} / \mathrm{ml})$ into lung microvessels. Each thrombin infusion was preceded by a Ringer's infusion to determine baseline F340/F380 values. t10 - thrombin (10 U/ml), hbs - Ringer's. (G) Tracings show temporal changes in F340/F380 in response to an infusion into microvessels of thrombin $(10 \mathrm{U} / \mathrm{ml})$ followed by $\mathrm{XeC}(25$ $\mu \mathrm{M})$ pretreatment and then another thrombin $(10 \mathrm{U} / \mathrm{ml})$ infusion. t10 - thrombin $(10$ $\mathrm{U} / \mathrm{ml}$ ), hbs - Ringer's, xec - XeC. (H) Bar graph shows the amplitude of $\mathrm{Ca}^{2+}$ oscillations in lung microvessels in response to infusions of 5 and $10 \mathrm{U} / \mathrm{ml}$ of thrombin. t-5 thrombin $(5 \mathrm{U} / \mathrm{ml}), \mathrm{t}-10-$ thrombin $(10 \mathrm{U} / \mathrm{ml}) . \dagger \dagger=\mathrm{p}<0.01$ compared to baseline; $\$+=$ $\mathrm{p}<0.01$ compared to $5 \mathrm{U}$ thrombin treatment. $\mathrm{n}=4$ lungs per treatment group. (I) Bar graph shows the $\%$ change in amplitude of $\mathrm{Ca}^{2+}$ oscillations in lung microvessels in response to the indicated treatments. $*=p<0.05$ compared to thrombin alone treatment at the respective concentration. $\mathrm{n}=4$ lungs per treatment group. 

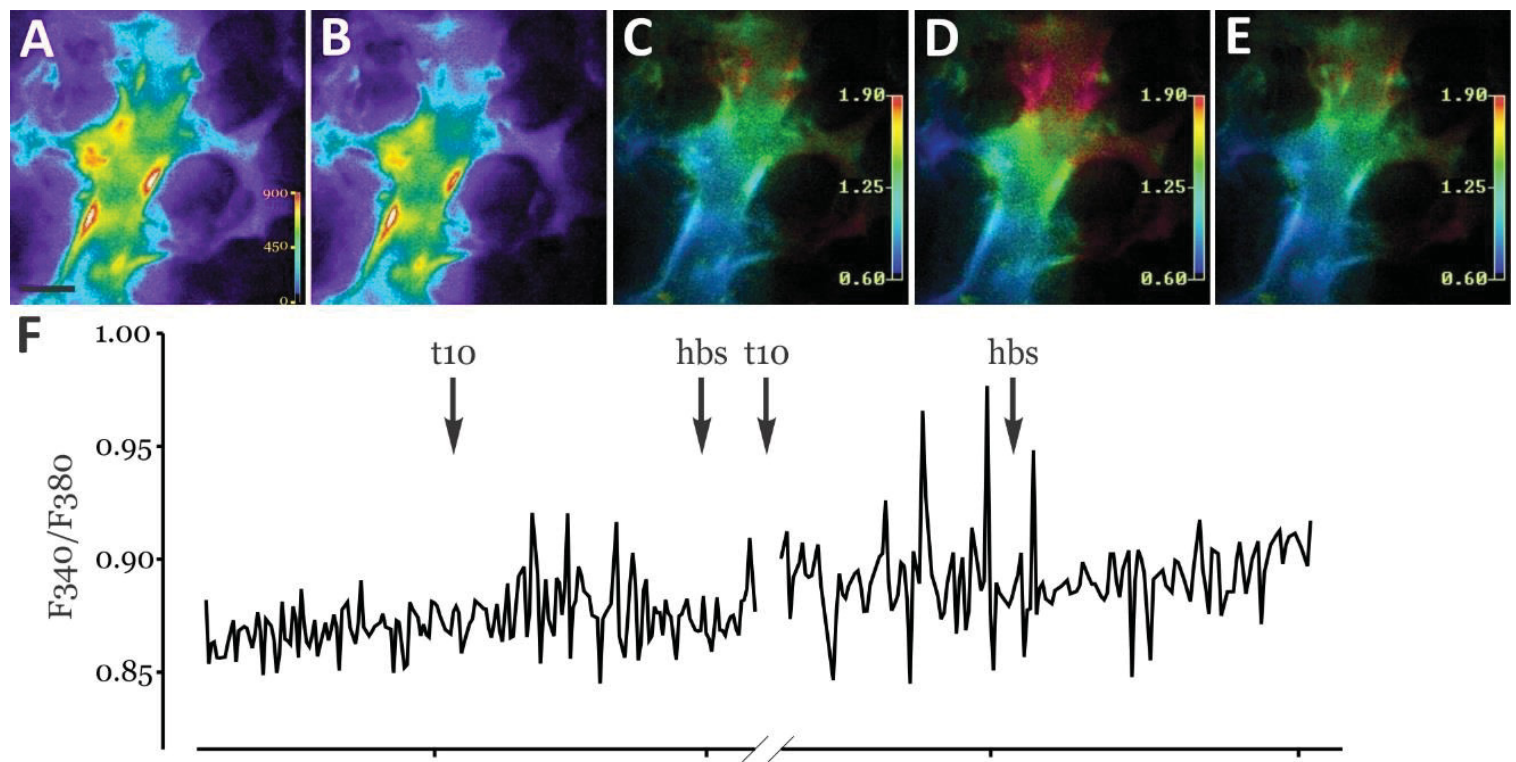

$\stackrel{\mathrm{t} 10}{\downarrow}$

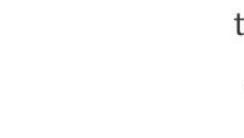

$\downarrow$

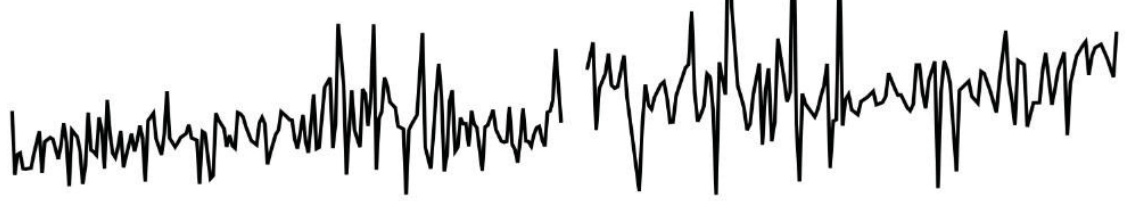

G

The present data that thrombin increases the amplitude of $\mathrm{Ca}^{2+}$ oscillations in microvessels contrasts with reported data showing increase in mean $\mathrm{Ca}^{2+}$ concentration in endothelial monolayers [118]. Hence to exclude the possibility that the absence of a mean $\mathrm{Ca}^{2+}$ increase in the present study was an artifact of the imaging system, we co-loaded rat lung microvessels with the $\mathrm{Ca}^{2+}$ cage, NP-EGTA and the $\mathrm{Ca}^{2+}$ indicator, Fluo 8, as reported [90]. A brief exposure to a $355 \mathrm{~nm}$ UV beam increased mean endothelial cytosolic $\mathrm{Ca}^{2+}$ above baseline (Figure 3-8A-C) both at the site of uncaging and adjoining microvessels. The uncaging-induced $\mathrm{Ca}^{2+}$ increase suggests that the imaging system captured increases in mean cytosolic $\mathrm{Ca}^{2+}$. Thus, we interpret that the predominant response to thrombin in microvessels was an increase in cytosolic $\mathrm{Ca}^{2+}$ oscillation magnitude.

\section{Focal Release of Caged-IP 3 Induces Cx43-Dependent $\mathrm{Ca}^{2+}$ Responses in Adjacent Microvessels}

In the lung microvascular network, $\mathrm{Cx} 43$-dependent mechanisms mediated the spread of $\mathrm{Ca}^{2+}$ in response to release of $\mathrm{Ca}^{2+}$ at a focal site [90]. Hence, to determine whether $\mathrm{IP}_{3}$ released focally will also spread similarly, we co-loaded NPE-IP 3 and Fluo4 into rat lung microvessels, and then exposed the microvessels to the $355 \mathrm{~nm}$ UV beam. UV uncaging caused a progressive increase in Fluo4 fluorescence at both the uncaging site and in adjoining microvessels (Figure 3-9A). Thus, $\mathrm{IP}_{3}$ release at a focal site, increased $\mathrm{Ca}^{2+}$ in microvessels spatially away from the uncaging site. At longer time periods post-uncaging, the $\mathrm{Ca}^{2+}$ response declined to baseline levels. Further, the increase in $\mathrm{Ca}^{2+}$ was highest at the site of uncaging and progressively declined at sites further away from the uncaging site (Figure 3-9B). To determine the role of Cx43 in the induction of responses in the spatially remote microvessels, we pretreated microvessels with the Cx43-gap junction inhibitor, Gap27 [81] and then uncaged $\mathrm{IP}_{3}$. Gap27 completely blocked the Fluo4 fluorescence increase in microvessels located outside the uncaging region, but not within it (Figure 3-9A, C). Thus, release of $\mathrm{IP}_{3}$ at focal sites by uncaging, spreads to adjacent microvessels and initiated responses in a $\mathrm{Cx} 43$-dependent manner.

\section{Thrombin Mediates Spatially Extensive Increases in Microvessel Permeability}

Since thrombin instillation increased F-actin in microvessels outside the thrombin-treated region, we determined whether fluid permeability was also altered in these microvessels. Toward this, thrombin was instilled into microvessels in a focal region of rat lungs followed by FDx20 infusion into both the thrombin-treated and thrombin-free neighboring regions. Images indicated that the residual fluorescence of FDx20 was higher in both the thrombin-treated and -free microvessels compared to Ringer's-treated microvessels (Figure 3-10A-D). However infusion of Gap27 prior to thrombin instillation restricted the high residual fluorescence to microvessels directly treated with thrombin (Figure 3-10E, F). Quantifying the normalized fluorescence revealed that thrombin increased permeability in microvessels located several hundred 

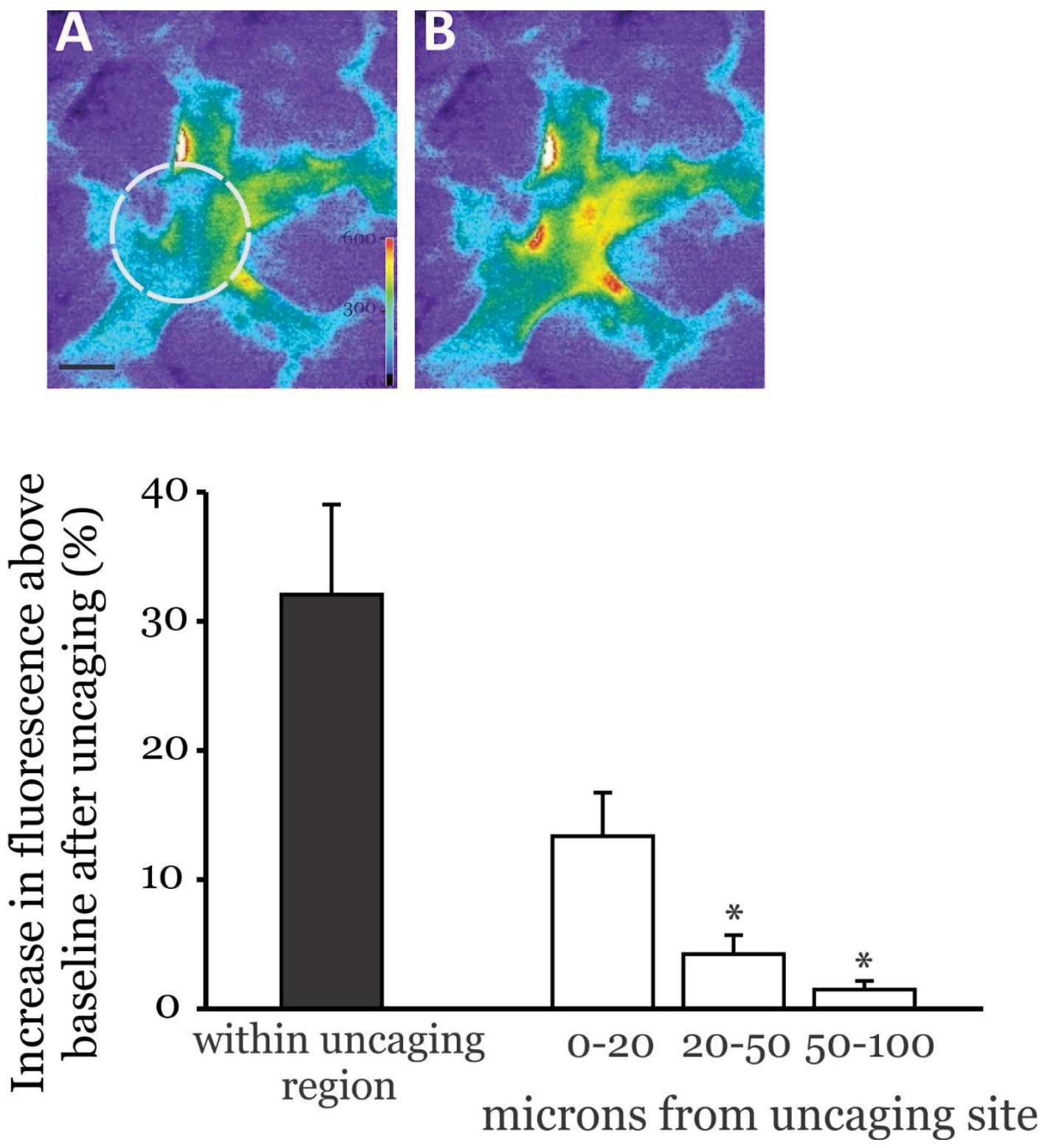

Figure 3-8. $\quad \mathrm{Ca}^{2+}$ uncaging in lung microvessels

$(\mathrm{A}, \mathrm{B})$ Pseudocolored images show the Fluo 8 fluorescence in rat lung microvessels coloaded with NP-EGTA $(75 \mu \mathrm{M})$ and Fluo 8 before (A) and after (B) UV uncaging of NPEGTA. Circle - site of uncaging. Bar - $10 \mu \mathrm{m}(\mathrm{C})$ Bar graph shows spatial changes in Fluo8 fluorescence in response to uncaging NP-EGTA. ${ }^{*}=\mathrm{p}<0.05$ compared to $0 \mu \mathrm{m} . \mathrm{n}$ $=4$ lungs. 


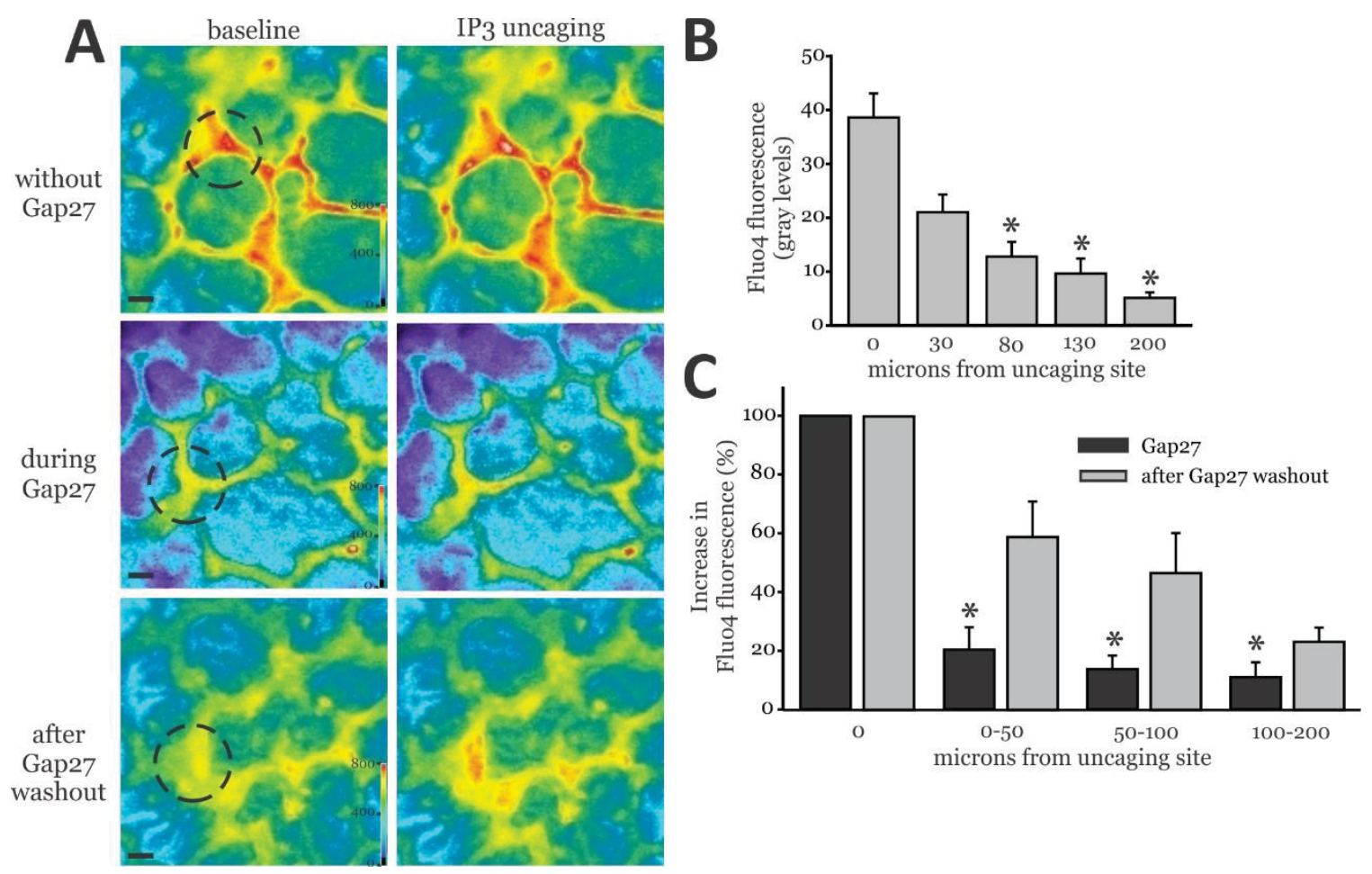

Figure 3-9. IP $\quad \mathrm{P}_{3}$ uncaging in lung microvessels

(A) Pseudocolored images show response to uncaging NPE-IP 3 in rat lung microvessels co-loaded with NPE-IP $3(2.5 \mu \mathrm{M})$ and Fluo4. NPE-IP 3 was loaded into microvessels using Chariot, as detailed in Methods. Images show control response in the absence of the Cx43 gap junction inhibitor, Gap27 (top row), during infusion of Gap27 (middle), and after wash-off of the Ga27 (bottom). Circle - site of uncaging. Bar - $20 \mu \mathrm{m}$. (B) Bar graph shows NPE-IP 3 uncaging-induced changes in Fluo4 fluorescence at increasing distance from the uncaging site. $₫ \mathrm{p}<0.05$ compared to $0 \mu \mathrm{m}$. $\mathrm{n}=3$ lungs. (C) Bar graph shows comparison of the spatial decay of Fluo4 fluorescence in response to $\mathrm{IP}_{3}$ uncaging in the presence of Gap27 and after washout of Gap27. $(B, C) *=p<0.05$ compared to 0 $\mu \mathrm{m} . \mathrm{n}=3$ lungs. 
Figure 3-10. Effect of inhibiting intercellular communication on microvessel permeability

PBS or thrombin $(5 \mathrm{U} / \mathrm{ml} ; 10 \mathrm{~min})$ was instilled into microvessels in a focal region of a rat lung. Subsequently, FDx20 was infused into microvessels followed by a Ringer's wash, as detailed in Methods. (A, B) Images show peak (A) and post-wash (B) FDx20 fluorescence in PBS-treated microvessels. Dashed line - outer boundary of microvessels instilled with PBS. Bar - $100 \mu \mathrm{m}$. (C, D) Images show peak (A) and post-wash (B) FDx20 fluorescence in thrombin-treated microvessels. Dashed line - outer boundary of microvessels instilled with thrombin. Bar - $100 \mu \mathrm{m}$. (E, F) Gap27 was infused into microvessels in a small region of a rat lung for $45 \mathrm{~min}$. followed by instillation of thrombin into subset of the Gap27-treated vessels. FDx20 was then infused into the Gap27-treated vessels followed by a Ringer's wash. Images show peak (E) and post-wash (F) FDx20 fluorescence in microvessels. Dashed line - outer boundary of microvessels instilled with thrombin. Bar - $100 \mu \mathrm{m}$. (G) Graph shows normalized fluorescence in single microvessels both within $(0 \mu \mathrm{m})$ and outside the treatment regions at distances as indicated. ${ }^{* * *}=\mathrm{p}<0.001$ compared to Ringer's treatment at same indicated distance. $\dagger$ $=\mathrm{p}<0.05, \dagger_{\dagger \dagger}+\mathrm{p}<0.001$ compared to Gap27+thrombin at same indicated distance. 

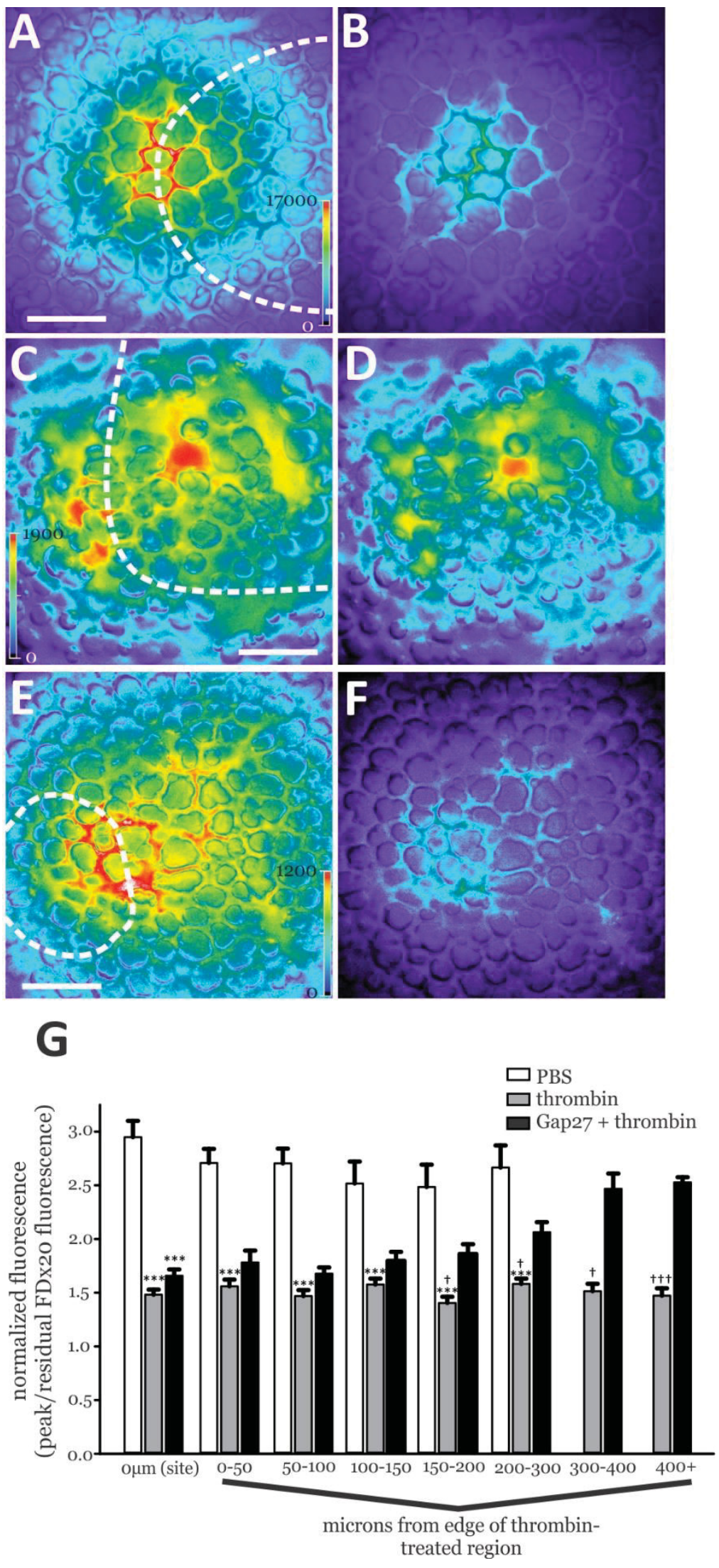
microns away from the outer edge of the thrombin-treated region (Figure 3-10G). The spatially extensive increase was blunted in Gap27-treated microvessels. Together the data suggested that thrombin causes $\mathrm{Cx} 43$-dependent hyperpermeability in lung microvessels.

\section{Discussion}

In this study, we show for the first time that the receptor-mediated agonist thrombin initiates spatially extensive responses in microvessels via interendothelial diffusion of $\mathrm{IP}_{3}$. Moreover, the experiments reveal that the diffusion is facilitated by Cx43 gap junctions. Together the present data reveal a novel relationship wherein $\mathrm{Cx} 43$ and $\mathrm{IP}_{3}$ act in tandem to expand the ambit of thrombin-induced responses in lung microvessels. Finally, the data suggests that signaling resulting from compartmental increases in second messengers elicited by activation of plasma membrane receptors differs from that generated by global cell-wide increases in second messengers elicited by photolytic uncaging.

Utilizing focal instillations of thrombin into lung microvessels, we provide the first evidence that $\mathrm{IP}_{3}$ increases $\mathrm{F}$-actin in thrombin-treated and -free microvessels. The present finding that $\mathrm{IP}_{3}$ increases F-actin in microvessels directly treated with thrombin is in agreement with the reported data on thrombin-mediated responses in endothelial monolayers [108, 119-122]. However, the finding that $\mathrm{IP}_{3}$ increases F-actin in microvessels located in adjacent thrombin-free regions is hereto unknown.

In addition to $\mathrm{IP}_{3}$, thrombin also increases $\mathrm{Ca}^{2+}$, cAMP and ATP levels in endothelial monolayers $[92,123,124]$. Thus, any of these diffusible second messengers could have mediated the cytosolic $\mathrm{Ca}^{2+}$ response in the spatially remote thrombin-free microvessels. ATP is released by endothelial cells via pannexins and connexinhemichannels on the luminal membrane, and acts on purinergic receptors of adjacent cells $[92,125]$. The luminal ATP release suggests that its actions would be evident in endothelial cells downstream from the stimulus site. In the present study, the responses in the thrombin-free regions were independent of blood-flow direction, thus excluding ATP as the diffusing messenger. Thrombin induces a temporally delayed increase in cAMP $[124,126]$, which signals through non-ER pathways. ER inhibition blocked the spatially remote responses, thus, excluding cAMP as the diffusing messenger. $\mathrm{XeC}$ blocked $\mathrm{IP}_{3}$ receptors and thus, $\mathrm{Ca}^{2+}$ release, thereby preventing the establishment of either $\mathrm{IP}_{3}$ or $\mathrm{Ca}^{2+}$ as the diffusible second messenger using global $\mathrm{XeC}$ treatment. Separate instillations of $\mathrm{XeC}$ and thrombin into focal, yet intersecting regions, solved this conundrum. In the thrombin-instilled region, neither $\mathrm{IP}_{3}$ nor $\mathrm{ER} \mathrm{Ca}^{2+}$ release was blocked. Hence, both second messengers were free to diffuse interendothelially into the thrombin-free microvessels, including microvessels in the $\mathrm{XeC}$-instilled region. If $\mathrm{Ca}^{2+}$ had been the diffusible second messenger, then increased F-actin would have been evident even in the $\mathrm{XeC}$-treated region. However, no increase in $\mathrm{F}$-actin was evident in microvessels in the $\mathrm{XeC}$-treated region. This lack of a response only in the $\mathrm{XeC}$-treated region implicated $\mathrm{IP}_{3}$ as the diffusible messenger mediating the spatially extensive responses from the thrombin-treated to the thrombin-free microvessels. 
The present experiments show that in lung microvessels, thrombin increased the amplitude of endothelial cytosolic $\mathrm{Ca}^{2+}$ oscillations via $\mathrm{ER} \mathrm{Ca}^{2+}$ release. In endothelial monolayers, thrombin also induces ER $\mathrm{Ca}^{2+}$ release $[110,113,114,119]$. However, the ER $\mathrm{Ca}^{2+}$ release increases the mean endothelial cytosolic $\mathrm{Ca}^{2+}$ concentration. Thus, the present data in microvessels stand in contrast to that from endothelial cells. The difference in $\mathrm{Ca}^{2+}$ response could point to differences in signaling between endothelial cells in situ and in culture. We previously noted that LPS-induced $\mathrm{Ca}^{2+}$ responses in microvessels were different from those in endothelial monolayers [103]. Moreover, it has recently been highlighted that thrombin activates different signaling pathways in these two experimental models [84]. Further, the thrombin-induced $\mathrm{Ca}^{2+}$ responses may be concentration dependent. Thus, the present data suggest that thrombin mediated responses are dependent on the experimental model used and hence, should be viewed from that context.

The current finding that $\mathrm{IP}_{3}$ is the diffusible messenger mediating thrombininduced responses among endothelial cells suggests that $\mathrm{IP}_{3}$-dependent $\mathrm{Ca}^{2+}$ release mediates the F-actin increases in both thrombin-treated and-free cells. $\mathrm{IP}_{3}$-dependent $\mathrm{ER}$ store $\mathrm{Ca}^{2+}$ release concomitantly increases activation of $\mathrm{p} 38$ mitogen-activated protein kinase (p38-MAPK) [127-130]. However, the relationship between store $\mathrm{Ca}^{2+}$ release and p38-MAPK activation is cell-type- and agonist-dependent. In endothelial cells, LPS increases activation of $\mathrm{p} 38$-MAPK[131]. We reported that LPS causes store $\mathrm{Ca}^{2+}$ release in lung microvessels [103]. Thus, it is possible that the thrombin-induced store $\mathrm{Ca}^{2+}$ release activated p38-MAPK. Activated p38-MAPK phosphorylates the actin-binding protein, heat-shock protein 27 (HSP27) in endothelial and other cells via MAP kinaseactivated protein kinase 2 (MAPKAP kinase 2) [130-134]. Phosphorylation of HSP27 facilitates F-actin polymerization and stress fiber formation [135-137]. Thus, activated p38-MAPK could increase F-actin levels via phosphorylation of HSP27 in endothelial cells. However, this pathway requires further delineation in lung microvessels. Moreover, other factors such as RhoA have been implicated in actin dynamics [138] and may modulate F-actin levels either separately or in tandem with the p38-MAPK pathway. Thus, the specific pathway and associated proteins involved in store $\mathrm{Ca}^{2+}$ releasedependent $\mathrm{F}$-actin increase in lung microvessels require further consideration.

Endothelial connexins play a role in the induction of P-selectin, endothelial permeability, and hypoxic arteriolar vasoconstriction in spatially remote microvessels [90, 94, 139]. While both $\mathrm{Cx} 43$ and $\mathrm{Cx} 40$ have been shown to mediate the above responses, the knockout mice experiments exclude a role for $\mathrm{Cx} 40$ in the present study. The photolytic uncaging experiments add further support for Cx43 as mediating the interendothelial diffusion of $\mathrm{IP}_{3}$ in the lung microvascular network. $\mathrm{Cx} 43$ supports the diffusion of $\mathrm{IP}_{3}$ in astrocytes [88] and endothelial monolayers [89]. The present observations concur with these previous reports. Thus, $\mathrm{Cx} 43$ is the predominant connexin mediating thrombin-induced responses in microvessels.

In $C x 43^{f l f l}$ mice, F-actin increased in microvessels in direct contact with thrombin. However, the increase was smaller in microvessels of $E C-C x 43^{-/}$mice. This 
difference is intriguing because the microvessels in both mouse types were exposed to the same concentration of thrombin and for the same duration. Thus, it is likely that $\mathrm{Cx} 43$ also contributed to signaling differences in thrombin-treated microvessels. Studies by Bhattacharya's group and others have suggested that in lung microvessels, proinflammatory responses are heterogeneous among endothelial cells [139-141]. Thus, some endothelial cells termed pacemakers may initiate the responses that then propagate to neighboring cells via interendothelial communication [139, 142]. Based on this, we propose that thrombin-induced-IP 3 release and downstream signaling may be heterogeneous in lung microvessels. The heterogeneity may be attributed to endothelial differences in thrombin receptor density or other factors involved in the signaling. Indeed, heterogeneity in the distribution of thrombin receptors among microvessels has been reported [143]. Thus, those endothelial cells with a higher receptor density may act as pacemakers. The higher levels of $\mathrm{IP}_{3}$ generated by the pacemaker could diffuse to adjacent endothelial cells along the microvessel and increase the overall response in the entire vessel. In the absence of interendothelial communication, this transfer of $\mathrm{IP}_{3}$ may be blocked and thus the overall microvessel response to thrombin may be mitigated. However, the establishment of this or other possible mechanisms as the specific factors responsible for reduction in thrombin-induced endothelial response in $E C-C \times 43^{-/-}$mice requires further elucidation.

In addition to the smaller thrombin-induced increases, the baseline F-actin fluorescence was in itself lower in $E C-C x 43^{--}$mice. This difference could be due to interaction of $\mathrm{Cx} 43$ with the actin cytoskeleton. Cx43 interaction with the actin cytoskeleton is reported in several cell types, including brain endothelium, astrocytes and B-cells [144-148]. Thus, it is possible that reduction in Cx43 expression lowers Cx43-Factin interaction, likely through modifying the interactions among proteins in the $\mathrm{Cx} 43$ interactome. For example, reduction in $\mathrm{Cx} 43-\mathrm{ZO} 1$ interaction reduced $\mathrm{F}$-actin levels in brain endothelial cells [144]. Accordingly, it is possible that in the EC-Cx43-/- mice, the lack of $\mathrm{Cx} 43$ may have resulted in the loss of interaction among proteins in the $\mathrm{Cx} 43$ interactome, and thus resulted in the reduced F-actin levels. The specific proteins involved in this interaction and the signaling involved behind the reduction in F-actin levels will require further elucidation.

The current study indicates that activation of plasma membrane receptors induces $\mathrm{IP}_{3}$-mediated spatial expansion of pro-inflammatory responses. In contrast, increase in cell-wide $\mathrm{Ca}^{2+}$ by photolytic uncaging of $\mathrm{Ca}^{2+}$ induces $\mathrm{Ca}^{2+}$-diffusion-mediated spatial expansion of responses [90]. Thus, signal compartmentalization associated with activation of plasma membrane receptors likely defines the specific second messenger that diffuses through the gap junctions. Since thrombin activates $\mathrm{G}$ protein-coupled receptors [50], $\mathrm{IP}_{3}$ is generated closer to the plasma membrane, and thus in proximity to gap junctions. This proximity likely facilities $\mathrm{IP}_{3}$ diffusion through the gap junctions. This argument is further supported by the smaller spatial spread of the response associated with $\mathrm{IP}_{3}$ uncaging. As uncaging increased $\mathrm{IP}_{3}$ in a cell-wide manner, relatively low levels of $\mathrm{IP}_{3}$ would be available at the cell-cell junction and thus for diffusion via gap junctions. This would limit the ambit of responses to $\mathrm{IP}_{3}$ uncaging, but not for receptormediated $\mathrm{IP}_{3}$ increase. While $\mathrm{IP}_{3}$ also triggers ER store $\mathrm{Ca}^{2+}$ release, the inherent 
compartmentalization of $\mathrm{Ca}^{2+}$ due to the steep decline in its concentration from the release site [149] may also limit its availability in the vicinity of gap junctions. In addition, in the present study, the cellular $\mathrm{Ca}^{2+}$ response was an increase in the magnitude of cytosolic $\mathrm{Ca}^{2+}$ oscillations, rather than an increase in mean cytosolic $\mathrm{Ca}^{2+}$ concentration. This difference in $\mathrm{Ca}^{2+}$ response may underlie the preclusion of $\mathrm{Ca}^{2+}$ diffusion via gap junctions, and needs explored further. Whether these interpretations of spatial compartmentalization is applicable to other pro-inflammatory mediators that induce interendothelial signaling also remains to be elucidated.

In conclusion, our studies here showed that $\mathrm{IP}_{3}$ generated in response to thrombin is the specific second messenger mediating the thrombin-induced responses of increased F-actin formation and permeability in the pulmonary microvasculature, and that the interendothelial communication of $\mathrm{IP}_{3}$ via $\mathrm{Cx} 43$ mediates the spatial expansion of these responses. Our experiments also demonstrated that the origin of the second messenger, as determined by the stimulus, defines both the breadth and the type of response observed. Our work here highlights the differences between inflammatory signaling observed in culture and in in situ. Further investigations utilizing more physiologically-relevant in situ preparations may reveal strategies that limit these expansive inflammatory responses through the targeted blocking of interendothelial communication. 


\section{CHAPTER 4. COOPERATIVE SIGNALING OF THROMBIN AND S1P2 IN BARRIER DYSFUNCTION}

\section{Introduction}

$\mathrm{S} 1 \mathrm{P}$ is a lysophospholipid signaling molecule that acts through G-protein coupled receptors on endothelial cells to mediate various cellular activities, including microvascular permeability $[9,62,67]$. While signaling through the primary receptor $\mathrm{S} 1 \mathrm{P} 1$ is barrier-protective, signaling through S1P2 has been found to be barrier-disruptive $[4,68,69]$. The expression of both S1P and the receptor S1P2 has been shown to be increased in inflammation $[62,65,70]$. In HMVEC monolayers, inflammatory mediators LPS and TNF $\alpha$ were shown to induce increases in both S1P2 mRNA and protein, and blocking S1P2 signaling in these cells blocked the LPS- and TNF $\alpha$-induced increases in barrier permeability [70]. In addition, in isolated perfused rat lungs, it was found that blocking S1P2 signaling also blocked in the induction of lung edema and increased permeability by hydrogen peroxide [69] While S1P2 signaling displays a clear link to hyperpermeability in the context of inflammatory mediators, little has been shown on direct effects in lung microvessels.

The inflammatory mediator thrombin activates the receptor PAR-1, and activation of PAR-1 has been shown to activate SphK1 and induce local increases in S1P [62, 63, 67]. In fact, in endothelial monolayers, it has been indicated that this increase may mediate the thrombin-induced hyperpermeability [150]. In addition, the inhibition of SphK1 in endothelial cells also inhibits the thrombin-induced increases in cytokine production and secretion [63]. Both PAR-1 and S1P2 activation is mediated by the Gproteins $\mathrm{G}_{\alpha \mathrm{i}}, \mathrm{G}_{\alpha \mathrm{q}}$, and $\mathrm{G}_{\alpha 12 / 13}$, leading to calcium store release, RhoA activation, and subsequent increases in permeability [61, 69, 98, 151-154]. While the dual activation of these receptors may lead to a cooperative effort in inflammation, it is unknown the extent to which S1P2 signaling may actually participate in or contribute to thrombin-induced signaling within lung microvessels. Further, though other inflammatory mediators may affect S1P2 expression, it is unknown whether thrombin may have a similar effect, specifically within pulmonary microvascular endothelium.

To explore the possible role of S1P2-directed signaling in lung inflammation, we studied changes in S1P2 expression in pulmonary microvascular endothelial cells and microvessels induced by the inflammatory mediator thrombin in addition to exploring S1P2 signaling in the context of thrombin-induced endothelial hyperpermeability. As the gap junction channel protein $\mathrm{Cx} 43$ has been shown to mediate thrombin-induced spatially extensive responses, we investigated thrombin-induced changes in S1P2 in both our $\mathrm{Cx} 43^{\mathrm{fl} / \mathrm{fl}}$ and EC-Cx $43^{-/-}$mouse lines [155]. Our results show that thrombin is able to induce an increase in S1P2 expression in primary mouse pulmonary microvascular endothelial cells (PMVECs) as well as pulmonary microvessels in $\mathrm{Cx} 43^{\mathrm{fl} / \mathrm{fl}}$ and EC-Cx $43^{-}$ ${ }^{1}$ mouse lungs. Interestingly, while the increase in expression was nominal and confined to the thrombin-treated area in our EC-Cx $43^{-/-}$mouse line, in the $\mathrm{Cx} 43^{\mathrm{fl} / \mathrm{fl}}$ mouse lungs thrombin induced a significant increase in the treated area and an even greater increase 
outside of the treated microvessels. To further investigate this unique pattern of thrombin-induced effects, we also looked at ROS generation following thrombin treatment. Similar to S1P2 expression, we found that thrombin induced a greater increase in ROS outside of the treatment area than inside in the $\mathrm{Cx} 43^{\mathrm{fl} / \mathrm{fl}}$ mouse lungs. Finally, to study contributions of S1P2 signaling in thrombin-induced increases in microvascular permeability, we pretreated microvessels with the S1P2 antagonist JTE-013. We found that blocking S1P2 signaling effectively blocked thrombin-induced increases in ROS generation as well as hyperpermeability. Our results show that in pro-inflammatory signaling, thrombin may induce increased presence of S1P2 in pulmonary microvascular endothelial cells in a manner mediated by gap junctional communication, and signaling following S1P2 activation contributes to thrombin-induced effects in the microvasculature.

\section{Materials and Methods}

\section{Animals}

All mouse studies were approved by the Institutional Animal Care and Use Committee of the University of Tennessee Health Science Center. Endothelial specificCx43 knockout (EC-Cx43-/-) mice on a C57BL/6J background were bred in our animal facility as previously reported $[90,100,155]$, and age-matched floxed $\mathrm{Cx} 43\left(\mathrm{Cx} 43^{\mathrm{fl} / \mathrm{fl}}\right)$ mice were used as controls. Mice were given access to food and water ad libitum, and placed on a $12 \mathrm{~h}$ light-dark cycle.

\section{Fluorophores and Reagents}

Thrombin (10 U/mL), sphingosine-1-phosphate (S1P; $10 \mu \mathrm{M})$, fluorescein isothiocynate $20 \mathrm{kDa}(\mathrm{FDx} 20 ; 0.5 \mathrm{mg} / \mathrm{mL})$, rhodamine-dextran $70 \mathrm{kDa}(\mathrm{RDx} 70 ; 0.5$ $\mathrm{mg} / \mathrm{mL}$ ), and $\mathrm{N}$-acetyl cysteine (NAC; $5 \mu \mathrm{M}$ ) were from SigmaAldrich (St. Louis, MO). The nuclear marker Hoeschst-33342 $(10 \mu \mathrm{g} / \mathrm{mL})$ was from Teflabs (Austin, TX). The cell permeable dye Calcein AM $(1.25 \mu \mathrm{M})$ was from Invitrogen (Carlsbad, CA). The S1P2 receptor antagonist JTE-013 $(1 \mu \mathrm{M})$ was from Cayman Chemical. Collagenase Type II $(10 \mathrm{mg} / \mathrm{mL})$ was obtained from Worthington Biochemical (Lakewood, NJ). The fluorescent reactive oxygen species indicator CellROX deep red reagent $(15 \mu \mathrm{M})$ was from ThermoFisher (Waltham, MA). The anti-S1P2 Antibody $(5-10 \mu \mathrm{g} / \mathrm{mL})$ came from MilliporeSigma (Billerica, MA). The CF488A-conjugated goat anti-mouse secondary antibody $(1 \mu \mathrm{L} / \mathrm{mL})$ was from Biotium (Hayward, California). Fluorophores and reagents were infused into pulmonary microvessels in a $\mathrm{Ca}^{2+}$-rich HEPES-buffered Ringer's solution (HBS; $150 \mathrm{mM} \mathrm{Na}^{+}, 5 \mathrm{mM} \mathrm{K}^{+}, 1 \mathrm{mM} \mathrm{Ca}^{2+}, 1 \mathrm{mM} \mathrm{Mg}^{2+}, 10 \mathrm{mM}$ glucose, 20 $\mathrm{mM}$ HEPES) with $4 \%$ dextran $(40 \mathrm{kDa})$ and $1 \%$ fetal bovine serum at a final $\mathrm{pH}$ of 7.4 . Phosphate buffered saline with $\mathrm{Ca}^{2+}$ and $\mathrm{Mg}^{2+}$ (PBS) was from GE Life Sciences (Pittsburg, PA). 


\section{Lung Preparation}

Isolated perfused lungs were prepared from mice as reported [155]. Adult mice were anesthetized by intraperitoneal injection of ketamine and xylazine, exsanguinated via cardiac puncture, and the blood was collected in heparin. The chest cavity was opened, and cannulae were placed in the trachea, pulmonary artery, and left atrium. The lungs and heart were excised en bloc, and moved to the microscope stage. Through the tracheal cannula the lungs were constantly inflated with room air at a pressure of $5 \mathrm{~cm}$ $\mathrm{H}_{2} \mathrm{O}$. The lungs were constantly pump-perfused at a rate of $2 \mathrm{~mL} / \mathrm{min}$, and pressures in the pulmonary artery cannula and left atrial cannula were maintained at 10 and $3 \mathrm{~cm}_{2} \mathrm{O}$, respectively.

\section{S1P2 Expression in PMVECs}

Mouse lung microvascular endothelial cells were isolated from $\mathrm{Cx} 43^{\mathrm{fl} / \mathrm{fl}}$ and EC$\mathrm{Cx} 43^{-/-}$lungs by collagenase II digestion and cultured overnight at $37^{\circ} \mathrm{C}$ in medium 199 supplemented with growth factors on fibronectin-coated coverslips. The following day, coverslips were treated with thrombin $(10 \mathrm{U} / \mathrm{mL})$ for 10 minutes (or no treatment in the case of control). The coverslips were washed three times with PBS and then fixed for 10 minutes with 3.7\% paraformaldehyde. The cells were then again washed thrice with PBS and then permeabilized with $0.05 \%$ Triton $\mathrm{X}$ for 10 minutes. They were washed 3 more times with PBS and then blocked using 5\% bovine serum albumin for 1 hour. The cells were then incubated overnight at $4{ }^{\circ} \mathrm{C}$ with anti-S1P2 monoclonal $\mathrm{Ab}(5 \mu \mathrm{g} / \mathrm{mL})$. The next morning, the cells were again washed 3 times with PBS then incubated for 1 hour with CF488A-conjugated secondary antibody $(1 \mu \mathrm{L} / \mathrm{mL})$ and a nuclear stain (Hoeschst$33342,10 \mu \mathrm{g} / \mathrm{mL})$. After washing again with PBS, the coverslips were imaged using a confocal microscope (LSM710; Carl Zeiss Inc., Thornwood, NY). To quantify secondary antibody fluorescence, an outline was drawn at the perimeter of endothelial cells and a measurement of the average fluorescence was taken from several cells in each image.

\section{S1P2 Expression in Pulmonary Microvessels}

In IPLs from $\mathrm{Cx} 43^{\mathrm{fl} / \mathrm{fl}}$ and $\mathrm{EC}-\mathrm{Cx} 43^{-/-}$mice, a PE10 microcatheter was inserted through the left atrium and used to infuse HBS to clear a small section of the microvasculature of blood. Near a targeted post-capillary venule, an alveoli was micropunctured and filled with $2 \%$ Sudan black in oil to be used as a marker. A venule was then micropunctured and an instillation mixture of either Thrombin $(10 \mathrm{U} / \mathrm{mL})$ or PBS with RDx70 (.5 mg/mL) was given over 10 minutes. The RDx70 fluorescence was used to confirm instillation into the vasculature and to delineate treated microvessels. Microvessels in the cleared area were then fixed and permeabilized via catheter, with 30 minute infusions of $3.7 \%$ paraformaldehyde and $0.05 \%$ Triton X, respectively. Following a 30 minute blocking infusion of 5\% bovine serum albumin, successive infusions of S1P2 primary Ab in HBS for 30 minutes, HBS alone for 20 minutes, and finally CF488Aconjugated secondary $\mathrm{Ab}$ for 30 minutes were given to fluorescently tag the $\mathrm{S} 1 \mathrm{P} 2$ protein 
in the pulmonary microvasculature. Hoeschst-33342 was infused with the secondary antibody to stain the nuclei. Following staining, confocal images were obtained both in the area of micropuncture instillation as well as outside $(600+\mu \mathrm{m}$ away from treated microvessels). The nuclear stain was used to define vessel location in images with low CF488A-conjugated secondary Ab fluorescence. Secondary antibody fluorescence was measured at random sites along the microvasculature both within and outside of the treated vessels, and several vessels were measured in each image.

\section{Thrombin-induced ROS Generation}

In isolated perfuse lungs from $\mathrm{Cx} 43^{\mathrm{fl} / \mathrm{fl}}$ and $\mathrm{EC}-\mathrm{Cx} 43^{-/-}$mice, a PE10 microcatheter was used to clear an area of the vasculature and to give a 30 minute infusion of CellROX deep red reagent and Calcein AM. Following a 30 minute equilibration period during an HBS infusion, confocal images were taken of two separate venules $600+\mu \mathrm{m}$ apart. One of the imaged venules was then micropunctured with either Thrombin $(10 \mathrm{U} / \mathrm{mL})$ or PBS with RDx70 (.5 mg/mL) instilled over 10 minutes. The two previously targeted venules were then imaged again. CellROX and Calcein AM fluorescence was measured at random sites along the microvasculature in both areas, before and immediately after the micropuncture instillation. The change in the ratio of CellROX/Calcein AM fluorescence was used to determine induction of ROS generation. As this is a live-cell process, and CellROX fluorescence may decrease naturally even though ROS amounts continue to increase (by prolonged, continued oxidation of the dye), the Calcein AM fluorescence was used as a guide to ensure that increases or decreases in ROS generation were adequately determined.

In experiments to investigate $\mathrm{S} 1 \mathrm{P} / \mathrm{S} 1 \mathrm{P} 2$-induced changes in ROS generation, a PE10 microcatheter was used to clear a section of the vasculature of $\mathrm{Cx} 43 \mathrm{fl} / \mathrm{fl}$ mouse lungs and CellROX and Calcein AM were infused for $30 \mathrm{~min}$. Following the equilibration period, confocal z-stack images were taken of approximately 4 different areas surrounding a venule. Next, an infusion of either Thrombin $(10 \mathrm{U} / \mathrm{mL} ; 10$ minutes $)$ or S1P (10 $\mu \mathrm{M} ; 20$ minutes) was given via the microcatheter, with or without a 15 minute pretreatment infusion of JTE-013 $(1 \mu \mathrm{L} / \mathrm{mL})$. After treating the microvasculature, z-stack images were taken again of the same venular areas and changes in ROS were determined as described above.

\section{Microvascular Permeability}

In isolated perfused $\mathrm{Cx} 43^{\mathrm{fl} / \mathrm{fl}}$ mouse lungs, a PE10 microcatheter was used to clear an area of microvessels. Following treatment of Thrombin (10 U/mL; 10 minutes $)$ or S1P $(10 \mu \mathrm{M} ; 20$ minutes), an infusion of FDx20 $(.5 \mathrm{mg} / \mathrm{mL})$ was given over 1 hour. At least 20 minutes prior to the end of the FDx20 infusion, imaging was started, taking 1 image of the FDx20 fluorescence every minute, centered at a single microvessel. At the end of the FDx20 infusion, an infusion of HBS was started and continued for a minimum of 30 minutes, with imaging continuing at the same rate. FDx20 fluorescence was measured at 
random sites along the vasculature for the duration of the image series. Permeability was determined by normalizing the peak FDx20 fluorescence to $1000 \mathrm{AU}$ and calculating the average decrease in intensity over the first 10 minutes following the peak. In experiments in which S1P2 signaling was inhibited, JTE-013 $(1 \mu \mathrm{L} / \mathrm{mL})$ was infused for 15 minutes prior to treatment. In experiments were ROS generation was inhibited, NAC $(5 \mu \mathrm{M})$ was given for 1 hour prior to treatment. In experiments where thrombin and S1P were given at the same time, first S1P was infused for 10 minutes and then both S1P and thrombin were infused for an additional 10 minutes.

\section{Statistics}

All data reported as mean \pm SEM. All groups were compared with Kruskal-Wallis one-way ANOVA on Ranks, followed by pairwise multiple comparisons by Dunn's method.

\section{Results}

\section{Thrombin Induces Differing Effects on S1P2 Expression in Both PMVECs and Microvessels in $\mathrm{Cx} 43^{\mathrm{f} / \mathrm{fl}}$ and $\mathrm{EC}-\mathrm{Cx} 43^{-/-}$Mice}

S1P2 expression in PMVECs isolated from $\mathrm{Cx} 43^{\mathrm{fl} / \mathrm{fl}}$ and EC-Cx43 ${ }^{-/-}$mouse lungs following thrombin treatment. While different inflammatory mediators have been shown to induce an increase in S1P2 expression in endothelial cells [70], this effect has not been studied in relation to thrombin. We first established expression of the S1P2 receptor in primary PMVECs at baseline and following thrombin treatment. Briefly, from both $\mathrm{Cx} 43^{\mathrm{fl} / \mathrm{fl}}$ and $\mathrm{EC}-\mathrm{Cx} 43^{--}$mice, we removed the lungs, isolated the microvascular endothelial cells, and allowed them to adhere and grow on coverslips overnight. The cells were then fixed, permeabilized, and S1P2 expression was determined using immunofluorescence (Figure 4-1A). Primary endothelial cells isolated from $\mathrm{Cx} 43^{\mathrm{fl} / \mathrm{fl}}$ and $\mathrm{EC}-\mathrm{Cx} 43^{-/}$mouse lungs showed similar levels of baseline fluorescence, with the EC$\mathrm{Cx} 43^{-/-}$cells exhibiting slightly higher secondary Ab fluorescence $\left(\mathrm{Cx} 43^{\mathrm{fl} / \mathrm{fl}}\right.$ baseline $=$ $236.0 \pm 17.7$ gy lvls; EC-Cx43-/- baseline $=347.3 \pm 27.6$ gy lvls). Interestingly, EC-Cx $43^{-}$ ${ }^{1}$ cells that had been treated with thrombin prior to fixing displayed a slightly decreased S1P2 expression compared to baseline (EC-Cx43 $3^{-/}$thrombin $=249.3 \pm 20.1$ gy lvls). The opposite effect was observed in the $\mathrm{Cx} 43^{\mathrm{fl} / \mathrm{fl}}$ primary PMVECs in which thrombin induced a dramatic and significant increase in S1P2 expression $\left(\mathrm{Cx} 43^{\mathrm{fl} / \mathrm{fl}}\right.$ thrombin $=$ $1099.0 \pm 25.2$ gy lvls)(Figure 4-1B). Overall, this shows that thrombin treatment leads to an increase in S1P2 expression in $\mathrm{Cx} 43^{\mathrm{fl} / \mathrm{fl}}$, but not $\mathrm{EC}-\mathrm{Cx} 43^{-/}$, isolated PMVECs.

S1P2 expression in pulmonary microvessels. We further explored thrombininduced S1P2 expression in the pulmonary microvasculature of isolated $\mathrm{Cx} 43^{\mathrm{fl} / \mathrm{fl}}$ and EC$\mathrm{Cx}_{4} 3^{-/-}$mouse lungs. Similar to what was done in the isolated cells, S1P2 expression was 


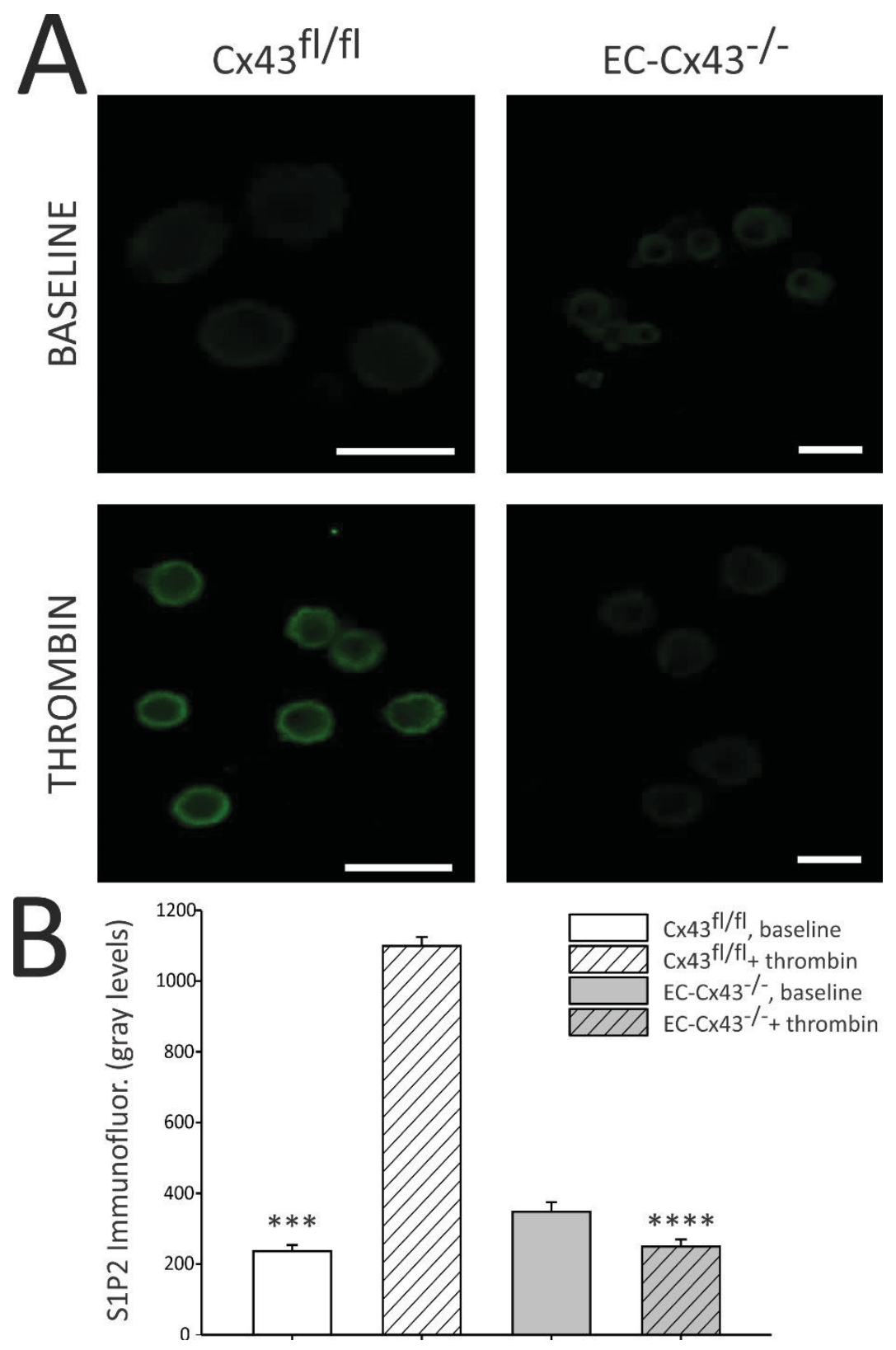

Figure 4-1. S1P2 expression in mouse PMVECs

$(\mathrm{A}, \mathrm{B})$ Confocal images and graph of immunofluorescence of S1P2 in isolated PMVECs from $\mathrm{Cx} 43^{\mathrm{fl} / \mathrm{fl}}$ (first column) and $\mathrm{EC}-\mathrm{Cx} 43^{-/-}$(second column) mice, at baseline (first row) and after thrombin (second row, $10 \mathrm{U} / \mathrm{mL}$ ) treatment. Bars $=5 \mu \mathrm{m} . * * *=\mathrm{p}<.001, * * * *=$ $\mathrm{p}<.0001$ compared to $\mathrm{Cx} 43^{\mathrm{fl} / \mathrm{fl}}+$ thrombin treatment. $\mathrm{n}=3$ coverslips for all groups. 
determined by immunofluorescence. At baseline, we found that in the $\mathrm{Cx} 43^{\mathrm{fl} / \mathrm{fl}}$ lungs there was a low level of S1P2 expression in both the venules and the capillaries (Figure 4-2A). However, in the EC-Cx $43^{-/-}$mouse lungs we saw strikingly higher levels of S1P2 expression, with immunofluorescence being approximately $5 \mathrm{x}$ and $15 \mathrm{x}$ what was seen in the $\mathrm{Cx} 43^{\mathrm{fl} / \mathrm{fl}}$ capillaries and venules, respectively (Figure 4-2B). This result was particularly surprising because, while EC-Cx $43^{-/-}$cells displayed elevated S1P2 expression over $\mathrm{Cx} 43^{\mathrm{fl} / \mathrm{fl}}$ cells, this was modest and not significant.

We next studied S1P2 expression following local micropuncture instillations of either thrombin or PBS (for control). Similar to what was observed in the isolated PMVECs, thrombin treatment induced an increase in S1P2-mediated fluorescence in both venules and capillaries (Figure 4-3A). For both, while the increase inside the actual thrombin-treated microvessels was minor, the increase in venules and capillaries $\sim 600 \mu \mathrm{m}$ away from the micropunctured area was quite sizeable and significantly higher compared

to inside (Figure 4-3B and C). These results indicate that the thrombin treatment induced an increase in the presence of S1P2 in microvessels directly treated and in neighboring, untreated microvessels.

Conversely, thrombin induced the opposite effect in the microvessels of the EC$\mathrm{Cx} 43^{-/-}$mouse lungs (Figure 4-4A). In the venules, there was an insignificant increase over PBS control within the treated area. In the outside venules, thrombin treatment actually led to a significant decrease in S1P2 expression compared to both the directly thrombin-treated venules as well as venules outside of the PBS-treated area (Figure 44B). In the capillaries, thrombin treatment induced a significant decrease in S1P2 immunofluorescence compared to PBS control both within and outside of the micropunctured areas (Figure 4-4C). Thus, the absence of $\mathrm{Cx} 43$ in endothelial cells blunts thrombin-induced $\mathrm{S} 1 \mathrm{P} 2$ responses.

In comparing the results from $\mathrm{Cx} 43^{\mathrm{fl} / \mathrm{fl}}$ and $\mathrm{EC}-\mathrm{Cx} 43^{-/-}$lungs, while there was no significant difference between thrombin-treated venules of the two genotypes, there were significant differences between the outside venules as well as the inside and outside capillaries from the $\mathrm{Cx} 43^{\mathrm{fl} / \mathrm{fl}}$ and $\mathrm{EC}-\mathrm{Cx} 43^{-/-}$mouse lungs (Figure 4-5). Therefore, while there is significantly more S1P2 present in pulmonary microvascular endothelium of EC$\mathrm{Cx} 43^{-/-}$mice at baseline, thrombin treatment induces an increase in expression in both directly-treated and faraway microvessels of the $\mathrm{Cx} 43^{\mathrm{fl} / \mathrm{fl}}$ mouse lungs as well as an overall decrease in S1P2 expression in the EC-Cx43 $3^{-/-}$lung microvessels.

\section{Induction of ROS Generation by Thrombin in Pulmonary Microvessels}

We next chose to explore thrombin-induced generation of ROS in microvessels following local thrombin treatment, as ROS may be generated through PAR-1-depedent activation of Nox $2[51,156]$. We have previously shown that thrombin is able to induce F-actin polymerization in both thrombin-treated and -free microvessels 

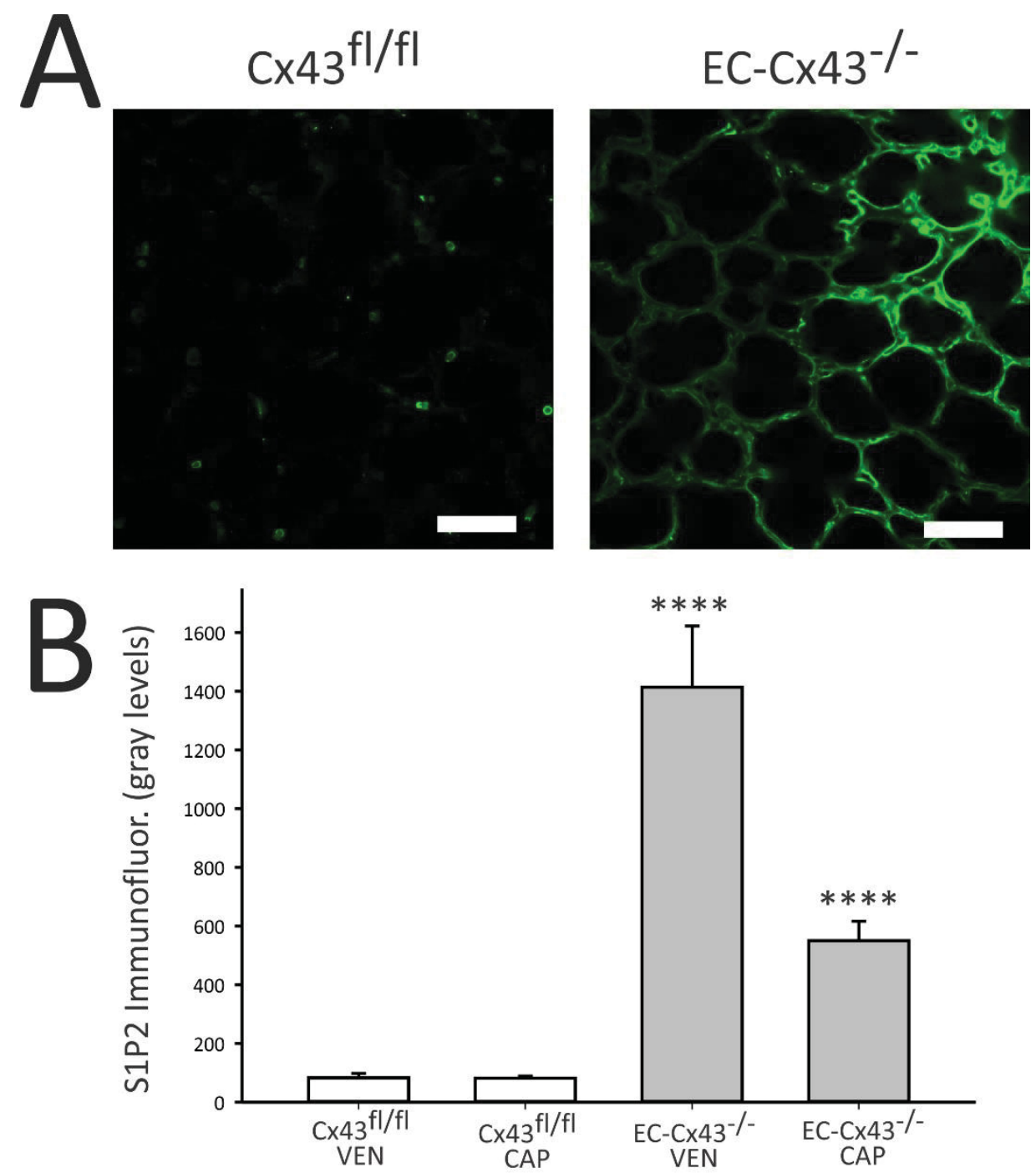

Figure 4-2. Baseline S1P2 expression in mouse pulmonary microvessels $(A, B)$ Confocal images and graph of immunofluorescence of S1P2 in pulmonary microvessels of $\mathrm{Cx} 43^{\mathrm{fl} / \mathrm{fl}}$ and EC-Cx $43^{-/}$mouse lungs at baseline. Bars $=100 \mu \mathrm{m}$. $* * * *=$ $\mathrm{p}<.0001$ compared to $\mathrm{Cx} 43^{\mathrm{fl} / \mathrm{fl}}$ microvessels. $\mathrm{n}=3$ lungs for both genotypes. 

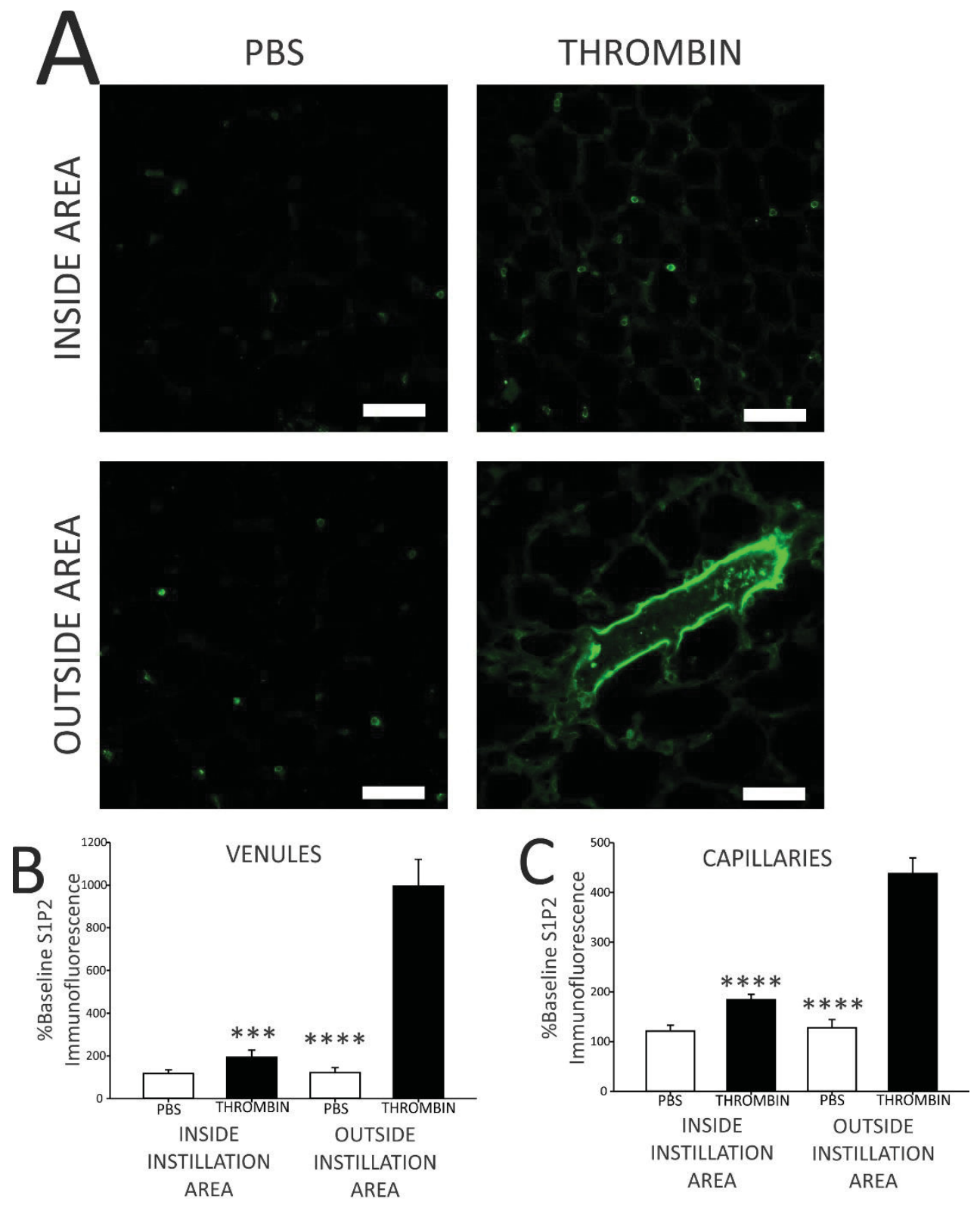

Figure 4-3. S1P2 expression in microvessels of $\mathrm{Cx} 43^{\mathrm{f} / \mathrm{fl}}$ mouse lungs instilled with PBS or Thrombin

(A) Confocal images of immunofluorescence of S1P2 in pulmonary microvessels of $\mathrm{Cx} 43^{\mathrm{fl} / \mathrm{fl}}$ mouse lungs following micropuncture instillation of either PBS (first column) or thrombin (second column, $10 \mathrm{U} / \mathrm{mL}$ ) treatment. Images captured in (first row) and out (second row) of micropunctured area. Bars $=100 \mu \mathrm{m}$. (B,C) Graphs showing S1P2 immunofluorescence normalized to baseline levels in venules (B) and capillaries (C). *** $=\mathrm{p}<.001, * * * *=\mathrm{p}<.0001$ compared to microvessels outside of thrombin-treated area. $\mathrm{n}$ $=3$ for PBS-treated lungs. $\mathrm{n}=4$ for thrombin-treated lungs. 

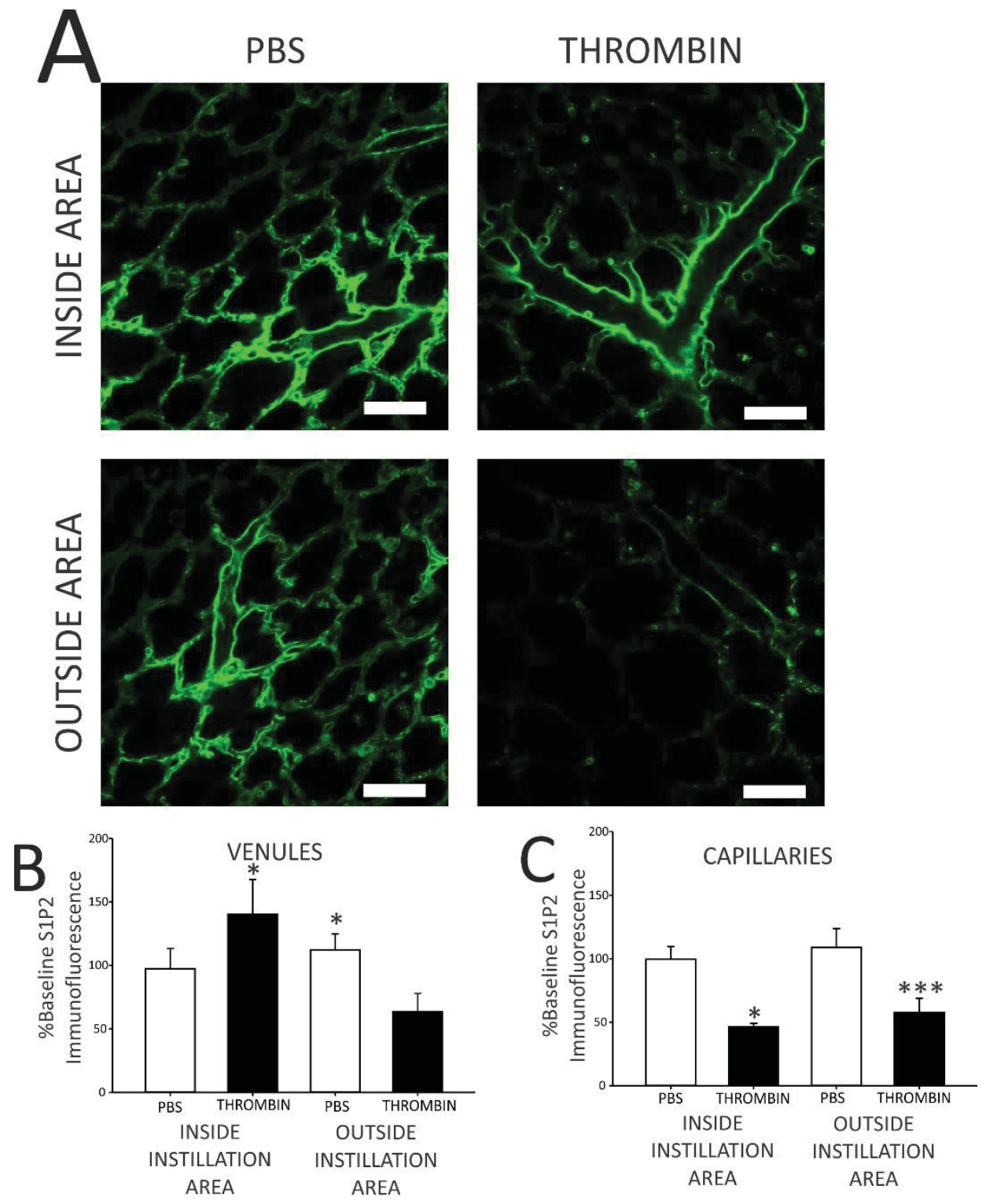

Figure 4-4. S1P2 expression in microvessels of EC-Cx43 ${ }^{-/}$mouse lungs instilled with PBS or Thrombin

(A) Confocal images of immunofluorescence of S1P2 in pulmonary microvessels of EC$\mathrm{Cx} 43^{--}$mouse lungs following micropuncture instillation of either PBS (first column) or thrombin (second column, $10 \mathrm{U} / \mathrm{mL}$ ) treatment. Images captured in (first row) and out (second row) of micropunctured area. Bars $=100 \mu \mathrm{m}$. (B,C) Graphs showing S1P2 immunofluorescence normalized to baseline levels in venules (B) and capillaries (C). $(B)^{*}=p<.05$ compared to venules outside of thrombin-treated region. (C) $*=p<.05, * * *$ $=\mathrm{p}<.001$ compared to capillaries in PBS-treated lungs in indicated areas. $\mathrm{n}=3$ for both treatment groups. 

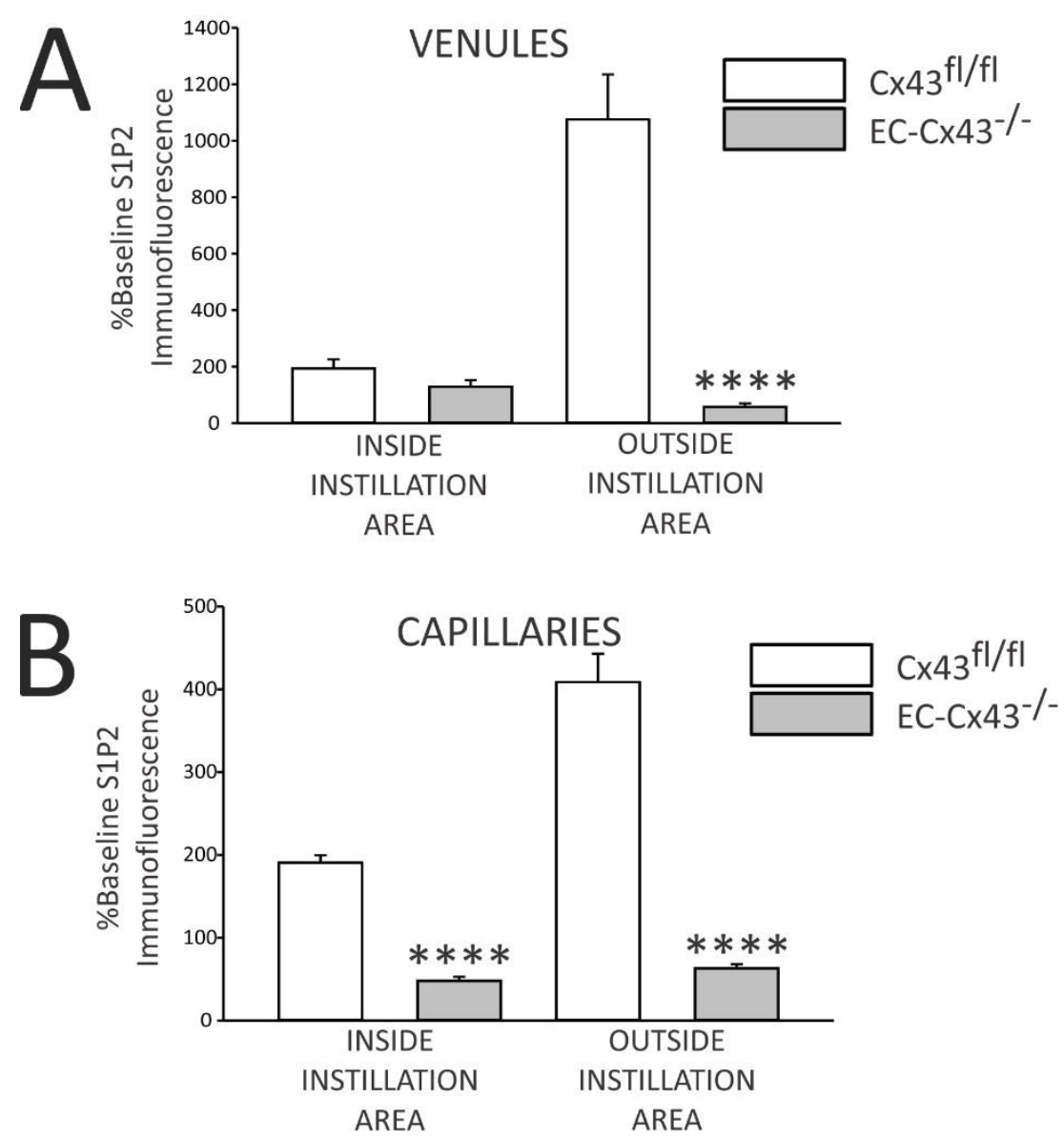

Figure 4-5. Comparison of S1P2 expression following Thrombin treatment in pulmonary microvessels of $\mathrm{Cx} 43^{\mathrm{fl} / \mathrm{fl}}$ and $\mathrm{EC}-\mathrm{Cx} 43^{-/-}$mouse lungs $(\mathrm{A}, \mathrm{B})$ Bar graphs depict S1P2 immunofluorescence following thrombin treatment normalized to baseline, untreated values in venules (A) and capillaries (B). **** $=$ $\mathrm{p}<.0001$ compared to $\mathrm{Cx} 43^{\mathrm{fl} / \mathrm{fl}}$ microvessels in indicated areas. $\mathrm{n}=4 \mathrm{Cx} 43^{\mathrm{fl} / \mathrm{fl}}$ mouse lungs, $\mathrm{n}=3 \mathrm{EC}-\mathrm{Cx} 43^{-/-}$mouse lungs. 
by intercellular communication through Cx43-containing gap junctions [155], and we sought to determine if this other mediator of the thrombin permeability response may be induced in a similar spatially extensive manner. We evaluated ROS generation as the change in the ratio of CellROX deep red reagent (an indicator of ROS) fluorescence over Calcein AM fluorescence, before and after a micropuncture instillation of either thrombin or PBS. Thrombin induced significant increases in ROS within treated microvessels, with the change in the CellROX/Calcein AM ratio being double what was seen in PBS control for both treated venules and capillaries (Figure 4-6). Thrombin treatment also lead to increases in the untreated microvessels, with the change in the CellROX/Calcein AM ratio being double and triple control values for the venules and capillaries, respectively.

However, in the EC-Cx $43^{-/}$, thrombin was able to induce only modest increases within thrombin-treated venules and capillaries that were not significant compared to control (Figure 4-7). In the untreated venules outside of the thrombin treatment, there was a significant decrease in the generation of ROS compared to treated venules, with values being nearly identical to PBS instillation values. In the outside capillaries, there was a minor increase compared to PBS instillation, but there was still less of a change in the CellROX/Calcein AM ratio compared to capillaries within the thrombin treated region.

Overall, there was a significantly higher increase in ROS generation following thrombin treatment in all evaluated venules and the outside capillaries of $\mathrm{Cx} 43^{\mathrm{fl} / \mathrm{fl}}$ mouse lungs when compared to EC-Cx $43^{-/-}$pulmonary microvasculature (Figure 4-8). Thus, thrombin induces increases in ROS generation in treated and faraway, untreated microvessels, and the spatial expansion of this response in dependent on $\mathrm{Cx} 43$-containing gap junctions.

\section{S1P2 Signaling Contributes to Thrombin-Induced Increase in Pulmonary Microvascular Permeability}

As both PAR-1 and S1P2 signaling has been shown to be barrier-destructive and stems from the activation of the same G-proteins, we evaluated whether or not there was any cooperation between the two pathways in pulmonary endothelial hyperpermeability.

$\mathrm{S} 1 \mathrm{P}$, through its receptor $\mathrm{S} 1 \mathrm{P} 2$, increases lung microvascular permeability. We first established the consequences of S1P2 signaling in permeability of pulmonary microvessels. To that end, following treatment with S1P with or without the S1P2 antagonist JTE-013, we infused FDx20 kDa via catheter for 60 minutes. We determined the fall in fluorescence within the first 10 minutes after peak FDx20 fluorescence and switch to HBS infusion (calculated as gray levels/min). Therefore, the higher the gy lvls/min value, the more FDx20 kDa is washing out, the lower the permeability. Interestingly, we found that in this microvascular bed S1P itself induced a statistically significant increase in permeability compared to control (no treatment) and microvessels treated with JTE-013(Figure 4-9 A,B). However, when S1P2 signaling was blocked by a JTE-013 pretreatment, this increase was likewise blocked. We also sought to determine 
Figure 4-6. Induction of ROS generation following Thrombin micropuncture instillation in microvessels of $\mathrm{Cx} 43^{\mathrm{fl} / \mathrm{fl}}$ mouse lungs

(A) Confocal images of CellROX deep red reagent fluorescence (first column), Calcein AM fluorescence (second column), and merge of the two (third column) following thrombin micropuncture instillation in $\mathrm{Cx} 43^{\mathrm{fl} / \mathrm{fl}}$ mouse lungs. Images captured inside instillation area before (first row) and after (second row) thrombin $(10 \mathrm{U} / \mathrm{mL})$ treatment, as well as outside micropunctured area before (third row) and after (fourth row)

treatment. Bars $=100 \mu \mathrm{m}$. $(\mathrm{B}, \mathrm{C})$ Bar graphs show the ratio of CellROX deep red reagent fluorescence over Calcein AM fluorescence, normalized to values before micropuncture instillation of either PBS or thrombin $(10 \mathrm{U} / \mathrm{mL})$, in venules $(\mathrm{B})$ and capillaries $(\mathrm{C}) .{ }^{*}=$ $\mathrm{p}<.05, * *=\mathrm{p}<.01$ compared to values obtained in PBS-instilled lungs in indicated areas. $\mathrm{n}=3$ for both treatment groups. 

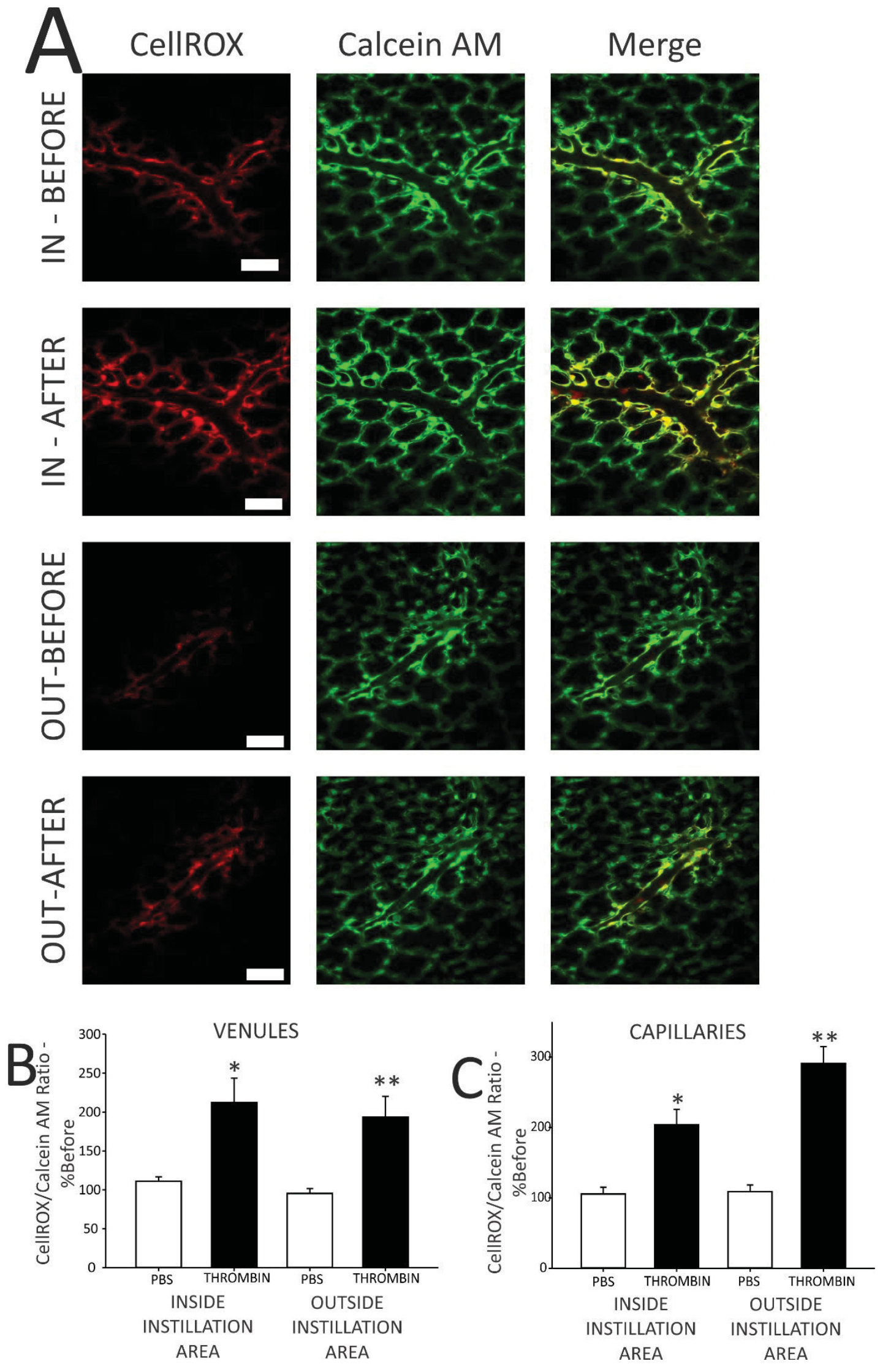
Figure 4-7. Induction of ROS generation following Thrombin micropuncture instillation in microvessels of $\mathrm{EC}-\mathrm{Cx} 43^{-/-}$mouse lungs

(A) Confocal images of CellROX deep red reagent fluorescence (first column), Calcein AM fluorescence (second column), and merge of the two (third column) following thrombin micropuncture instillation in $\mathrm{EC}-\mathrm{Cx} 43^{-/-}$mouse lungs. Images captured inside instillation area before (first row) and after (second row) thrombin (10 U/mL) treatment, as well as outside micropunctured area before (third row) and after (fourth row)

treatment. Bars $=100 \mu \mathrm{m}$. $(\mathrm{B}, \mathrm{C})$ Bar graphs show the ratio of CellROX deep red reagent fluorescence over Calcein AM fluorescence, normalized to values before micropuncture instillation of either PBS or thrombin $(10 \mathrm{U} / \mathrm{mL})$, in venules $(\mathrm{B})$ and capillaries $(\mathrm{C}) .{ }^{*}=$ $\mathrm{p}<.05$ compared to values obtained in venules inside thrombin-treated area. $n=3$ PBStreated lungs, $n=4$ thrombin-treated lungs. 


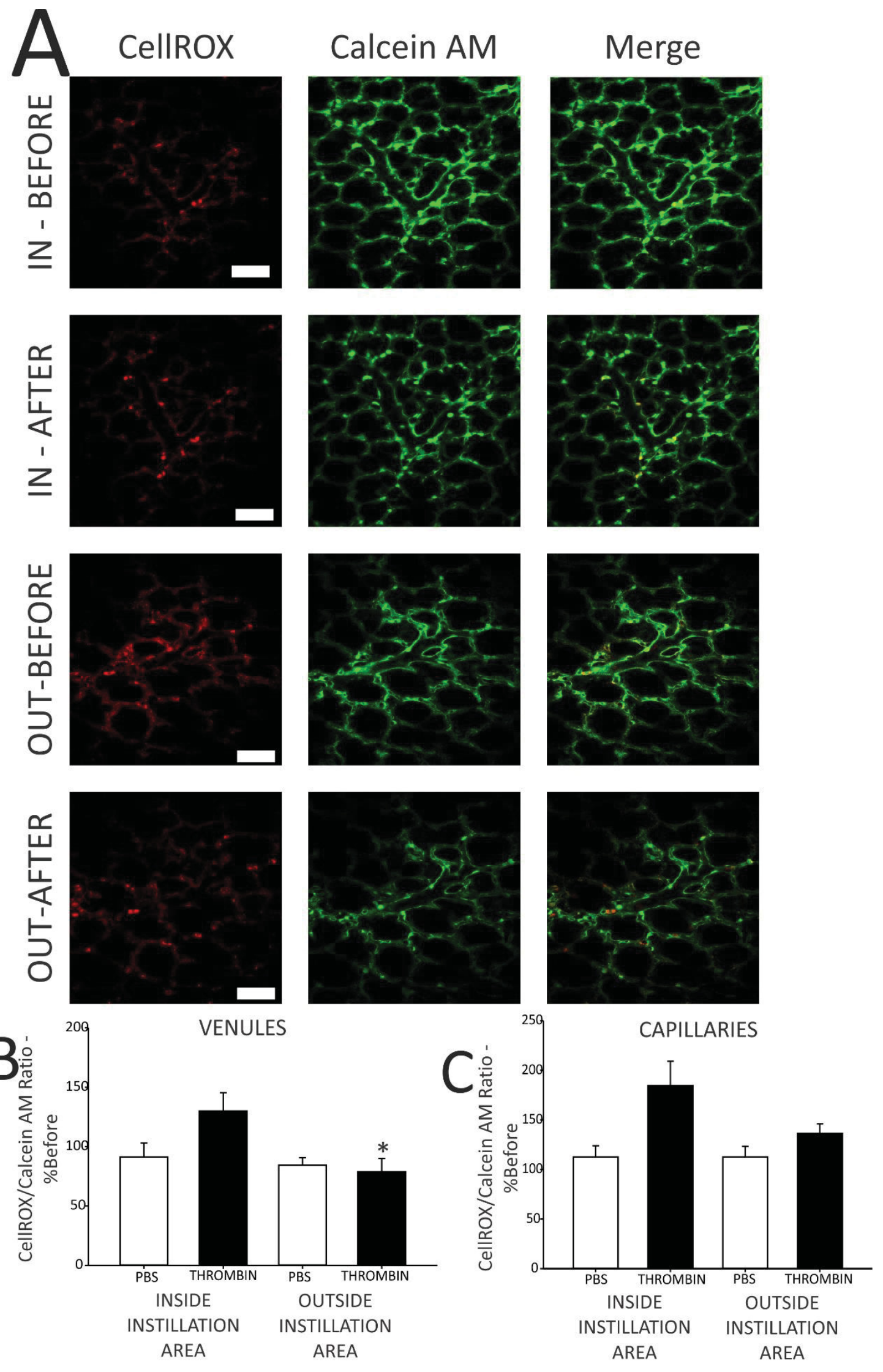



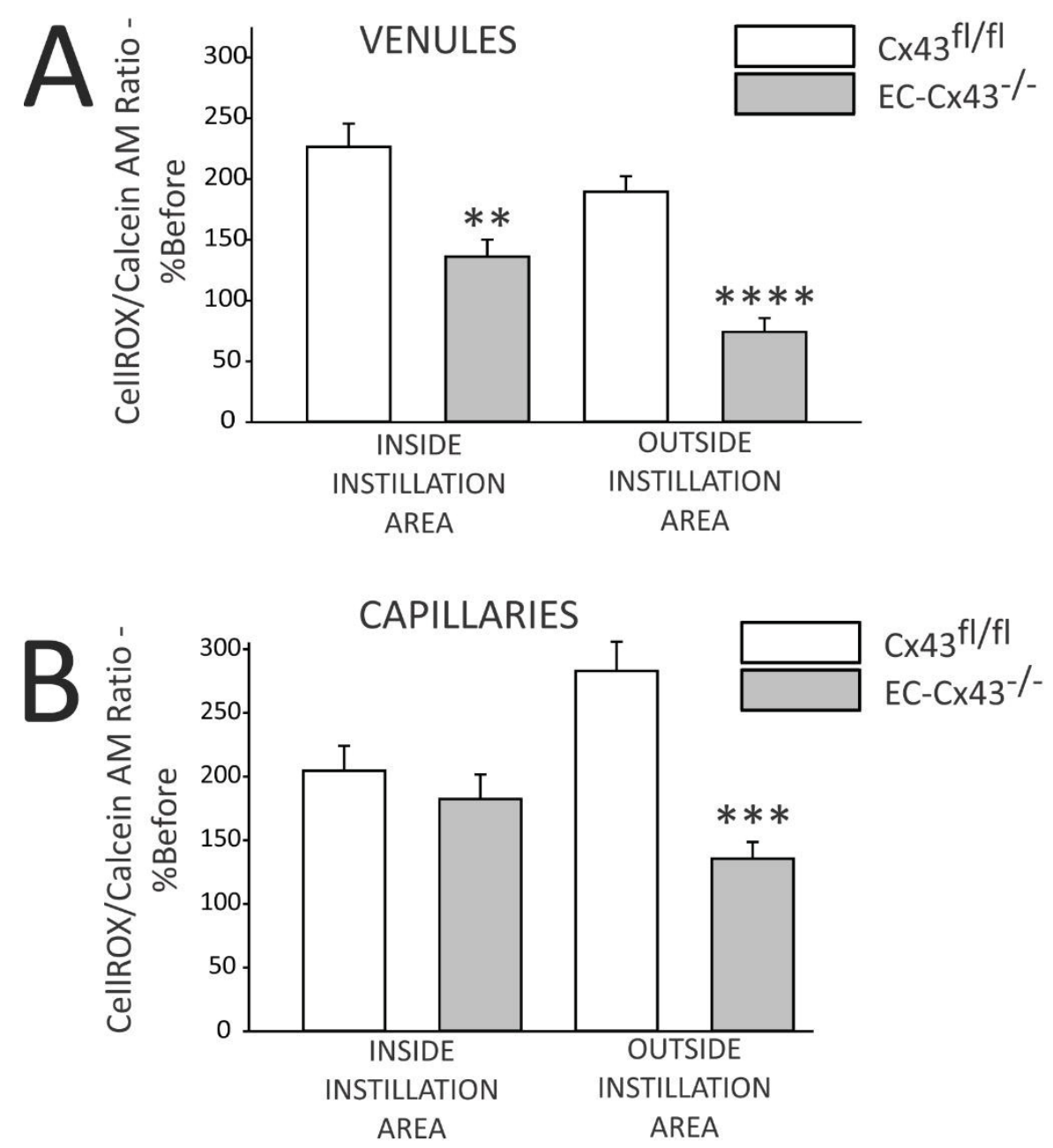

Figure 4-8. Comparison of ROS generation following Thrombin treatment in pulmonary microvessels of $\mathrm{Cx} 43^{\mathrm{fl} / \mathrm{fl}}$ and $\mathrm{EC}-\mathrm{Cx} 43^{-/-}$mouse lungs

$(A, B)$ Bar graphs show ratio of CellROX deep red reagent fluorescence over Calcein AM fluorescence, normalized to values before micropuncture instillation of thrombin (10 $\mathrm{U} / \mathrm{mL}$ ), in venules (A) and capillaries (B). ** $=\mathrm{p}<.01, * * *=\mathrm{p}<.001, * * * *=\mathrm{p}<.0001$ compared to $\mathrm{Cx} 43^{\mathrm{fl} / \mathrm{fl}}$ microvessels in indicated areas. $\mathrm{n}=3 \mathrm{Cx} 43^{\mathrm{fl} / \mathrm{fl}}$ lungs, $\mathrm{n}=4 \mathrm{EC}$ $\mathrm{Cx} 43^{-/}$lungs. 
Figure 4-9. S1P2 signaling in pulmonary microvascular permeability (A) Pseudocolored images showing FDx20 fluorescence at peak (first column) and 5 minutes into HBS wash following peak FDx20 fluorescence (second column) in $\mathrm{Cx} 43^{\mathrm{fl} / \mathrm{fl}}$ mouse lungs following treatment with JTE-013 (first row, $1 \mu \mathrm{M}$ ), S1P (second row, 10 $\mu \mathrm{M}$ ), S1P + JTE-013 (third row), thrombin (fourth row, 10U/ml) or thrombin+JTE-013 (fifth row). Bars $=100 \mu \mathrm{m}$. $(\mathrm{B}, \mathrm{C})$ Bar graph shows the change in FDx20 fluorescence, as gray levels/min, following microcatheter infusion of indicated treatments. $(B) * *=p<.01$, $* * * *=p<.0001$ compared to thrombin alone, respectively.. $\$=p<.05, \$ \$=p<.01$ compared to S1P alone, respectively. $\mathrm{n}=4$ for control, S1P-, S1P+JTE-013-, and thrombin-treated lungs, $\mathrm{n}=5$ for JTE-013- and thrombin+JTE-013-treated lungs. (C) $*=\mathrm{p}<.05$, $* *=$ $\mathrm{p}<.01$ compared thrombin followed by S1P treatment. $\mathrm{n}=4$ thrombin-treated lungs, $\mathrm{n}=3$ thrombin + S1P-treated lungs, $n=3$ thrombin- THEN S1P-treated lungs. 


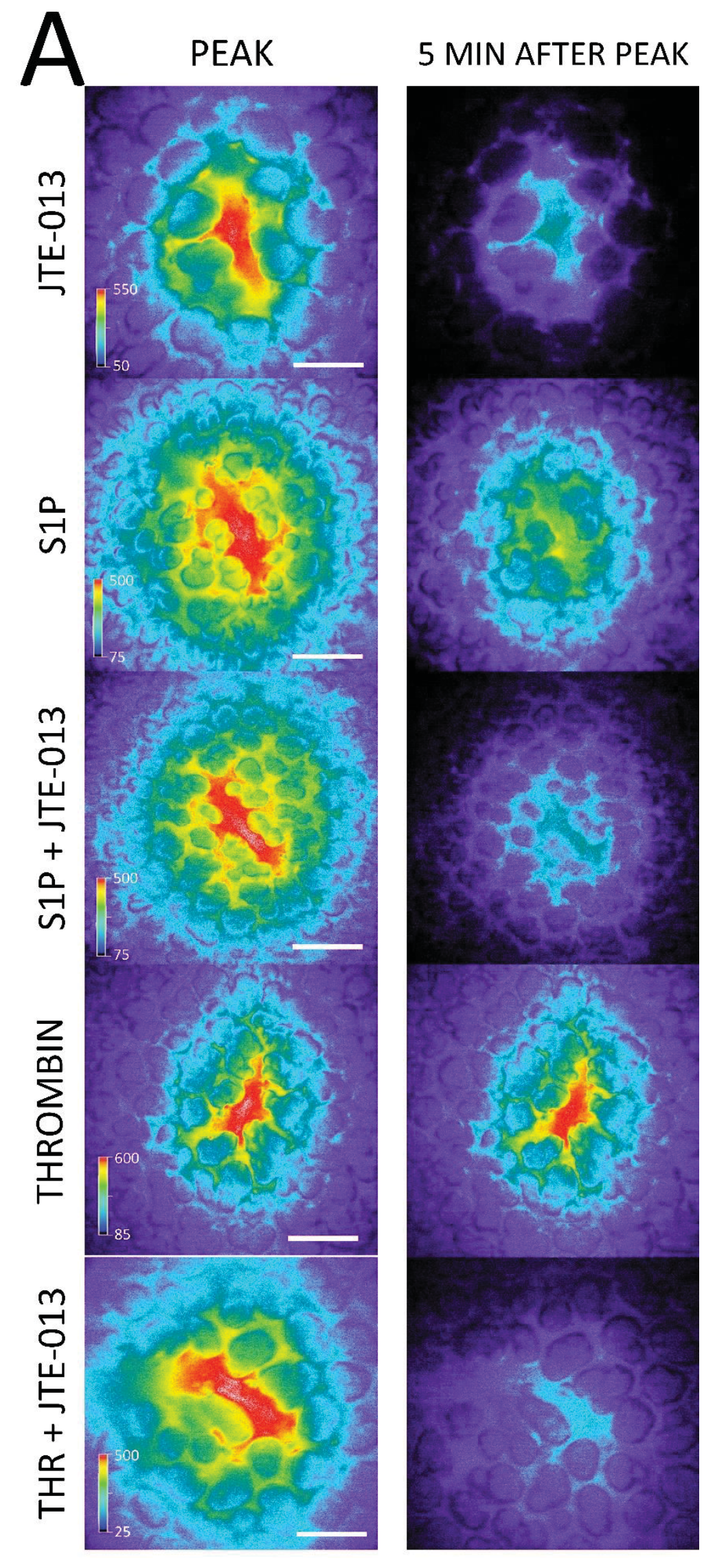





Figure 4-9 (Continued) 
the depth to which S1P2 signaling may contribute to thrombin-induced increases in permeability in pulmonary microvessels. As observed previously, a catheter infusion of thrombin greatly increased endothelial barrier permeability compared to control and treatment with JTE-013 alone (Figure 4-9 A,B). However, when JTE-013 was used to prior to thrombin infusion, barrier integrity returned to control levels (Figure 4-9B). These results show that, in lung microvessels, signaling originating from the S1P2 receptor leads to barrier disruption and that S1P2 signaling plays a role in thrombininduced permeability increases.

To further study this relationship, as well as the effects of increased S1P production, we examined the consequences on permeability of giving S1P both concurrently with thrombin as well as following thrombin treatment. We found that when $\mathrm{S} 1 \mathrm{P}$ is given following thrombin infusion, there is a significantly diminished impact on permeability compared to S1P given during thrombin as well as to thrombin alone (Figure 4-9C). This shows that S1P application, given following treatment with the inflammatory mediator thrombin, may help to alleviate the hyperpermeability response.

Inhibition of S1P2 signaling pathways blocks thrombin-induced ROS generation in $\mathbf{C x 4 3 f 1 / f l}$ pulmonary microvasculature. Because we observed both that $\mathrm{S} 1 \mathrm{P} 2$ signaling was able to augment thrombin-induced signaling and that S1P itself can induce an increase in permeability, we next sought to establish whether signaling through S1P2 had any effect on thrombin-initiated ROS production. For this, we again used the change in the ratio of CellROX fluorescence over Calcein AM fluorescence, before and after treatment with thrombin and/or JTE-013, to determine changes in ROS content of the microvasculature. As we observed in previous experiments, thrombin infusion initiated a significant increase in ROS (Figure 4-10). However, when thrombin was given following infusion of JTE-013, this increase was completely abolished. In addition, we found that S1P treatment also lead to an increase in ROS generation that was blocked by JTE-013 pre-treatment. Thus, S1P2 signaling is required for the thrombin- and S1Pinduced increase in ROS production in pulmonary microvessels.

Increases in permeability induced by S1P and thrombin are due to increases in ROS generation. Finally, we sought to investigate whether the increase in ROS generation that is being mediated by S1P2 is also responsible for the subsequent changes to barrier integrity induced by thrombin and S1P. Towards this, the microvessels were pretreated with NAC, an antioxidant and inhibitor of ROS generation. We found that blocking ROS generation completely abolished increases in permeability due to thrombin and S1P (Figure 4-11). Thus, the increased ROS generation induced by thrombin and $\mathrm{S} 1 \mathrm{P}$ is mediating the increased permeability caused by these two inflammatory mediators.

\section{Discussion}

This study shows for the first time that, in both isolated primary PMVECs as well as in pulmonary microvessels from $\mathrm{Cx} 43^{\mathrm{fl} / \mathrm{fl}}$ mouse lungs, the inflammatory mediator 
Figure 4-10. S1P2 signaling in Thrombin-induced ROS generation

(A) Confocal images of CellROX deep red reagent fluorescence (first column), Calcein AM fluorescence (second column), and merge of the two (third column) before and after treatment of microvasculature with JTE-013 $(1 \mu \mathrm{M})$ and/or thrombin $(10 \mathrm{U} / \mathrm{mL})$ in ECCx43-/- mouse lungs. Bars $=100 \mu \mathrm{m}$. (B) Bar graph shows the ratio of CellROX deep red reagent fluorescence over Calcein AM fluorescence, normalized to values before treatment with indicated agents. $* * *=p<.001$ compared to thrombin treatment group. $\$=\mathrm{p}<.05, \$ \$ \$=\mathrm{p}<.001$ compared to $\mathrm{S} 1 \mathrm{P}$ treatment group. $\mathrm{n}=3$ for JTE-013-, thrombin+JTE-013-, S1P-, and S1P+JTE-013-treated lungs. $\mathrm{n}=4$ for thrombin-treated lungs. 
A

CellROX
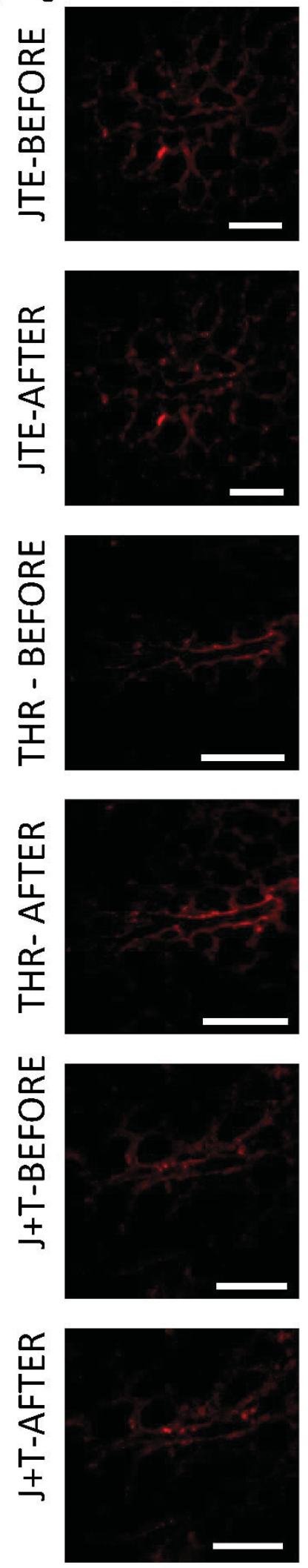

Calcein AM
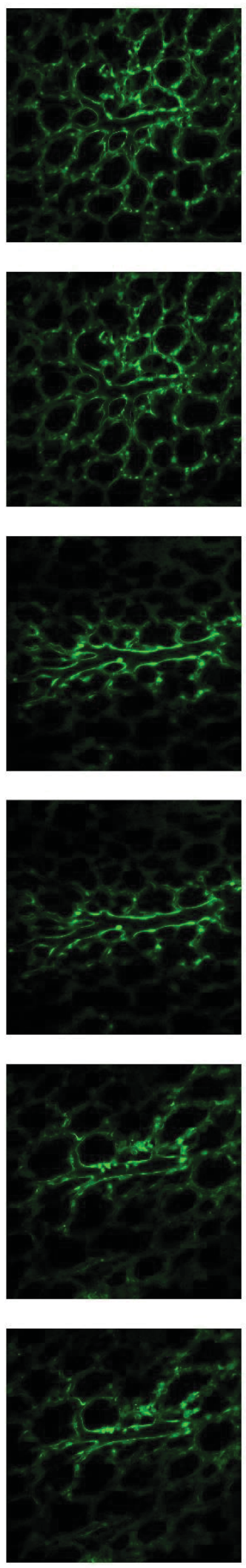

Merge
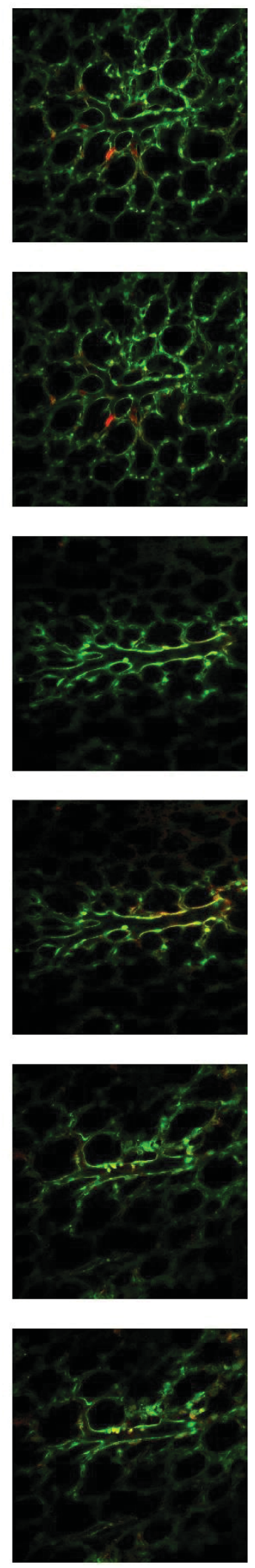

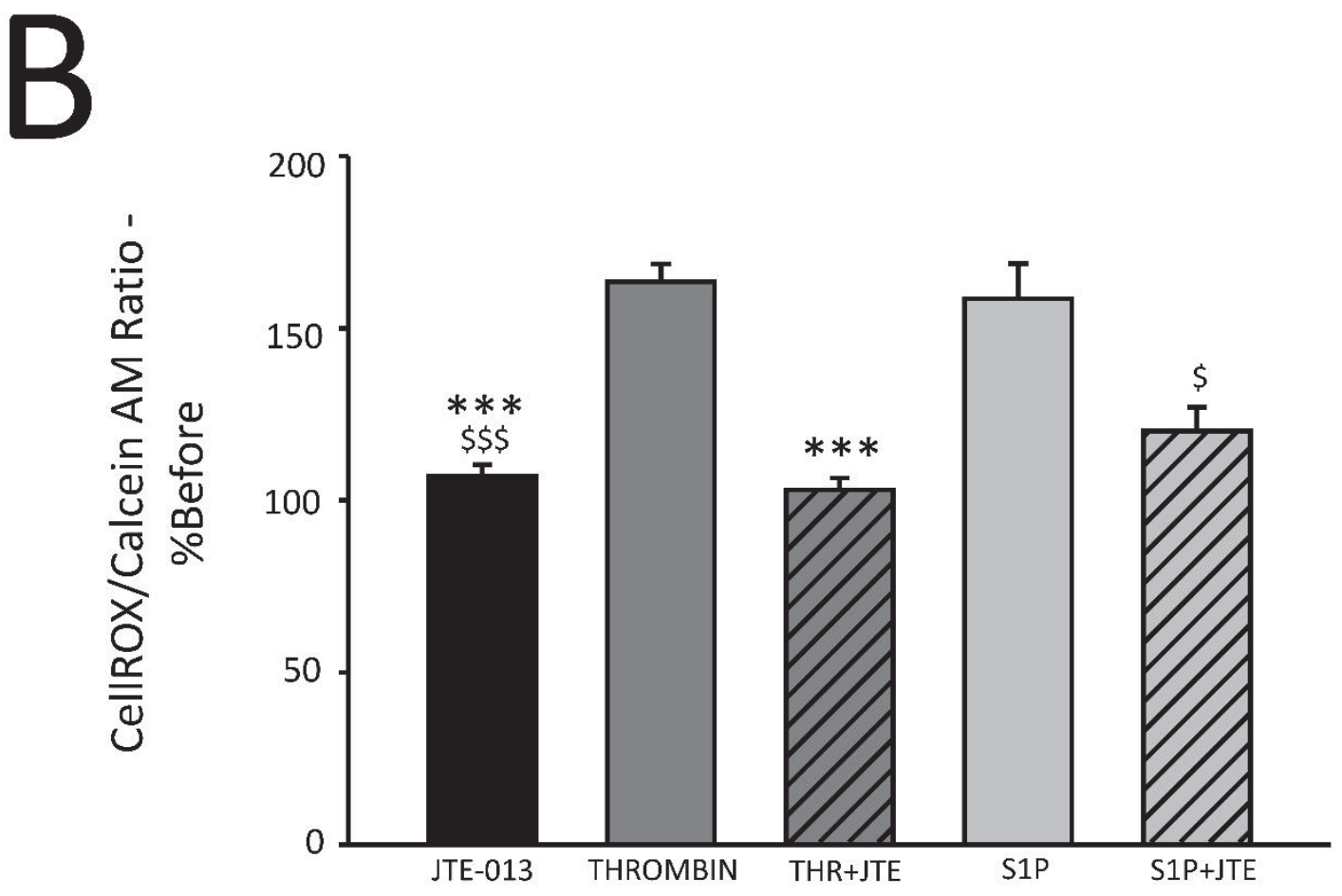

Figure 4-10 (Continued) 
Figure 4-11. Inhibition of ROS generation in S1P- and Thrombin-induced hyperpermeability

(A) Bar graph shows the change in FDx20 fluorescence, as gray levels/min, following microcatheter infusion of indicated treatments. $* * *=\mathrm{p}<.001, * * * *=\mathrm{P}<.0001$ compared to thrombin treatment group. $\$ \$=\mathrm{p}<.01, \$ \$ \$=\mathrm{p}<.001$ compared to $\mathrm{S} 1 \mathrm{P}$ treatment group.

$\mathrm{n}=4$ for S1P- and thrombin-treated lungs; $\mathrm{n}=3$ for NAC-, thrombin+NAC-, and $\mathrm{S} 1 \mathrm{P}+\mathrm{NAC}$-treatedgroups. (B) Line graph shows average decline in FDx20 fluorescence within first 10 minutes of Ringer's wash for each indicated treatment. Fluorescence normalized such that "Peak" fluor. equals 1000 gray levels. 
A

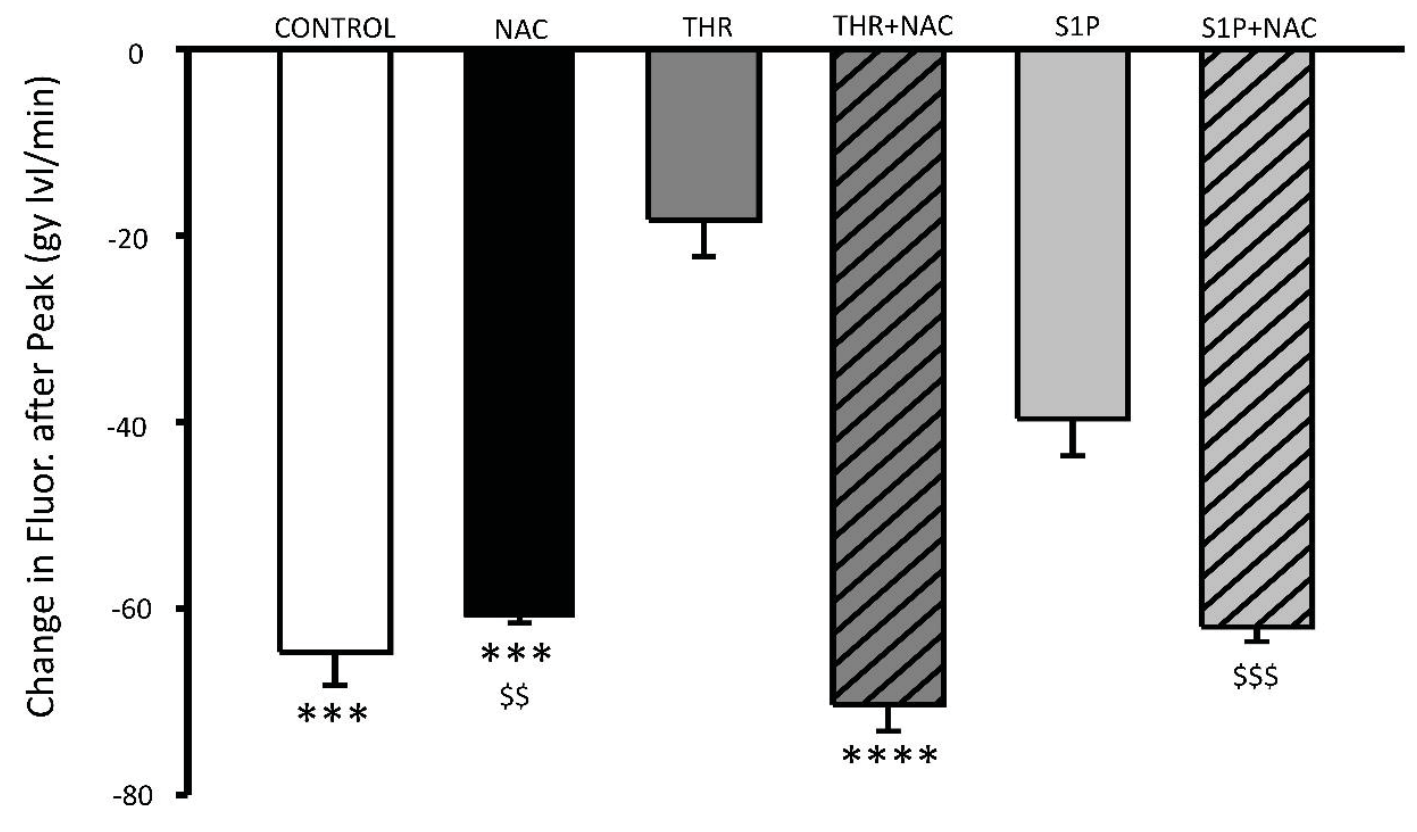

B

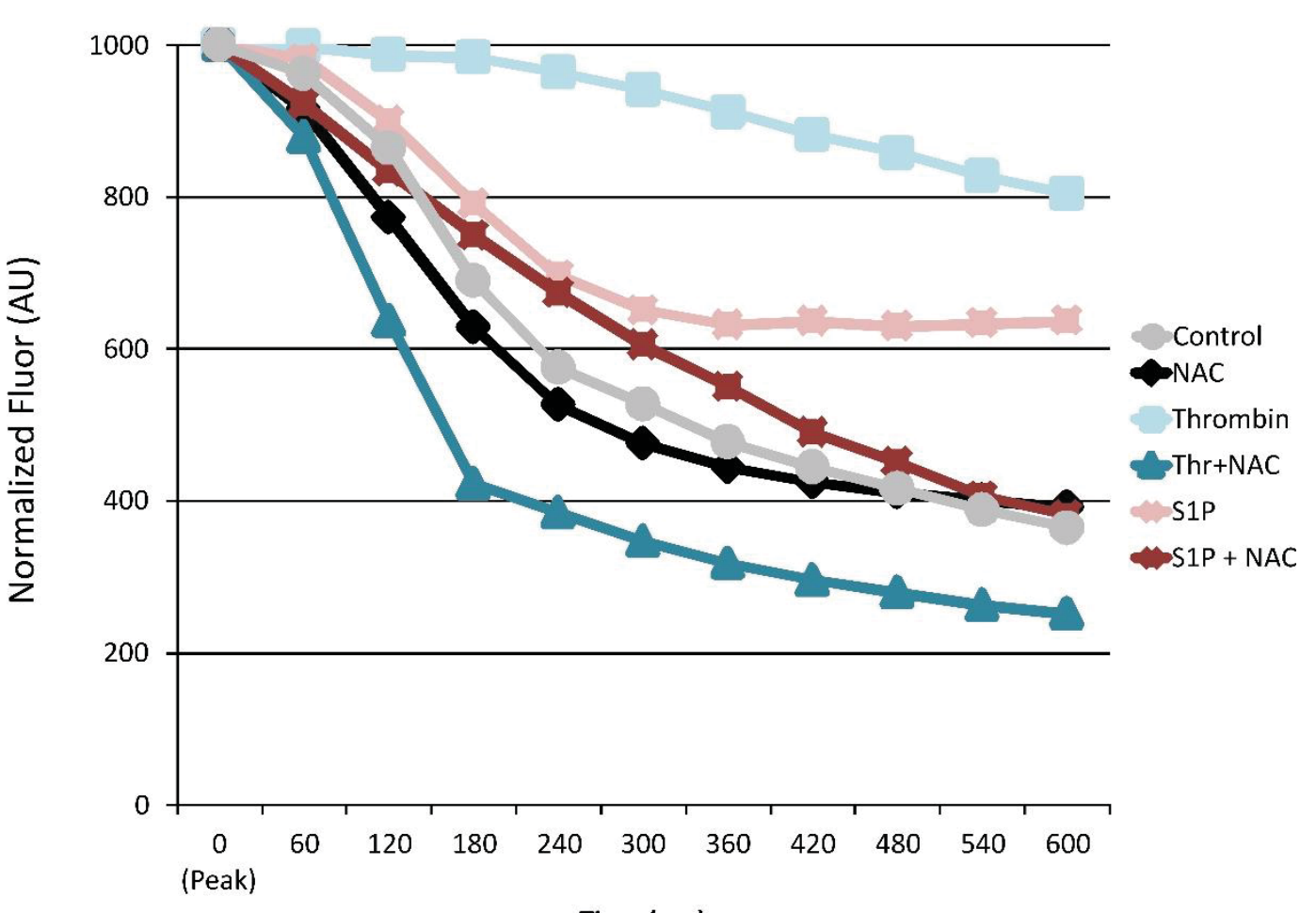

Time (sec) 
thrombin induces an increase in S1P2 expression. In contrast, while at baseline S1P2 expression was significantly higher in EC-Cx $43^{-/-}$lungs than in $\mathrm{Cx} 43^{\mathrm{fl} / \mathrm{l} l}$ mouse lungs, thrombin treatment induces a general decrease in S1P2 expression in pulmonary microvessels of EC-Cx $43^{-/-}$mouse lungs. S1P2 signaling contributes significantly to thrombin-induced increased microvascular permeability, and blocking S1P2 signaling greatly attenuates that permeability increase. In addition, this is the first study to examine whether thrombin-induced increases in ROS may be spatially expansive and shows increases in both locally-treated and neighboring, untreated microvessels of $\mathrm{Cx} 43 \mathrm{fl} / \mathrm{fl}$ mouse lungs. In EC-Cx $43^{-/-}$mouse lungs, however, there was no significant increase in ROS production with thrombin treatment compared to PBS treatment. Interestingly, this study is the first to show that, while S1P may not affect the vascular barrier to the extent of thrombin, S1P alone induces increases in microvascular permeability, and this affect was mediated by the activation of S1P2 and subsequent increases in ROS generation.

The data suggests that, as has been observed in various inflammatory states and with the treatment of inflammatory mediators, thrombin treatment induces an increase in the expression of S1P2 in endothelial cells. In addition, thrombin induced this effect in both thrombin-treated and -free microvessels within the $\mathrm{Cx} 43^{\mathrm{fl} / \mathrm{fl}}$ mouse lungs. This suggests the involvement of intercellular diffusion of second messengers, as this increase was not seen in endothelial cells or microvessels of mouse lungs lacking the major gap junction protein $\mathrm{Cx} 43$. This second messenger and the specific thrombin-induced signaling mechanism leading to this change in S1P2 expression is unclear and requires further elucidation. Activation of the thrombin receptor PAR-1 has been shown to activate SphK1, which subsequently leads to an increase in S1P production [63, 157]. In turn, the $\mathrm{S} 1 \mathrm{P}$ is exported from the cell by various $\mathrm{ABC}$ transporters, most notably spinster homolog 2 (Spns2) in endothelial cells [65, 67, 71]. Following export, S1P itself has been shown to be a second messenger and acts in a paracrine, or even autocrine, manner to activate S1P receptors on neighboring cells $[62,70,158-160]$. In one study, treatment with S1P was shown to cause an increase in S1P2 mRNA in a thyroid cell line [161]. In another study, preadipocytes cultured with S1P showed a greater expression of S1P2 receptor than when not cultured with $\mathrm{S} 1 \mathrm{P}$ [162]. It is possible that this may point to the mechanism by which thrombin acts on S1P2 expression. PAR-1 activation leads to increased S1P, and the S1P is exported from the cell and acts upon nearby cells to lead to an increase in the S1P2 receptor. Interestingly, thrombin induced a greater increase in S1P2 in thrombin-free microvessels far removed from the thrombin instillation region in the $\mathrm{Cx} 43^{\mathrm{fl} / \mathrm{fl}}$ mouse lungs. As we begin fixing the lung surface immediately following thrombin treatment, it could be that thrombin was already able to induce increases in both $\mathrm{S} 1 \mathrm{P} 2$ expression and S1P production. However, in the thrombin-treated area, the newlygenerated S1P has already had the opportunity to bind to the newly-expressed S1P2 receptors and lead to their internalization. This and other possible mechanisms by which thrombin and/or PAR-1 activation may affect S1P2 membrane expression necessitate further examination.

Intriguingly, basal S1P2 expression was significantly higher in endothelial cells and microvessels of EC-Cx $43^{-/-}$mouse lungs compared to $\mathrm{Cx} 43^{\mathrm{t} / \mathrm{fl}}$, and thrombin treatment curiously led to a decrease in S1P2. S1P signaling is a relatively new field of 
research, and $\mathrm{S} 1 \mathrm{P}$ has only really been seen as an important mediator within the past 15 years. There have been a few studies showing a relationship between S1P and Cx43 expression and communication, but these focus on S1P signaling and not an association or relationship with a specific receptor. One group found that, in cardiomyocytes, S1P treatment led to a decrease in gap junction intercellular communication by inducing phosphorylation of Cx43 specifically at serine 368, and this effect was blocked by inhibiting S1P2 signaling $[163,164]$. On the other hand, in astrocytes S1P treatment has also been shown to inhibit gap junction communication by dephosphorylation of $\mathrm{Cx} 43$ $[165,166]$. In addition, in differentiating myoblasts, S1P treatment induced increases in both Cx43 mRNA and protein levels and also increased gap junction communication [167]. This response was dependent upon S1P activation of $\mathrm{Ca}^{2+}$ - and p38-MAPKdependent pathways. However, while these studies detail the effect of S1P on Cx43, there has been no studies exploring how $\mathrm{Cx} 43$ may effect S1P signaling or if there exists an association between $\mathrm{Cx} 43$ and $\mathrm{S} 1 \mathrm{P}$ receptors. In addition, there has been no investigations as to the regulation of $\mathrm{Cx} 43$ function by S1P in endothelial cells. Our results do suggest that gap junction communication itself is not involved in the intensified expression in the knockout line as our studies in isolated mouse PMVECs used nonconfluent cells. The observed difference in S1P2 expression, both at baseline and following thrombin treatment, in the $\mathrm{EC}-\mathrm{Cx} 43^{-/-}$mouse line adds another link in the connection between S1P signaling and $\mathrm{Cx} 43$-containing gap junctions, and this connection requires further study.

This study is the first to detail the contributions of S1P2 signaling to microvascular permeability increases induced by thrombin. It has been determined that S1P signaling is generally barrier protective, but this has primarily been attributed to signaling through the S1P1 receptor $[168,169]$. Using our $\mathrm{Cx} 43^{\mathrm{fl} / \mathrm{fl}}$ mouse line, we show that under normal conditions S1P signaling did not enhance the microvascular barrier but infact lead to a statistically significant decrease in barrier integrity, and this hyperpermeability was prevented with the use of the S1P2 antagonist JTE-013. In thrombin-induced microvascular hyperpermeability, blocking S1P2 signaling also effectively blocked the increase in permeability. The effect of using JTE-013 during thrombin treatment was quite striking and seems to suggests that, in pulmonary microvessels, S1P2 signaling is a major factor in the induction of increased microvascular permeability by thrombin. Following this, we wanted to explore the role of $\mathrm{S} 1 \mathrm{P}$ in protecting the microvascular barrier in inflammation. We treated microvessels with thrombin and S1P, both simultaneously as well as consecutively. We observed that while S1P given during thrombin challenge provided no benefit, there was a significant difference in the thrombin-induced response when S1P was given following treatment with the inflammatory mediator. These results support the conclusion that pharmacological targeting of S1P2 may be effective in combating inflammatory mediator-induced increases in pulmonary microvascular permeability, and suggest delayed therapy may be more effective to particularly amerliorate hypermeability mediated by thrombin [153, 170-172].

In addition, we explored the ability of thrombin-induced signaling to increase ROS generation in pulmonary microvessels. Using local micropuncture instillations of 
thrombin, we observed subsequent significant increases in ROS in both thrombin-treated and -free microvessels in $\mathrm{Cx} 43^{\mathrm{fl} / \mathrm{fl}}$ mouse lungs. Conversely, we found little to no increase in ROS in the EC-Cx $43^{-/-}$lungs. This would suggest that, indeed, increases in ROS in the microvessels outside of the instillation area in the $\mathrm{Cx} 43^{\mathrm{fl} / \mathrm{fl}}$ lungs requires intercellular communication. Interestingly, in both thrombin-induced increases in ROS generation as well as S1P2 expression, the response in EC-Cx $43^{-/-}$lungs was lower compared to $\mathrm{Cx} 43^{\mathrm{fl} / \mathrm{fl}}$ lungs, even within the thrombin-treated microvessels. We observed a similar relationship in a previous study in which thrombin-induced increases in F-actin polymerization were less pronounced in the thrombin-treated vessels of the EC-Cx $43^{-/-}$ mouse lungs compared to microvessels from $\mathrm{Cx} 43^{\mathrm{fl} / \mathrm{fl}}$ mice [155]. This would suggest the involvement of intercellular communication of second messengers to see the full response to thrombin, even in the treated areas, due to the presense of pacemaker cells and the heterogenous distribution of membrane receptors. These results highlight the importance of using physiological relevant models, such as IPL, to study responses in intact tissues and organs.

We further investigated whether S1P2 may play a role in thrombin induction of ROS generation, and found that the thrombin-induced increase that is observed in these microvessels is dependent on S1P2 signaling. When these microvessels were pre-treated with the S1P2 receptor blocker JTE-013 prior to thrombin, virtually no increase in ROS was observed. Additionally, we found that, in pulmonary microvascular endothelial cells, $\mathrm{S} 1 \mathrm{P}$ itself induces an increase in ROS generation that was dependent on activation of S1P2. Through subsequent permeability experiments utilizing the ROS blocker NAC, we determined that the increase in permeability induced by S1P was due to the increase in ROS mediated by S1P2.

Increases in ROS due to inflammatory mediators, including thrombin, have been shown to contribute to hyperpermeability through the disruption of AJs [173]. While a link between S1P-induced changes in ROS generation has been studied, the direct effect of $\mathrm{S} 1 \mathrm{P}$ receptor signaling on ROS generation is unclear, as $\mathrm{S} 1 \mathrm{P}$ has been shown to induce increases and decreases in ROS depending on the cell type [64]. In one study, treatment of HLMVECs with S1P was shown to induce increases in ROS generation [174], however the contributions of specific receptors was not investigated. In another study in HUVECs, it was observed that treatment with high glucose concentrations increased both S1P2 expression and ROS generation, and that blocking the increase in S1P2 was able to subsequently block the increase in ROS production [175]. Our results here show that, not only does signaling through S1P2 lead to increased ROS generation in lung microvascular endothelial cells, but also that this increase is mediating the increase in permeability induced by both S1P and thrombin.

In summary, while at baselinse microvascular endothelium lacking gap junction protein $\mathrm{Cx} 43$ has a higher expression of S1P2 compared to normal, thrombin induces increases in treated and faraway, untreated microvessels of $\mathrm{Cx} 43^{\mathrm{fl} / \mathrm{fl}}$ mouse lungs that are absent in the EC-Cx43 $43^{-/}$microvessels. S1P2 signaling negatively regulates microvascular barrier integrity both at baseline and in thrombin-induced hyperpermeability. Blocking $\mathrm{S} 1 \mathrm{P} 2$ was able to block the thrombin-induced increase in permeability, and S1P given 
post-thrombin treatment helped to rescue barrier integrity. S1P2 signaling was found to mediate increases in ROS generation induced by both thrombin and S1P treatment, and it it through this ROS increase that S1P is able to induce increases in microvascular permeability. Similar to S1P2 expression, local thrombin treatment induced increases in ROS generation in both treated and non-treated microvessels of $\mathrm{Cx} 43^{\mathrm{f} / \mathrm{fl}}$ mouse lungs. With both thrombin-induced increases in S1P2 expression and ROS production, the response was considerably smaller in treated $\mathrm{EC}-\mathrm{Cx} 43^{-/-}$microvessels compared to those in $\mathrm{Cx} 43^{\mathrm{fl} / \mathrm{fl}}$, suggesting the involvement of pacemaker endothelial cells and intercellular communication. These results demonstrate the involvement of S1P2 signaling in hyperpermeability stimulated by inflammatory mediators, the role of intercellular communication in thrombin-induced endothelial responses, and bring into focus the need for physiologically relevant models to study inflammation. 


\section{CHAPTER 5. CONCLUSION}

\section{Summary}

In the studies detailed in this dissertation, we employed the physiologicallyrelevant model of isolated perfused lungs to study signaling initiated by inflammatory mediators. We focused on the signaling mechanisms related to the induction of increased permeability, which in the lungs presents itself as a particularly harmful response that may often lead to death.

In studies involving thrombin, we examined responses that have been extensively studied in endothelial monolayers but not in actual microvessels. We studied thrombininduced responses of F-actin polymerization, ROS generation, and microvascular hyperpermeability. We used micropuncture instillations to observe how thrombin may trigger these effects not just in microvessels directly treated with thrombin but also in faraway and untreated microvessels. In the case of F-actin polymerization, we found that local thrombin application may trigger significant increases in treated microvessels as well as microvessels up to $0.7 \mathrm{~mm}$ away when compared to PBS instillations. Similarly, thrombin micropuncture instillation was able to induce significant increases in ROS in microvessels inside the treated area as well in microvessels roughly $0.6 \mathrm{~mm}$ outside the instillation area, and increases in microvascular permeability itself where seen within and outside of local thrombin treatment. These results showed that, in pulmonary microvessels thrombin activation of PAR-1 led to spatially extensive responses such that both microvessels directly treated with the inflammatory mediator and those far away showed evidence of signaling that may lead to increased microvascular permeability.

We determined the role of $\mathrm{Cx} 43$-containing gap junctions in terms of the spatial expansion of these thrombin responses. In endothelial-specific Cx43 knockout mice, thrombin micropuncture instillation was unable to initiate the same degree of increase as was seen in the floxed-control mice in F-actin polymerization or ROS generation in either the microvessels outside the thrombin treatment site or even within microvessels directly treated with the inflammatory mediator. In the case of microvascular permeability, the use of the gap junction inhibitor Gap27 had no significant effect on the endothelial integrity in microvessels in the treated site or the immediate, neighboring microvessels. However, microvessels approximately $150 \mu \mathrm{m}$ outside of the instillation area began exhibiting significantly less permeability compared to thrombin alone treatment, and microvessels approximately $300 \mu \mathrm{m}$ outside approached PBS control values. As it is clear that the spread of these thrombin-induced responses was dependent on intercellular communication through $\mathrm{Cx} 43$ containing gap junctions, we endeavored to determine the specific second messenger communicated and dictating these responses in the outside microvessels. Intracellular $\mathrm{Ca}^{2+}$ concentration mediates these responses in endothelial cells. As PAR-1 activation induces the generation of $\mathrm{IP}_{3}$, which then initiates a subsequent increase in intracellular $\mathrm{Ca}^{2+}$, and both of these molecules may be diffused intercellularly through gap junctions, we used the ER $\mathrm{IP}_{3} \mathrm{R}$ inhibitor $\mathrm{XeC}$ to curtail this signaling. Pretreatment of all microvessels with $\mathrm{XeC}$ via catheter infusion blocked the 
thrombin-induced increase in F-actin polymerization, demonstrating the requirement for $\mathrm{IP}_{3}$-induced $\mathrm{Ca}^{2+}$ release in this response. We then gave overlapping micropuncture instillations of thrombin and $\mathrm{XeC}$. In this way, if $\mathrm{Ca}^{2+}$ alone was mediating the response in the outside microvessels, even in those treated with $\mathrm{XeC}, \mathrm{Ca}^{2+}$ would be free to intercellularly diffuse into this area and induce the F-actin increase. However, we observed that focal $\mathrm{XeC}$ application blocked the thrombin-induced increase in F-actin polymerization. In addition, to confirm that $\mathrm{IP}_{3}$ may be intercellularly diffused and initiate responses in endothelial cells of intact microvessels, we used a caged-IP 3 molecule $\left(\mathrm{NPE}-\mathrm{IP}_{3}\right)$ in UV photolysis experiments in which we also co-loaded vessels with the fluorescence calcium indicator Fluo4 AM. We observed increases in $\mathrm{Ca}^{2}+$ in microvessels within and outside of the UV uncaging site. These results demonstrate that $\mathrm{IP}_{3}$ is the specific second messenger mediating the spatial expansion of F-actin polymerization in pulmonary microvessels.

We also wanted to explore the relationship between thrombin- and S1P2-mediated signaling, as well as the role of $\mathrm{Cx} 43$-containing gap junctions in this relationship. We confirmed expression of the sphingolipid receptor S1P2 in cells and microvessels of both floxed Cx43 mouse lungs as well as lungs from endothelial-specific Cx43 knockout mice. Interestingly, we observed a significantly higher level of S1P2 expression in microvessels from the EC-Cx $43^{-/-}$compared to $\mathrm{Cx} 43^{\mathrm{fl} / \mathrm{fl}}$. However, though we observed a dramatic increase in S1P2 following thrombin treatment in $\mathrm{Cx} 43^{\mathrm{fl} / \mathrm{fl}}$ pulmonary endothelial cells and microvessels, we were unable to detect similar increases in the absence of $\mathrm{Cx} 43$ expression. We then studied S1P2 signaling in relation to endothelial barrier integrity. We observed that in the absence of pro-inflammatory signaling in pulmonary microvessels, there was a major increase in microvascular permeability with S1P treatment, and this was blocked with treatment of the S1P2 antagonist JTE-013. When the microvessels were treated with thrombin via a microcatheter infusion, JTE-013 also blocked the thrombin-induced hyperpermeability, and microvascular integrity remained at control values. To determine whether S1P signaling in general may alleviate thrombininduced increases in permeability, we treated microvessels with both mediators, both together and sequentially. We saw no difference when S1P was given with thrombin. However, we observed a significantly lower increase in permeability when S1P was given following thrombin infusion. We next explored possible mechanisms by which signaling via S1P2 may mediate the permeability increase. We found that increases in ROS generation due to both thrombin and S1P were blocked when the microvessels were pretreated with JTE-013. Further, we found that inhibiting ROS production attenuated the increase in permeability induced by S1P. These results showed that thrombin, like other inflammatory mediators, initiates pro-inflammatory signaling leading to increased expression of S1P2 at the membrane of endothelial cells. In addition, they shed light on a previously unknown relationship between S1P and thrombin in the induction of hyperpermeability in pulmonary microvessels. 


\section{Future Directions}

In endothelial cells, thrombin activation of PAR-1 induces change in intracellular $\mathrm{Ca}^{2+}$ in two phases: first through the release of $\mathrm{ER} \mathrm{Ca}^{2+}$ stores, then a subsequent induction of external calcium entry. These changes in cytosolic $\mathrm{Ca}^{2+}$ precede the responses studied here, including ROS generation [9, 51]. While we show here that, like F-actin polymerization and microvascular permeability, the thrombin-induced increase in ROS is a spatially extensive response spreading far outside the treatment region, what is unknown is the second messenger being communicated for this specific response. It is probable that, like what was observed in F-actin polymerization, $\mathrm{IP}_{3}$ is the mediating signaling molecule in this case as well. In addition to the increased ROS generation being mediated by changes in cytosolic $\mathrm{Ca}^{2+}$ and therefore $\mathrm{IP}_{3}, \mathrm{IP}_{3}$ is logically the more efficient signaling molecule. The movement of $\mathrm{IP}_{3}$ into a cell and activation of its receptor leads to a much greater change in cytosolic $\mathrm{Ca}^{2+}$ than intercellular movement of $\mathrm{Ca}^{2+}$ molecules alone. Thus, a similar experiment as to what was done for F-actin polymerization, using micropuncture instillations of an $\mathrm{IP}_{3} \mathrm{R}$ blocker, would be beneficial in making this determination.

The insights gained from these experiments highlight the utility of ex vivo and in situ models in studying inflammation in the lung. Our results showing that thrombin induces increases in $\mathrm{Ca}^{2+}$ oscillation amplitude rather than mean $\mathrm{Ca}^{2+}$ in particular show the differences between studying these signaling mechanisms in intact tissues versus cultured cells. The responses induced by thrombin here were rapid, usually occurring within 10 minutes of thrombin treatment. Key to the repair of the endothelial barrier is the reannealing of the interendothelial junctions [176]. In addition to activation of RhoA, thrombin-induced inactivation of Rac1 can lead to the disruption of AJs and contribute to increased permeability. In endothelial monolayers, it has been seen that interendothelial junctions reseal 1-2 hours after beginning sustained thrombin challenge [126]. It is unknown, however, how sustained thrombin treatment may effect permeability of lung microvessels. Therefore, future studies investigating the effects of a longer, sustained thrombin treatment in pulmonary microvessels may further reveal valuable information towards the repair of this microvascular bed following increased permeability.

In pulmonary microvessels, we observed an interesting trend in that thrombininduced responses were attenuated in the absence of $\mathrm{Cx} 43$, even in the directly treated vessels. Numerous studies have already shown the effects of intercellular communication in inflammation, including the contributions made by $\mathrm{Cx} 43$-containing gap junctions to the severity of hyperpermeability and edema formation in lung inflammation $[72,73,79$, $81,90]$. However, those studies tend to look at whole monolayer or whole tissue permeability, in which all affected cells have been treated with the permeability-inducing agent and/or have a reduction in $\mathrm{Cx} 43$ expression or function, and are therefore unable to explore spatial expansion of signaling outside of a focal treated area. These are the first results to show that, not only does inhibiting or knocking out $\mathrm{Cx} 43$ seem to block the spatial expansion of a detrimental response into untreated or healthy tissues, but also that blocking intercellular communication affects the gravity of the response even within the treated pulmonary microvessels. This clearly points to the therapeutic utility of limiting 
gap junctional communication in inflammation. Indeed, though not approved specifically for lung inflammation, one such drug, carbenoxolone (CBX), is currently used to treat gastrointestinal inflammation. In studies looking at the effects of this drug in the lung, CBX was found to block increases in cytokine expression and infiltration of inflammatory cells in a murine asthma model [177]. In a CLP model of sepsis and lung inflammation, CBX blocked secretions of high-mobility group box protein 1 (HMGB1), a late pro-inflammatory mediator and a negative indicator of survival in sepsis $[178,179]$. Thus, studies that more closely examine the use of gap junction blockers in clinical models of lung inflammation will likely show them to be beneficial towards survival.

In conclusion, our data detail: the spatially-extensive induction of responses by thrombin that contribute to increased microvascular permeability in lung inflammation; demonstrate the specific signaling molecule being intercellularly communicated through $\mathrm{Cx} 43$-containing gap junctions for the thrombin-induced increase in F-actin polymerization; show that S1P2 expression is affected by thrombin treatment and that this is dependent on the presence of $\mathrm{Cx} 43$ in the cell; and that S1P2-mediated signaling contributes substantially to the induction of increased microvascular permeability by thrombin. These experiments utilized a physiologically-relevant model to study responses that were both dependent on receptor activation by inflammatory mediators as well as contributed to the detrimental hyperpermeability response seen in lung inflammation. The results highlight previous work towards the importance of intercellular communication in the spread of inflammatory responses while also providing a hereto unseen visualization and quantification on the extent of the spread into unchallenged tissues. They also point out a novel relationship between $\mathrm{Cx} 43$, thrombin, and S1P2 expression, and also the contributions of S1P2 signaling in thrombin-induced pulmonary microvascular disruption. 


\section{LIST OF REFERENCES}

1. Price, L.C., et al., Pathophysiology of pulmonary hypertension in acute lung injury. American Journal of Physiology - Lung Cellular and Molecular Physiology, 2012. 302(9): p. L803-L815.

2. Evans, C.E. and Y.-Y. Zhao, Impact of thrombosis on pulmonary endothelial injury and repair following sepsis. American Journal of Physiology - Lung Cellular and Molecular Physiology, 2017. 312(4): p. L441-L451.

3. Koh, Y., How to approach the acute respiratory distress syndrome: Prevention, plan, and prudence. Respiratory Investigation, 2017. 55(3): p. 190-195.

4. Opal, S.M. and T. van der Poll, Endothelial barrier dysfunction in septic shock. Journal of Internal Medicine, 2015. 277(3): p. 277-293.

5. Reiss, L.K. and S. Uhlig, Toward the Molecular Signature of Acute Respiratory Distress Syndrome. American Journal of Respiratory and Critical Care Medicine, 2016. 194(8): p. 922-924.

6. Gill, S.E., C.M. Yamashita, and R.A.W. Veldhuizen, Lung remodeling associated with recovery from acute lung injury. Cell and Tissue Research, 2017. 367(3): p. 495-509.

7. Confalonieri, M., F. Salton, and F. Fabiano, Acute respiratory distress syndrome. European Respiratory Review, 2017. 26(144).

8. Parissopoulos, S., M.D.A. Mpouzika, and F. Timmins, Optimal support techniques when providing mechanical ventilation to patients with acute respiratory distress syndrome. Nursing in Critical Care, 2017. 22(1): p. 40-51.

9. Vandenbroucke, E., et al., Regulation of Endothelial Junctional Permeability. Annals of the New York Academy of Sciences, 2008. 1123(1): p. 134-145.

10. Schnoor, M., et al., Actin dynamics in the regulation of endothelial barrier functions and neutrophil recruitment during endotoxemia and sepsis. Cellular and Molecular Life Sciences, 2017. 74(11): p. 1985-1997.

11. Millar, F.R., et al., The pulmonary endothelium in acute respiratory distress syndrome: insights and therapeutic opportunities. Thorax, 2016. 71(5): p. 462473.

12. Hickey, M.J. and C.L.V. Westhorpe, Imaging inflammatory leukocyte recruitment in kidney, lung and liver[mdash] challenges to the multi-step paradigm. Immunol Cell Biol, 2013. 91(4): p. 281-289.

13. Mai, J., et al., An evolving new paradigm: endothelial cells - conditional innate immune cells. Journal of Hematology \& Oncology, 2013. 6(1): p. 61.

14. Murakami, K. and D.L. Traber, Pathophysiological Basis of Smoke Inhalation Injury. Physiology, 2003. 18(3): p. 125.

15. Barletta, K.E., et al., Leukocyte compartments in the mouse lung: Distinguishing between marginated, interstitial, and alveolar cells in response to injury. Journal of Immunological Methods, 2012. 375(1-2): p. 100-110.

16. Barnes, P.J., Inflammatory mechanisms in patients with chronic obstructive pulmonary disease. J Allergy Clin Immunol, 2016. 138(1): p. 16-27.

17. Mokra, D. and P. Kosutova, Biomarkers in acute lung injury. Respiratory Physiology \& Neurobiology, 2015. 209: p. 52-58. 
18. Aman, J., et al., Using cultured endothelial cells to study endothelial barrier dysfunction: Challenges and opportunities. American Journal of Physiology Lung Cellular and Molecular Physiology, 2016. 311(2): p. L453-L466.

19. Herwig, M.C., et al., Vascular Endothelial Cadherin Expression in Lung Specimens of Patients with Sepsis-Induced Acute Respiratory Distress Syndrome and Endothelial Cell Cultures. Pathobiology, 2013. 80(5): p. 245-251.

20. Liu, M.-W., et al., Effect of Melilotus suaveolens extract on pulmonary microvascular permeability by downregulating vascular endothelial growth factor expression in rats with sepsis. Molecular Medicine Reports, 2015. 11(5): p. 3308-3316.

21. Chelazzi, C., et al., Glycocalyx and sepsis-induced alterations in vascular permeability. Critical Care, 2015. 19(1): p. 26.

22. Monahan, L.J., Acute Respiratory Distress Syndrome. Current Problems in Pediatric and Adolescent Health Care, 2013. 43(10): p. 278-284.

23. Gill, S.E., et al., Pulmonary Microvascular Albumin Leak Is Associated with Endothelial Cell Death in Murine Sepsis-Induced Lung Injury In Vivo. PLoS ONE, 2014. 9(2): p. e88501.

24. Mondrinos, M.J., et al., Pulmonary Endothelial Protein Kinase C-Delta (PKC $)$ Regulates Neutrophil Migration in Acute Lung Inflammation. The American Journal of Pathology, 2014. 184(1): p. 200-213.

25. Iwasaki, A. and R. Medzhitov, Control of adaptive immunity by the innate immune system. Nat Immunol, 2015. 16(4): p. 343-353.

26. Müller-Redetzky, H.C., N. Suttorp, and M. Witzenrath, Dynamics of pulmonary endothelial barrier function in acute inflammation: mechanisms and therapeutic perspectives. Cell and Tissue Research, 2014. 355(3): p. 657-673.

27. Salvador, B., et al., Modulation of endothelial function by Toll like receptors. Pharmacological Research, 2016. 108: p. 46-56.

28. Nickols, J., et al., Lipopolysaccharide-induced pulmonary endothelial barrier disruption and lung edema: critical role for bicarbonate stimulation of AC10. American Journal of Physiology - Lung Cellular and Molecular Physiology, 2015. 309(12): p. L1430-L1437.

29. Müller-Redetzky, H.C., et al., Mechanical ventilation drives pneumococcal pneumonia into lung injury and sepsis in mice: protection by adrenomedullin. Critical Care, 2014. 18(2): p. R73-R73.

30. Kuebler, W.M., Inflammatory pathways and microvascular responses in the lung. Pharmacol Rep, 2005. 57 Suppl: p. 196-205.

31. Looney, M.R. and J. Bhattacharya, Live Imaging of the Lung. Annual Review of Physiology, 2014. 76(1): p. 431-445.

32. Garcia Ponce, A., et al., Loss of cortactin causes endothelial barrier dysfunction via disturbed adrenomedullin secretion and actomyosin contractility. Sci Rep, 2016. 6: p. 29003.

33. Tasaka, S., et al., Attenuation of endotoxin-induced acute lung injury by the Rhoassociated kinase inhibitor, Y-27632. Am J Respir Cell Mol Biol, 2005. 32(6): p. 504-10.

34. de Prost, N., et al., Effects of ventilation strategy on distribution of lung inflammatory cell activity. Critical Care, 2013. 17(4): p. R175-R175. 
35. Ochiai, R., Mechanical ventilation of acute respiratory distress syndrome. Journal of Intensive Care, 2015. 3(1): p. 25.

36. Wang, T., et al., Endothelial cell signaling and ventilator-induced lung injury: molecular mechanisms, genomic analyses, and therapeutic targets. American Journal of Physiology - Lung Cellular and Molecular Physiology, 2017. 312(4): p. L452-L476.

37. Komarova, Y.A., et al., Protein Interactions at Endothelial Junctions and Signaling Mechanisms Regulating Endothelial Permeability. Circulation Research, 2017. 120(1): p. 179-206.

38. Tian, X., et al., Asef controls vascular endothelial permeability and barrier recovery in the lung. Molecular Biology of the Cell, 2015. 26(4): p. 636-650.

39. Ganter, M.T., et al., Role of Small GTPases and $\alpha v \beta 5$ Integrin in Pseudomonas aeruginosa-Induced Increase in Lung Endothelial Permeability. American Journal of Respiratory Cell and Molecular Biology, 2009. 40(1): p. 108-118.

40. Grommes, J. and O. Soehnlein, Contribution of Neutrophils to Acute Lung Injury. Molecular Medicine, 2011. 17(3-4): p. 293-307.

41. Tauseef, M., et al., TLR4 activation of TRPC6-dependent calcium signaling mediates endotoxin-induced lung vascular permeability and inflammation. The Journal of Experimental Medicine, 2012. 209(11): p. 1953-1968.

42. Goldenberg, N.M. and W.M. Kuebler, Endothelial Cell Regulation of Pulmonary Vascular Tone, Inflammation, and Coagulation, in Comprehensive Physiology. 2015, John Wiley \& Sons, Inc.

43. Souza, M.C., T.A. Padua, and M.G. Henriques, Endothelial-Leukocyte Interaction in Severe Malaria: Beyond the Brain. Mediators of Inflammation, 2015. 2015: p. 168937.

44. Ploppa, A., et al., Mechanisms of leukocyte distribution during sepsis: an experimental study on the interdependence of cell activation, shear stress and endothelial injury. Critical Care, 2010. 14(6): p. R201.

45. Schmidt, E.P., et al., The pulmonary endothelial glycocalyx regulates neutrophil adhesion and lung injury during experimental sepsis. Nature medicine, 2012. 18(8): p. 10.1038/nm.2843.

46. Gane, J. and R. Stockley, Mechanisms of neutrophil transmigration across the vascular endothelium in COPD. Thorax, 2012. 67(6): p. 553-561.

47. Saffarzadeh, M., et al., Neutrophil Extracellular Traps Directly Induce Epithelial and Endothelial Cell Death: A Predominant Role of Histones. PLoS ONE, 2012. 7(2): p. e32366.

48. Caudrillier, A., et al., Platelets induce neutrophil extracellular traps in transfusion-related acute lung injury. The Journal of Clinical Investigation, 2012. 122(7): p. 2661-2671.

49. Narasaraju, T., et al., Excessive Neutrophils and Neutrophil Extracellular Traps Contribute to Acute Lung Injury of Influenza Pneumonitis. The American Journal of Pathology, 2011. 179(1): p. 199-210.

50. Tiruppathi, C., et al., Role of Ca2+ signaling in the regulation of endothelial permeability. Vascul Pharmacol, 2002. 39(4-5): p. 173-85. 
51. Andrikopoulos, P., et al., Endothelial Angiogenesis and Barrier Function in Response to Thrombin Require $\mathrm{Ca}(2+)$ Influx through the $\mathrm{Na}(+) / \mathrm{Ca}(2+)$

Exchanger. The Journal of Biological Chemistry, 2015. 290(30): p. 18412-18428.

52. Gill, S.E., M. Rohan, and S. Mehta, Role of pulmonary microvascular endothelial cell apoptosis in murine sepsis-induced lung injury in vivo. Respiratory Research, 2015. 16(1): p. 109.

53. Mehta, D. and A.B. Malik, Signaling Mechanisms Regulating Endothelial Permeability. Physiological Reviews, 2006. 86(1): p. 279-367.

54. Finigan, J.H., The coagulation system and pulmonary endothelial function in acute lung injury. Microvascular Research, 2009. 77(1): p. 35-38.

55. Bogatcheva, N.V., et al., Molecular mechanisms mediating protective effect of cAMP on lipopolysaccharide (LPS)-induced human lung microvascular endothelial cells (HLMVEC) hyperpermeability. Journal of cellular physiology, 2009. 221(3): p. 750-759.

56. Kandasamy, K., et al., Changes in endothelial connexin 43 expression inversely correlate with microvessel permeability and VE-cadherin expression in endotoxin-challenged lungs. American Journal of Physiology - Lung Cellular and Molecular Physiology, 2015. 309(6): p. L584-L592.

57. Banerjee, A., et al., Hyperosmolarity attenuates TNF $\alpha$-mediated proinflammatory activation of human pulmonary microvascular endothelial cells. Shock (Augusta, Ga.), 2013. 39(4): p. 366-372.

58. Abraham, E., et al., Efficacy and safety of monoclonal antibody to human tumor necrosis factor alpha in patients with sepsis syndrome. A randomized, controlled, double-blind, multicenter clinical trial. TNF-alpha MAb Sepsis Study Group. Jama, 1995. 273(12): p. 934-41.

59. Raghavendran, K., et al., Pharmacotherapy of Acute Lung Injury and Acute Respiratory Distress Syndrome. Current medicinal chemistry, 2008. 15(19): p. 1911-1924.

60. Oishi, H., et al., Olprinone and colforsin daropate alleviate septic lung inflammation and apoptosis through CREB-independent activation of the Akt pathway. American Journal of Physiology - Lung Cellular and Molecular Physiology, 2012. 303(2): p. L130-L140.

61. Wilkerson, B.A. and K.M. Argraves, The role of sphingosine-1-phosphate in endothelial barrier function. Biochimica et Biophysica Acta (BBA) - Molecular and Cell Biology of Lipids, 2014. 1841(10): p. 1403-1412.

62. Mahajan-Thakur, S., et al., Sphingosine-1-Phosphate and Its Receptors: A Mutual Link between Blood Coagulation and Inflammation. Mediators of Inflammation, 2015. 2015: p. 831059.

63. Billich, A., et al., Sphingosine kinase 1 is essential for proteinase-activated receptor-1 signalling in epithelial and endothelial cells. The International Journal of Biochemistry \& Cell Biology, 2009. 41(7): p. 1547-1555.

64. Herr, D.R., et al., Sphingosine 1-phosphate receptor 2 (S1P2) attenuates reactive oxygen species formation and inhibits cell death: implications for otoprotective therapy. 2016. 6: p. 24541. 
65. Olivera, A., M.L. Allende, and R.L. Proia, Shaping the landscape: Metabolic regulation of S1P gradients. Biochimica et biophysica acta, 2013. 1831(1): p. 193-202.

66. Zhang, W., et al., Sphingosine-1-phosphate receptor-2 mediated NF $\kappa B$ activation contributes to tumor necrosis factor- $\alpha$ induced VCAM-1 and ICAM-1 expression in endothelial cells. Prostaglandins \& Other Lipid Mediators, 2013. 106: p. 62-71.

67. Rauch, B.H., Sphingosine 1-Phosphate as a Link between Blood Coagulation and Inflammation. Cellular Physiology and Biochemistry, 2014. 34(1): p. 185-196.

68. Igarashi, J., et al., Hydrogen peroxide induces S1P\&lt;sub\&gt; $1 \& l t ; / s u b \& g t$; receptors and sensitizes vascular endothelial cells to sphingosine 1-phosphate, a platelet-derived lipid mediator. American Journal of Physiology - Cell Physiology, 2007. 292(2): p. C740.

69. Sanchez, T., et al., Induction of Vascular Permeability by the Sphingosine-1Phosphate Receptor-2 (S1P2R) and its Downstream Effectors ROCK and PTEN. Arteriosclerosis, Thrombosis, and Vascular Biology, 2007. 27(6): p. 1312.

70. Du, J., et al., LPS and TNF- $\alpha$ induce expression of sphingosine-1-phosphate receptor-2 in human microvascular endothelial cells. Pathology - Research and Practice, 2012. 208(2): p. 82-88.

71. Yanagida, K. and T. Hla, Vascular and Immunobiology of the Circulatory Sphingosine 1-Phosphate Gradient. Annual Review of Physiology, 2017. 79(1): p. 67-91.

72. Sarieddine, M.Z.R., et al., Connexin43 modulates neutrophil recruitment to the lung. Journal of Cellular and Molecular Medicine, 2009. 13(11-12): p. 4560-4570.

73. Scheckenbach, K.E., et al., Connexin channel-dependent signaling pathways in inflammation. J Vasc Res, 2011. 48(2): p. 91-103.

74. Nielsen, M.S., et al., Gap junctions. Compr Physiol, 2012. 2(3): p. 1981-2035.

75. Abed, A., et al., Targeting connexin 43 protects against the progression of experimental chronic kidney disease in mice. Kidney Int, 2014. 86(4): p. 768-779.

76. Langer, J., et al., Gap junctions mediate intercellular spread of sodium between hippocampal astrocytes in situ. Glia, 2012. 60(2): p. 239-252.

77. Shintani-Ishida, K., K. Unuma, and K.-i. Yoshida, Ischemia Enhances Translocation of Connexin43 and Gap Junction Intercellular Communication, Thereby Propagating Contraction Band Necrosis After Reperfusion. Circulation Journal, 2009. 73(9): p. 1661-1668.

78. Decrock, E., et al., Transfer of IP3 through gap junctions is critical, but not sufficient, for the spread of apoptosis. Cell Death Differ, 2012. 19(6): p. 947-957.

79. O’Donnell, J.J., III, et al., Gap Junction Protein Connexin43 Exacerbates Lung Vascular Permeability. PLOS ONE, 2014. 9(6): p. e100931.

80. Takenaka, T., et al., Expression and role of connexins in the rat renal vasculature. Kidney Int, 2007. 73(4): p. 415-422.

81. Parthasarathi, K., Endothelial connexin43 mediates acid-induced increases in pulmonary microvascular permeability. Am J Physiol Lung Cell Mol Physiol, 2012. 303(1): p. L33-42.

82. Nikolian, V.C., et al., Lung Protective Effects of Low-Volume Resuscitation and Pharmacologic Treatment of Swine Subjected to Polytrauma and Hemorrhagic Shock. Inflammation, 2017. 40(4): p. 1264-1274. 
83. Schnyder-Candrian, S., et al., Neutrophil Inhibitory Factor Selectively Inhibits the Endothelium-Driven Transmigration of Eosinophils In Vitro and Airway Eosinophilia in OVA-Induced Allergic Lung Inflammation. Journal of Allergy, 2012. 2012: p. 245909.

84. Uhlig, S., et al., Differential regulation of lung endothelial permeability in vitro and in situ. Cell Physiol Biochem, 2014. 34(1): p. 1-19.

85. Fazal, F., et al., Critical Role of Non-Muscle Myosin Light Chain Kinase in Thrombin-Induced Endothelial Cell Inflammation and Lung PMN Infiltration. PLoS ONE, 2013. 8(3): p. e59965.

86. Nahar, K., et al., In vitro, in vivo and ex vivo models for studying particle deposition and drug absorption of inhaled pharmaceuticals. European Journal of Pharmaceutical Sciences, 2013. 49(5): p. 805-818.

87. Sanchez, P.G., et al., State of Art: Clinical ex vivo lung perfusion: Rationale, current status, and future directions. The Journal of Heart and Lung Transplantation, 2012. 31(4): p. 339-348.

88. Fry, T., J.H. Evans, and M.J. Sanderson, Propagation of intercellular calcium waves in C6 glioma cells transfected with connexins 43 or 32. Microsc Res Tech, 2001. 52(3): p. 289-300.

89. Paemeleire, K., Calcium signaling in and between brain astrocytes and endothelial cells. Acta Neurol Belg, 2002. 102(3): p. 137-40.

90. Parthasarathi, K., et al., Connexin 43 mediates spread of Ca2+-dependent proinflammatory responses in lung capillaries. J Clin Invest, 2006. 116(8): p. 2193-200.

91. Kanaporis, G., et al., Gap junction channels exhibit connexin-specific permeability to cyclic nucleotides. J Gen Physiol, 2008. 131(4): p. 293-305.

92. Godecke, S., et al., Thrombin-induced ATP release from human umbilical vein endothelial cells. Am J Physiol Cell Physiol, 2012. 302(6): p. C915-23.

93. Weir, E.K. and S.L. Archer, The mechanism of acute hypoxic pulmonary vasoconstriction: the tale of two channels. The FASEB Journal, 1995. 9(2): p. 183-9.

94. Wang, L., et al., Hypoxic pulmonary vasoconstriction requires connexin 40mediated endothelial signal conduction. J Clin Invest, 2012. 122(11): p. 4218-30.

95. Ichimura, H., et al., Lung surfactant secretion by interalveolar Ca2+ signaling. Am J Physiol Lung Cell Mol Physiol, 2006. 291(4): p. L596-601.

96. Lum, H., et al., Calcium dependence of the thrombin-induced increase in endothelial albumin permeability. J Appl Physiol (1985), 1989. 66(3): p. 1471-6.

97. Wang, Z., et al., Calcium/Calmodulin-dependent Protein Kinase II Delta 6 (CaMKIIS(6)) and RhoA Involvement in Thrombin-induced Endothelial Barrier Dysfunction. The Journal of Biological Chemistry, 2010. 285(28): p. 2130321312.

98. Gudermann, T. and D. Steinritz, STIMulating stress fibers in endothelial cells. Sci Signal, 2013. 6(267): p. pe8.

99. Arachiche, A., et al., Protease-activated Receptor 1 (PAR1) and PAR4 Heterodimers Are Required for PARI-enhanced Cleavage of PAR4 by $\alpha$ Thrombin. Journal of Biological Chemistry, 2013. 288(45): p. 32553-32562. 
100. Liao, Y., et al., Endothelial cell-specific knockout of connexin 43 causes hypotension and bradycardia in mice. Proceedings of the National Academy of Sciences of the United States of America, 2001. 98(17): p. 9989-9994.

101. Kandasamy, K., G. Sahu, and K. Parthasarathi, Real-time imaging reveals endothelium-mediated leukocyte retention in LPS-treated lung microvessels. Microvasc Res, 2012. 83(3): p. 323-31.

102. Kandasamy, K. and K. Parthasarathi, Quantifying single microvessel permeability in isolated blood-perfused rat lung preparation. J Vis Exp, 2014(88): p. e51552.

103. Kandasamy, K., et al., Lipopolysaccharide induces endoplasmic store Ca2+dependent inflammatory responses in lung microvessels. PLoS One, 2013. 8(5): p. e63465.

104. Thiede, B.R. and J.T. Corwin, Permeation of fluorophore-conjugated phalloidin into live hair cells of the inner ear is modulated by P2Y receptors. $\mathrm{J}$ Assoc Res Otolaryngol, 2014. 15(1): p. 13-30.

105. Gonzales, J.N., et al., Low anticoagulant heparin blocks thrombin-induced endothelial permeability in a PAR-dependent manner. Vascular Pharmacology, 2014. 62(2): p. 63-71.

106. Adyshev, D.M., et al., Ezrin/radixin/moesin proteins differentially regulate endothelial hyperpermeability after thrombin. American Journal of Physiology Lung Cellular and Molecular Physiology, 2013. 305(3): p. L240-L255.

107. Kasa, A., et al., Protein phosphatase $2 \mathrm{~A}$ activity is required for functional adherent junctions in endothelial cells. Microvasc Res, 2013. 89: p. 86-94.

108. Rajput, C., et al., Neural Wiskott-Aldrich syndrome protein (N-WASP)-mediated p120-catenin interaction with Arp2-Actin complex stabilizes endothelial adherens junctions. J Biol Chem, 2013. 288(6): p. 4241-50.

109. Szulcek, R., et al., Localized RhoA GTPase activity regulates dynamics of endothelial monolayer integrity. Cardiovascular Research, 2013. 99(3): p. 471482.

110. Goligorsky, M.S., et al., Nature of thrombin-induced sustained increase in cytosolic calcium concentration in cultured endothelial cells. J Biol Chem, 1989. 264(28): p. 16771-5.

111. Wong, M.K. and A.I. Gotlieb, Endothelial monolayer integrity. Perturbation of $F$-actin filaments and the dense peripheral band-vinculin network.

Arteriosclerosis, 1990. 10(1): p. 76-84.

112. Minshall, R.D., et al., Role of protein kinase Czeta in thrombin-induced RhoA activation and inter-endothelial gap formation of human dermal microvessel endothelial cell monolayers. Microvasc Res, 2010. 80(2): p. 240-9.

113. Murphy, J.T., et al., Thrombin-mediated permeability of human microvascular pulmonary endothelial cells is calcium dependent. J Trauma, 2001. 50(2): p. 21322.

114. Tiruppathi, C., et al., Ca2+ signaling, TRP channels, and endothelial permeability. Microcirculation, 2006. 13(8): p. 693-708.

115. Kameritsch, P., et al., Gap junctional communication controls the overall endothelial calcium response to vasoactive agonists. Cardiovascular Research, 2012. 93(3): p. 508-515. 
116. Gafni, J., et al., Xestospongins: Potent Membrane Permeable Blockers of the Inositol 1,4,5-Trisphosphate Receptor. Neuron, 1997. 19(3): p. 723-733.

117. Sauer, H., et al., Hypotonic Ca2+ signaling and volume regulation in proliferating and quiescent cells from multicellular spheroids. J Cell Physiol, 1998. 175(2): p. 129-40.

118. Singh, I., et al., Gaq-TRPC6-mediated Ca2+Entry Induces RhoA Activation and Resultant Endothelial Cell Shape Change in Response to Thrombin. Journal of Biological Chemistry, 2007. 282(11): p. 7833-7843.

119. Shinde, A.V., et al., STIM1 controls endothelial barrier function independently of Orail and Ca2+ entry. Sci Signal, 2013. 6(267): p. ra18.

120. Dudek, S.M. and J.G. Garcia, Cytoskeletal regulation of pulmonary vascular permeability. J Appl Physiol (1985), 2001. 91(4): p. 1487-500.

121. Vogel, S.M. and A.B. Malik, Cytoskeletal dynamics and lung fluid balance. Compr Physiol, 2012. 2(1): p. 449-78.

122. Prasain, N. and T. Stevens, The actin cytoskeleton in endothelial cell phenotypes. Microvasc Res, 2009. 77(1): p. 53-63.

123. Mehta, D. and A.B. Malik, Signaling Mechanisms Regulating Endothelial Permeability. Physiological Reviews, 2005. 86(1): p. 279-367.

124. Werthmann, R.C., M.J. Lohse, and M. Bunemann, Temporally resolved cAMP monitoring in endothelial cells uncovers a thrombin-induced [cAMP] elevation mediated via the Ca(2)+-dependent production of prostacyclin. J Physiol, 2011. 589(Pt 1): p. 181-93.

125. Lohman, A.W., M. Billaud, and B.E. Isakson, Mechanisms of ATP release and signalling in the blood vessel wall. Cardiovasc Res, 2012. 95(3): p. 269-80.

126. Aslam, M., et al., cAMP controls the restoration of endothelial barrier function after thrombin-induced hyperpermeability via Racl activation. Physiol Rep, 2014. 2(10).

127. Liu, F.-C., et al., The anti-aggregation effects of ondansetron on platelets involve IP3 signaling and MAP kinase pathway, but not 5-HT3-dependent pathway. Thrombosis Research, 2012. 130(3): p. e84-e94.

128. Evans, J., et al., Arachidonic acid induces brain endothelial cell apoptosis via p38-MAPK and intracellular calcium signaling. Microvascular Research, 2015. 98: p. 145-158.

129. Bickler, P.E. and C.S. Fahlman, The Inhaled Anesthetic, Isoflurane, Enhances Ca2+-Dependent Survival Signaling in Cortical Neurons and Modulates MAP Kinases, Apoptosis Proteins and Transcription Factors During Hypoxia. Anesthesia \& Analgesia, 2006. 103(2).

130. Kása, A., C. Csortos, and A.D. Verin, Cytoskeletal mechanisms regulating vascular endothelial barrier function in response to acute lung injury. Tissue Barriers, 2015. 3(1-2): p. e974448.

131. Hirano, S., et al., Endothelial barrier dysfunction caused by LPS correlates with phosphorylation of HSP27in vivo. Cell Biology and Toxicology, 2004. 20(1): p. $1-14$.

132. Wolfson, R.K., E.T. Chiang, and J.G.N. Garcia, HMGB1 induces human lung endothelial cell cytoskeletal rearrangement and barrier disruption. Microvascular Research, 2011.81(2): p. 189-197. 
133. Guay, J., et al., Regulation of actin filament dynamics by p38 map kinasemediated phosphorylation of heat shock protein 27. Journal of Cell Science, 1997. 110(3): p. 357-368.

134. Huot, J., et al., Oxidative Stress-Induced Actin Reorganization Mediated by the p38 Mitogen-Activated Protein Kinase/Heat Shock Protein 27 Pathway in Vascular Endothelial Cells. Circulation Research, 1997. 80(3): p. 383-392.

135. Piotrowicz, R.S. and E.G. Levin, Basolateral Membrane-associated 27-kDa Heat Shock Protein and Microfilament Polymerization. Journal of Biological Chemistry, 1997. 272(41): p. 25920-25927.

136. Huot, J., et al., SAPK2/p38-dependent F-Actin Reorganization Regulates Early Membrane Blebbing during Stress-induced Apoptosis. The Journal of Cell Biology, 1998. 143(5): p. 1361-1373.

137. Sawada, J., F. Li, and M. Komatsu, R-Ras Inhibits VEGF-Induced p38MAPK Activation and HSP27 Phosphorylation in Endothelial Cells. Journal of Vascular Research, 2015. 52(5): p. 347-359.

138. Wu, T., J. Xing, and A.A. Birukova, Cell-type-specific crosstalk between p38 $M A P K$ and Rho signaling in lung micro- and macrovascular barrier dysfunction induced by $<$ em $>$ Staphylococcus aureus $</$ em $>$-derived pathogens. Translational Research, 2013. 162(1): p. 45-55.

139. Parthasarathi, K., et al., Mitochondrial reactive oxygen species regulate spatial profile of proinflammatory responses in lung venular capillaries. J Immunol, 2002. 169(12): p. 7078-86.

140. Burns, A.R., C.W. Smith, and D.C. Walker, Unique structural features that influence neutrophil emigration into the lung. Physiol Rev, 2003. 83(2): p. 30936.

141. Ofori-Acquah, S.F., et al., Heterogeneity of barrier function in the lung reflects diversity in endothelial cell junctions. Microvasc Res, 2008. 75(3): p. 391-402.

142. Ying, X., et al., Ca2+ waves in lung capillary endothelium. Circ Res, 1996. 79(4): p. 898-908.

143. Kawanami, O., et al., Heterogeneous distribution of thrombomodulin and von Willebrand factor in endothelial cells in the human pulmonary microvessels. $\mathrm{J}$ Nippon Med Sch, 2000. 67(2): p. 118-25.

144. Chen, C.-H., et al., The connexin 43/ZO-1 complex regulates cerebral endothelial $F$-actin architecture and migration. American Journal of Physiology - Cell Physiology, 2015. 309(9): p. C600-C607.

145. Machtaler, S., et al., The role of the gap junction protein connexin 43 in $B$ lymphocyte motility and migration. FEBS Letters, 2014. 588(8): p. 1249-1258.

146. Matsuuchi, L. and C.C. Naus, Gap junction proteins on the move: Connexins, the cytoskeleton and migration. Biochimica et Biophysica Acta (BBA) Biomembranes, 2013. 1828(1): p. 94-108.

147. Ambrosi, C., et al., Connexin43 Forms Supramolecular Complexes through NonOverlapping Binding Sites for Drebrin, Tubulin, and ZO-1. PLOS ONE, 2016. 11(6): p. e0157073.

148. Olk, S., et al., Proteomic analysis of astroglial connexin43 silencing uncovers a cytoskeletal platform involved in process formation and migration. Glia, 2010. 58(4): p. 494-505. 
149. Mehta, S. and J. Zhang, Dynamic visualization of calcium-dependent signaling in cellular microdomains. Cell Calcium, 2015. 58(4): p. 333-341.

150. Itagaki, K., et al., Sphingosine 1-Phosphate Has Dual Functions in the Regulation of Endothelial Cell Permeability and Ca $<$ sup $>2+</$ sup $>$ Metabolism. Journal of Pharmacology and Experimental Therapeutics, 2007. 323(1): p. 186-191.

151. Li, X., et al., Role of protein kinase C $\zeta$ in thrombin-induced endothelial permeability changes: inhibition by angiopoietin-1. Blood, 2004. 104(6): p. 17161724.

152. Wei, X.N., et al., An Integrated Mathematical Model of Thrombin-, Histamineand VEGF-Mediated Signalling in Endothelial Permeability. BMC Systems Biology, 2011. 5: p. 112-112.

153. Wang, Z., et al., Pharmacologic Targeting of Sphingosine-1-Phosphate Receptor 1 Improves the Renal Microcirculation during Sepsis in the Mouse. The Journal of Pharmacology and Experimental Therapeutics, 2015. 352(1): p. 61-66.

154. Sobel, K., et al., FTY720 Phosphate Activates Sphingosine-1-Phosphate Receptor 2 and Selectively Couples to Galpha12/13/Rho/ROCK to Induce Myofibroblast Contraction. Mol Pharmacol, 2015. 87(6): p. 916-27.

155. Escue, R., K. Kandasamy, and K. Parthasarathi, Thrombin Induces Inositol Trisphosphate-Mediated Spatially Extensive Responses in Lung Microvessels. The American Journal of Pathology, 2017. 187(4): p. 921-935.

156. Huang, Q., et al., Activation of PAR-1/NADPH Oxidase/ROS Signaling Pathways is Crucial for the Thrombin-Induced sFlt-1 Production in Extravillous Trophoblasts: Possible Involvement in the Pathogenesis of Preeclampsia. Cellular Physiology and Biochemistry, 2015. 35(4): p. 1654-1662.

157. Tauseef, M., et al., Activation of Sphingosine Kinase-1 Reverses the Increase in Lung Vascular Permeability Through Sphingosine-1-Phosphate Receptor Signaling in Endothelial Cells. Circulation Research, 2008. 103(10): p. 11641172.

158. Pyne, S. and N. Pyne, Sphingosine 1-phosphate signalling via the endothelial differentiation gene family of G-protein-coupled receptors. Pharmacology \& Therapeutics, 2000. 88(2): p. 115-131.

159. Kondo, S., et al., Memo Has a Novel Role in S1P Signaling and Crucial for Vascular Development. PLoS ONE, 2014. 9(4): p. e94114.

160. Marfia, G., et al., Autocrine/paracrine sphingosine-1-phosphate fuels proliferative and stemness qualities of glioblastoma stem cells. Glia, 2014. 62(12): p. 19681981.

161. Björklund, S., et al., Effects of sphingosine 1-phosphate on calcium signaling, proliferation and S1P2 receptor expression in PC Cl3 rat thyroid cells. Molecular and Cellular Endocrinology, 2005. 231(1): p. 65-74.

162. Moon, M.H., J.K. Jeong, and S.Y. Park, Activation of S1P2 receptor, a possible mechanism of inhibition of adipogenic differentiation by sphingosine 1phosphate. Mol Med Rep, 2015. 11(2): p. 1031-6.

163. Morel, S., et al., The natural cardioprotective particle HDL modulates connexin43 gap junction channels. Cardiovascular Research, 2012. 93(1): p. 4149. 
164. Morel, S., et al., Sphingosine-1-phosphate reduces ischaemia-reperfusion injury by phosphorylating the gap junction protein Connexin43. Cardiovascular Research, 2016. 109(3): p. 385-396.

165. Rouach, N., et al., S1P inhibits gap junctions in astrocytes: involvement of Gi and Rho GTPase/ROCK. European Journal of Neuroscience, 2006. 23(6): p. 14531464.

166. Tence, M., et al., Increased interaction of connexin43 with zonula occludens-1 during inhibition of gap junctions by $G$ protein-coupled receptor agonists. Cell Signal, 2012. 24(1): p. 86-98.

167. Squecco, R., et al., Sphingosine 1-Phosphate Induces Myoblast Differentiation through Cx43 Protein Expression: A Role for a Gap Junction-dependent and independent Function. Molecular Biology of the Cell, 2006. 17(11): p. 48964910.

168. Yang, Y. and S. Uhlig, The role of sphingolipids in respiratory disease. Therapeutic Advances in Respiratory Disease, 2011. 5(5): p. 325-344.

169. Sammani, S., et al., Differential effects of sphingosine 1-phosphate receptors on airway and vascular barrier function in the murine lung. Am J Respir Cell Mol Biol, 2010. 43(4): p. 394-402.

170. Liu, W., et al., Sphingosine-1-phosphate receptor 2 mediates endothelial cells dysfunction by PI3K-Akt pathway under high glucose condition. Eur J Pharmacol, 2016. 776: p. 19-25.

171. Zhang, G., et al., Critical role of sphingosine-1-phosphate receptor 2 (S1PR2) in acute vascular inflammation. Blood, 2013. 122(3): p. 443-455.

172. Kim, G.S., et al., Critical role of sphingosine-1-phosphate receptor-2 in the disruption of cerebrovascular integrity in experimental stroke. Nature Communications, 2015. 6: p. 7893.

173. Mittal, M., et al., Reactive Oxygen Species in Inflammation and Tissue Injury. Antioxidants \& Redox Signaling, 2014. 20(7): p. 1126-1167.

174. Harijith, A., et al., Sphingosine Kinase 1 Deficiency Confers Protection against Hyperoxia-Induced Bronchopulmonary Dysplasia in a Murine Model. The American Journal of Pathology, 2013. 183(4): p. 1169-1182.

175. Chen, et al., Role of sphingosine-1-phosphate receptor 1 and sphingosine-1phosphate receptor 2 in hyperglycemia-induced endothelial cell dysfunction. International Journal of Molecular Medicine, 2015. 35(4): p. 1103-1108.

176. Bhattacharya, J. and M.A. Matthay, Regulation and repair of the alveolarcapillary barrier in acute lung injury. Annu Rev Physiol, 2013. 75: p. 593-615.

177. Ram, A., et al., Inhaled carbenoxolone prevents allergic airway inflammation and airway hyperreactivity in a mouse model of asthma. Int Arch Allergy Immunol, 2009. 149(1): p. 38-46.

178. $\quad$ Li, W., et al., Carbenoxolone Blocks Endotoxin-Induced Protein Kinase R (PKR) Activation and High Mobility Group Box 1 (HMGB1) Release. Molecular Medicine, 2013. 19(1): p. 203-211.

179. Wang, H., et al., HMG-1 as a late mediator of endotoxin lethality in mice. Science, 1999. 285(5425): p. 248-51. 


\section{VITA}

Rachel Escue Helms was born in 1988 to Catherine Denise and Gregory Stephen Escue in Memphis, TN. In 2010, she earned her Bachelor of Science in Biomedical Sciences from Christian Brothers University. Following a "year off" during which she worked in Dr. Clinton Stewart's lab in the Pharmaceutial Sciences department of St. Jude Children's Research Hospital, Rachel matriculated into the Integrated Program of Biomedical Sciences at the University of Tennessee Health Science Center. Under the mentorship of Dr. Kaushik Parthasarathi, she completed her PhD candidacy in 2015 and defended her thesis work in September of 2018. She expects to graduate with her doctorate in Biomedical Sciences in December 2018. 